Göttinger Zentrum

für Biodiversitätsforschung und Ökologie

- Göttingen Centre for Biodiversity ANd Ecology -

\title{
CONCEPT FOR PLANNING CONSERVATION SCHEMES FOR FARM ANIMAL GENETIC DIVERSITY FOCUSED ON GERMAN CHICKEN BREEDS
}

\author{
Dissertation to obtain the Doctoral Degree at the Faculty of \\ Mathematics and Science \\ Georg-August-Universität Göttingen
}

\author{
presented by \\ Tamina Pinent \\ born in Paris (France)
}

Göttingen, Mai 2009 
Referent:

Korreferent:

Date of disputation:
Prof. Dr. Henner Simianer

Prof. Dr. Michael Mühlenberg

28. April 2009 


\section{Acknowledgements}

I would like to greatly acknowledge:

Prof. Dr. Henner Simianer offering me the opportunity to work on this fascinating topic and for accepting this thesis.

Prof Dr. Michael Mühlenberg for taking over co-reference and for accepting this thesis.

Dr. Harald Schneider PhD habil. for taking over co-reference and for accepting this thesis.

The Bundesministerium für Ernährung, Landwirtschaft und Verbraucherschutz (BMELV) for the financial support of the project.

Dr. Steffen Weigend and his group, especially Annet Weigend and Anke Flörke for giving me insight in genotyping and making my stay in Mariensee a pleasant rememberance and for providing the genotype data used in this thesis.

The Bund Deutscher Rassegeflügelzüchter e.V. (BDRG) for supporting the sampling for loving and supporting all chicken breeds and for increasing my enthusiasm for poultry.

Janet Schmidtko and Sven Schierenbeck for sharing the office with me and my dogs Amanda and Voodoo, a wagtail named Piepsi and the chicken named Küki.

Friederike Köhn for correcting parts of the thesis and Rebecca Natter for supporting me even at night in my office and for making me laugh every day. Peter Lange for providing me with food while I was writing and Till Bockemühl for online via Skype advices and inspiration in all areas of life. Christine Brenninkmeyer for accompany me all the scientific and non-scientific way from undergraduate to doctor's degree 
and for endless discussions. Christine Flury for exchange of experience. All of them for their friendship beyond working.

My parents Helga and Marcelino Pinent for giving me all I needed to get here and to master life in an enjoyable and inspired way. For mental and financial support. 


\section{TABLE OF CONTENTS}

LIST OF FIGURES

LIST OF TABLES 10

ZUSAMMENFASSUNG

SUMMARY 12

$1^{\text {ST }}$ CHAPTER Introduction 13

1.1 Main question $\quad 14$

1.2 Farm animal genetic resources 14

1.2.1 Variety of breeds and losing genetic diversity 14

1.2.2 Importance of genetic diversity 15

1.2.3 Genetic data and diversity measures 17

1.2.4 Genetic identity and distances 17

$\begin{array}{ll}\text { 1.2.5 Graphical illustration } & 19\end{array}$

1.3 Gallus gallus as a farm animal 20

1.3.1 Domestication 20

$\begin{array}{ll}1.3 .2 \text { Breeds } & 21\end{array}$

1.3.3 Breeding practice 21

1.3.4 Phenotypes of colour, shape and plumage 21

1.3.5 Fanciers' role in development of strains and conservation of unique alleles 22

1.4 Conservation $\quad 23$

1.4.1 Conservation background 23

1.4.2 Conservation programmes 24

1.4.3 Conventional conservation strategy 25

1.4.4 Weitzman's approach and genetic diversity 26

$\begin{array}{ll}1.5 \text { Conclusion } & 27\end{array}$ 


\section{$2^{\text {ND }}$ CHAPTER Weitzman's approach and} conservation of breed diversity considering relations to external populations

2.2 Material and Methods 31

2.2.1 Breeds 31

2.2.2 Genotyping 33

2.2.3 Genetic distances and phylogenetic trees $\quad 33$

2.2.4 Weitzman's Approach 34

2.2.5 Total Diversity 35

2.2.6 Extinction probability $z$

2.2.7 Contribution and marginal diversity of a breed $\quad 35$

2.2.8 Conservation potential 36

2.3 Results $\quad 36$

2.3.1 Genetic distances and phylogenetic trees $\quad 36$

2.3.2 Extinction probability 40

2.3.3 Current and expected diversity and marginal diversity of a breed 42

2.3.4 Conservation potential 43

2.4 Discussion $\quad 45$

2.4.1 Genetic distances $\quad 45$

2.4.2 Extinction probability $\quad 45$

2.4.3 Conservation potential 46

$3^{\mathrm{RD}}$ CHAPTER An approximation to Weitzman's approach allowing bigger sample size and calculations considering between and within breed diversity $\quad 48$ 
3.2 Material and Methods

3.2.1 Exact algorithm 49

3.2.2 Approximation 50

3.2.3 Extinction probability $\quad 51$

3.2.4 Relative diversity index (RDI) 53

3.4 Results $\quad 54$

3.4.1 Approximation $\quad 54$

3.4.2 Extinction probability $\quad 55$

3.4.3 Relative diversity index (RDI) 56

3.5 Discussion $\quad 59$

3.5.1 Approximation $\quad 59$

3.5.2 Relative diversity index RDI 60

$4^{\text {TH }}$ CHAPTER Fancy breeds as a source of genetic diversity 62

4.1 Introduction 63

4.2 Material and Methods $\quad 64$

4.2.1 Probability of normal densities 64

4.2.2 Contribution $\quad 64$

4.2.3 Shape and colour phenotypes 64

4.3 Results 69

4.3.1 Probability of normal densities $\quad 69$

4.3.2 Contribution $\quad 70$

4.3.3 Shape and colour phenotypes $\quad 71$

4.4 Discussion $\quad 73$

4.4.1 Probability of normal densities $\quad 73$

4.4.2 Phenotypes $\quad 74$ 
$5^{\text {TH }}$ CHAPTER $\quad$ General Discussion 76

REFERENCES $\quad 82$

$\begin{array}{ll}\text { APPENDIX } & 90\end{array}$

$\begin{array}{ll}\text { Involved organizations } & 90\end{array}$

Breeds and traits used in this study 91

$\begin{array}{ll}\text { Microsatellite markers } & 101\end{array}$

How to use the programmes 103 


\section{LIST OF FIGURES}

Figure 1: Maximum likelihood tree calculated based on Weitzman's diversity measurement. White and brown egg layers (upper branch) as well as the broiler group (lower branch) are highlighted.

Figure 2: Neighbor-Joining tree calculated on Reynolds's distance. White and brown egg layers (upper branch) as well as the broiler group (lower branch) are highlighted.

Figure 3: Calculated conservation potential for 20 fancy breeds only and considering 8 commercial lines

Figure 4: Approximated and exact diversity values for a subset of breed

Figure 5: Relative Diversity Index of the breeds. 100\% represents the expected diversity for the sample size of each breed.

Figure 6: Regression of expected diversity for different sample size if including both, within and between breed diversity (grey line) and for samples out of each specific breed having a given sample size due to accessibility of individuals for the study (black line).

Figure 7: Relative diversity index RDI (representing the diversity within breeds) plotted against the conservation potential obtained using between breed diversity.

Figure 8: Sorted results of diversity estimations based on 1000 replicates from 10 animals, respectively, sampled from either 8 randomly sampled breeds or out of 8 commercial lines.

Figure 9: Contribution of breeds to total diversity. Zero line representing diversity obtained when all breeds are mixed and equal probably chosen by random.

Figure 10: Phylogenetic tree based on phenotypic characteristics using a) PARS general parsimony b) DOLPENNY branch and bound program with Dollo algorithm. c) MIX general parsimony program with Camin-Sokal algorithm. d) PENNY branch and bound program with Camin-Sokal algorithm. 


\section{LIST OF TABLES}

Table I: List of breeds

Table II: Population size of breeds in 2000 corrected for the proportion of participating breeders to the survey (all specified breeding animals by BDRG)

Table III: Calculated extinction probability of breeds

Table IV: Calculated conservation potential, marginal diversity and expected diversity of breeds for 20 fancy breeds only and considering 8 commercial lines.

Table V: Calculated conservation potential for 20 fancy breeds only and considering 8 commercial lines.

Table VI: Variables and criteria for estimation of the relative extinction probability in German chicken populations.

Table VII: Estimated values for the extinction probability of breeds.

Table VIII: Relative Diversity Index calculated for all breeds.

Table IX: Phenotypic and cultural characteristics used in the study.

Table X: Used microsatellite markers 


\section{ZUSAMMENFASSUNG}

Die genetische Vielfalt stellt die Basis für zukünftige Zuchtarbeit in allen Nutztierarten dar und muss daher erhalten werden. Für die Konzeption von Erhaltungsprojekten ist es nötig Kriterien für die Wahl der Rassen zu finden, die mit höchster Priorität erhalten werden sollen. In dieser Studie wurden am Modell der Biodiversität des Huhnes auf der Grundlage des Weitzman'schen Biodiversitätskonzepts solche Kriterien entwickelt. Aufgrund der besonderen Gegebenheiten bei Nutztieren wurde die Methodik um die folgenden Aspekte erweitert: (a) Entwicklung eines Ansatzes zur Berechnung der Weitzman-Diversität innerhalb und zwischen Rassen, (b) Entwicklung approximativer Algorithmen und Programme zur Berechnung der Weitzman'schen Diversitätsstatistik für viele Rassen, und (c) Berücksichtigung sicherer externer Populationen bei der Ableitung von Erhaltungsprioritäten. Es konnte gezeigt werden, dass die Ableitung von Erhaltungsprioritäten nach dem Kriterium Erhaltungspotential im vorliegenden Fall nicht dazu führt, dass besonders stark ingezüchtete Linien die höchste Priorität erlangen.

Für 20 nichtkommerzielle Hühnerrassen und acht kommerzielle Broiler- und LegerElternlinien wurden Reynolds Distanzen anhand von 29 Mikrosatelliten geschätzt. Es wurden zwischen 9 und 50 Individuen pro Rasse genotypisiert. Die Diversität zwischen den Rassen, die marginale Diversität und das Erhaltungspotential für alle Rassen wurden mit dem exakten Algorithmus von Weitzman berechnet.

Um größere Datensätze bearbeiten zu können wurde eine Approximation des Weitzman Algorithmus entwickelt. Dies ermöglicht die Diversität zwischen und innerhalb der Rasse in einem Analyseschritt zu ermitteln.

Die Beurteilung der, in verschiedenen Populationen enthaltenen Diversität konnte durch den Relativen Diversität Index (RDI) und durch die Wahrscheinlichkeit normaler Dichten bei Rassehühnern und in kommerziellen Linien erreicht.

Es konnte gezeigt werden, dass ein Großteil der genetischen Diversität innerhalb der Rassen angesiedelt ist, und dass die nicht kommerziell genutzten Rassen einen erheblichen Beitrag zur gesamten Diversität leisten. Die entwickelten Methoden und Programme können für die Ableitung von Erhaltungsprioritäten in anderen Tierarten genutzt werden. Vor allem aber für Geflügel mangelt es an Förderprogrammen, die durch diese Arbeit unterstützt werden und Länderübergreifend Verwendung finden könnten. 


\section{SUMMARY}

Genetic diversity is the base for future breeding in all farm animal species and therefore needs to be conserved. Criteria for the choice of breeds to be included in conservation programs are essential for the design of conservation strategies. In this study, such criteria were developed based on Weitzman's diversity concept using domestic chicken biodiversity as a model. Taking into account the specific features of farm animal biodiversity, the following extensions of the methodology were developed: (a) an approach to assess the Weitzman diversity within and between breeds, (b) development of an approximate algorithm and software to calculate Weitzman's diversity statistics for many breeds, and (c) an approach to account for safe external (international or commercial) populations in the derivation of conservation priorities.

Based on 29 microsatellites genotyped for 9 to 50 individuals in 20 non-commercial fancy breeds and 8 commercial layer and broiler lines the Reynolds distance was calculated. Diversity between breeds, marginal diversity and conservation potential were calculated for the fancy breeds, with or without accounting for the safe commercial breeds, using Weitzman's exact recursive algorithm.

An approximation was developed to cope with bigger sample sizes. This enabled us to account for diversity between and within breeds in one step analyzing single animal data. Estimation of diversity contained in different populations could be calculated establishing a Relative Diversity Index and looking for the probability of normal densities in fancy breeds and commercial lines.

Several tool s to support decisions in planning and conducting conservation concepts were suggested. Especially for poultry lacking an existing promotion programme this is expected to be reasonable to use an area-wide approach. 
$1^{\text {st }}$ CHAPTER

INTRODUCTION 


\section{INTRODUCTION}

\subsection{Main question}

Method and software development to be used for the derivation of conservation priorities in farm animal species was the main intention of this study. How to assess and compute breed information? How to take into account within and between breed diversity? How to define conservation priorities and what kind of support would be appropriate? These are main questions for every conservation project. But additionally there are always practical questions when having large data sets. Especially for calculations in which each possible scenario has to be compared the complexity of a problem increases very fast. If the number of breeds that should be considered is a permutation for each number of elements, the computational and computing dimensions increase by the factor $\mathrm{n}$ with each additional element.

\subsection{Farm animal genetic resources}

\subsubsection{Variety of breeds and losing genetic diversity}

The definition of a scientific measure to distinguish breeds is not reliable. K. Hammont reportedly stated to $\mathrm{J}$. Woolliams: "A breed is a breed if enough people say it is" (WOOlLIAMS and TORO 2007). There is no clear definition of criteria that has to be fulfilled to call a population a separate breed. This problem occurs for all level of taxa, even for some species but is particularly strong in breed definition. Breeds can be defined in a standard book through only few phenotypic characteristics, or by occurring in some regions, they can and do interbred and are very dynamic. The Food and Agriculture Organization of the United Nations (FAO) argues that a breed is a cultural term and should be respected as such. For chicken breeds in Germany usually the standard defined by Bund deutscher Rassegeflügelzüchter e.V. (BDRG) is used when assuming a chicken population to be a breed.

Genetic diversity provides an additional reference to phenotypic, performance and historical clues to distinguish populations and thus to sort given breeds into clusters of similarity and kinship. For conservation issues it is necessary to define units of 
preservation interest. Therefore the terms breed and population have to be defined. Breed similarities, divergences within breeds of different variations and exotic, closely related populations should be taken into account.

The actual problem in loosing breeds is more than a given dynamic of breed development, improvement and migration. Chicken production is a good example for dramatic expansion of few lines. In the last 50 years international breeding companies are dominating nearly the complete commercial chicken market. The high rate of loss of breeds and the limited resources available for conservation require prioritisation and decisions which breeds to care for first. Assessing the degree of endangerment for each population would provide additional information for conservation programmes.

Not only genetic diversity but also production system diversity is shrinking. A Global market and economical development favours a shift from multi-purpose local to few specialized global breeds (TISDELL 2003).

\subsubsection{Importance of genetic diversity}

The value of a high diversity in the global and local chicken population for commercial use and future breeding work should be strongly considered. In order to access the global market production systems tend to become standardized and uniform allowing the use of specialized, global breeds (TISDELL 2003). Production with global and specialized breeds can not consider the local market and local production conditions. This problem is more prominent if we consider that highly specialized layer and broiler hybrids are sold to developing countries where climate and infrastructural differences in feeding, air-conditioning or housing have to be managed. Economic calculations for breeding programs oftentimes are made on microeconomic scale for a short to medium term perspective (SIMIANER 2005b). Nevertheless future changes in market demand affect not only exotic countries. One example might be the increasing popularity of organic products worldwide. However, genetic diversity is known to be an insurance against future changes (SMITH 1984).

Genetic variation is the basis for any kind of breeding and selection. Farm animal phenotypic characteristics of interest can be divided into production traits and fitness traits. 
Neutral genetic diversity is - by definition - not linked to present phenotypic variability but may contain a potential for future adaptations. Neutral genetic variants may mutate, interact with other genes or display measurable phenotypic characteristics only in a specific environment.

The importance of genetic variation is mainly for future challenges but also for present research, market niches, culture, history and ecology.

- Future challenges are changing market demands and production circumstances or outbreaks of diseases or wars. (BROWN and GOLDSTEIN 1984; JATURASITHA et al. 2008; RIKIMARU and TAKAHASHI 2007).

- In research different breeds and crossbreeds are currently used in molecular genetics. If searching for new genes for production or health traits associations between highly polymorphic markers and the quantitative and qualitative trait loci are essential (ATZMON et al. 2008; RUBIN et al. 2007; SCHUTZ et al. 2002; WANG et al. 2007; ZHANG et al. 2008; ZHOU et al. 2006a; ZHOU et al. 2006b; ZHOU et al. 2007a; ZHOU et al. 2007b; ZHOU et al. 2008).

- Local breeds are often used by farmers for special purpose or in special landscapes. These breeds provide income for farmers in developing countries and developed countries with an increasing interest in local products and different qualities (JATURASITHA et al. 2008; WILSON 2008).

- Many breeds are of historical and cultural value. They illustrate a long domestication process and adaptation to special environments such as breeding and housing systems, use by humans and climates (BOOGARD et al. 2008; SAMBraus 1989; SCHibleR and SCHLUMBaUm 2007).

- Due to these adaptations local breeds are often used in local adapted farm management systems. The awareness is growing for the ecological value of landscapes formed by different multifaceted housing systems (BEINLICH and POSCHLOD 2002). 


\subsubsection{Genetic data and diversity measures}

A number of different genetic markers can help the measurement of genetic diversity. Despite SNP's are becoming more and more popular due to their very high density and high throughput genotyping techiques, microsatellites provide considerable information within a few genotypes. Microsatellites are typically neutral, co-dominant and widely used for population analysis. The European database AVIANDIV (WEIGEND et al. 1999) is building a chicken DNA collection and biodiversity database to evaluate strategic questions relating to the assessment of genetic diversity in chicken using molecular information at DNA level.

Allele frequency is one way of assessing diversity through genetic markers. By defining an allele frequency for each individual as $0,1 / 2$ or 1 both, between and within breed diversity, can be assessed. In this approach the breed mean is the estimate of the allele frequency of the breed.

The interpretation of microsatellite data outcome has to take into account that the positioning of the markers used may bias the results. Linkage between markers supposed to be neutral and alleles with significant selective advantage are important since most models assume that the change in allele frequency is only due to genetic drift and not to selection. A given locus may differ in neutrality between different breeds since important alleles may segregate in one breed that are not segregating in another and livestock breeds will be subject to different selection criteria (WOOLLIAMS and TORO 2007).

The problems of biased mutation when using microsatellites to compare species may not be of large importance for our data of close related breeds. A bias in the sense that larger alleles contain more bases and are therefore more likely to be mistranslated in DNA replication becomes primary a problem with increased genetic distance of species. The same is valid for the problem of increased instability during recombination at meiosis if there is a large size difference between individual alleles (JARNE and LAGODA 1996).

\subsubsection{Genetic identity and distances}

Genetic distance is generally defined as a degree of gene or genome differentiation between individuals or populations measured on a numerical scale. There are 
several metrics for genetic similarities and differences between populations. The best known and most frequently used dimensions are the genetic distance $D$ and the genetic identity I of $\mathrm{Nei}$ (1972). Basic assumption is an ideal population, having a size where the influence of mutation is larger than that of genetic drift. NEl defines the genetic identity I between two panmictic populations as follows:

$$
I_{j}=\frac{x_{i} y_{i}}{\sqrt{x_{i}^{2} y_{i}^{2}}},
$$

where $x_{i}$ and $y_{i}$ being the frequency of the $i^{\text {th }}$ allele at the $f^{\text {th }}$ locus of population $x$ and $y$. For the assessment of genetic differentiation between populations multiple loci are needed to be considered and the genetic identity is then represented as:

$$
I=\frac{J_{x y}}{\sqrt{J_{x} J_{y}}},
$$

where $J_{x y}, J_{x}$ and $J_{y}$ are the arithmetic averages of gene identities over all loci. Let $x_{i}$ and $y_{i}$ be the frequency if the $i^{\text {th }}$ allele at a locus in population $X$ and $Y$, respectively. The gene identities within and between populations are then computed by $j_{x} \sum x_{i}^{2}$, $j_{y} \sum y_{i}^{2}$ and $j_{x y} \sum x_{i} y_{i}$, where $\sum$ stands for the summation for all alleles at the locus. The average gene identities over all loci are the averages of these quantities, that is,

$J_{x}=\frac{\sum_{k=1}^{n} j_{x k}}{n}, \quad J_{y}=\frac{\sum_{k=1}^{n} j_{y k}}{n}$, and $J_{x y}=\frac{\sum_{k=1}^{n} j_{x y k}}{n}$

Where $\mathrm{k}$ refers to the $\mathrm{k}^{\text {th }}$ locus and $\mathrm{n}$ is the number of loci examined.

Genetic distance $D$ is derived from genetic identity as follows:

$$
D=-\ln I
$$

Another genetic distance was developed by Reynolds (REYNOLDS et al. 1983). While NEI's distance is based on a classical infinite mutation-drift model REYNOLDS-distance is a pure drift model. Monomorphic loci and mutation is not included, because there is no certainty whether an allele is appearing by mutation or disappearing by genetic drift and/or inbreeding. REYNOLDS distance was developed to analyze micro evolutionary processes as accurately as possible. It is calculated as follows: 


$$
D^{2}=\frac{\sum_{k=1}^{n} \sum_{i=1}^{m}\left(x_{k i}-y_{k i}\right)^{2}}{2 \sum_{k=1}^{n}\left(1-\sum_{i=1}^{m} x_{k i}-y_{k i}\right)}
$$

where $i$ is the number of the $i^{\text {th }}$ allele of $\mathrm{m}$ alleles on locus $\mathrm{k}$ and $x_{k i}$ is the frequency of the $i^{\text {th }}$ allele on locus $k$ of population $x . D^{2}$ is the mathematical value expected to increase linearly with increasing genetic drift (REYNOLDS et al. 1983). The accuracy of NEI'S and REYNOLDS genetic distance measurements increases with the number of investigated loci and individuals. Small sample sizes produce large statistical errors and less meaningful genetic distances. Both methods are used for domestic animal breeds and produce very similar results (HILLEL et al. 2003).

\subsubsection{Graphical illustration}

Constructing phylogenetic trees is not a trivial problem. A huge number of possible phylogenetic trees exist for any set of data; for example, only ten species give over two million possible unrooted trees (FELSENSTEIN 1978). These possibilities must be searched to find a tree that best fits the data according to an optimality criterion. However, the data themselves do not lead to a simple, arithmetic solution to the problem. Expecting the distribution of whatever trait (such as alleles of phenotypic traits) to directly follow the branching pattern of evolution, would be an oversimplification. Well understood phenomena of convergent evolution, parallel evolution, and evolutionary reversals (collectively termed homoplasy) add an unpleasant wrinkle to the problem of estimating phylogeny. Real phylogenetic data include considerable homoplasy, with different parts of the data suggesting sometimes very different relationships. Methods used to estimate phylogenetic trees are explicitly intended to resolve the conflict within the data by picking the phylogenetic tree that is best fitting to the data overall, accepting that some data simply will not fit.

However data that do not fit a tree are not simply "noise", they can contain relevant information in some parts of a tree, even if they conflict with the tree overall.

Two types of phylogenetic trees will be discussed for microsatellite data: NeighborJoining, a general data clustering method and Maximum likelihood where 
probabilities for possible phylogenetic trees are inferred (FELSENSTEIN 1980). It evaluates a hypothesis about evolutionary history in terms of the probability that the proposed model and the hypothesised history would give rise to the observed data set. The supposition is that a history with a higher probability of reaching the observed state is preferred to a history with a lower probability. The method searches for the tree with the highest probability or likelihood.

For trees based on phenotype only, different maximum parsimony methods will be used where a tree requiring the smallest number of mutations is build. Different knowledge about the data, mechanisms and criteria can be assumed.

\subsection{Gallus gallus as a farm animal}

\subsubsection{Domestication}

The genetic variability in chicken populations evolved during domestication in different climate zones, housing systems, purpose of use and breeding systems. When ever people moved, they took their breeds with them. The symbiosis of Homo sapiens and Gallus gallus started around 5400 BC (WEST and ZHOU 1988) from different geographic points, all located in Asia. Domestication centres seem to be Yunnan province/China, Southwest China and surroundings (i.e., Vietnam, Burma and Thailand) and the Indian subcontinent as suggested by Liu (LIU et al. 2006). Hutt's (1949) assumption that more than one species have contributed to the domestic chicken genome was supported by Eriksson (ERIKSSON et al. 2008). $\mathrm{He}$ found strong evidence for introgression of different species expressed by yellow leg colour and the candidate gene BCD02. Most commercial layer and broiler lines are homozygote for the BCD02 inhibiting allele but it is not found in the Gallus gallus species. The yellow skin allele originates from a different species, most likely Gallus sonneratii.

Domesticated chicken arrived Europe with Indo-European clans through Iran and Greece. Finally the Romans spread them out over the whole Roman Empire where cocks were largely used as gamecocks with high cultic value.

Up to our days cock fighting is a popular and wide spread activity in many countries. Different breeds evolved with different fighting techniques and adapted to different environments and human preferences. In Indonesia there are still funerary rituals 
where a chicken has to be present as channel for evil spirits and in Confucian Chinese weddings a chicken can even substitute a person that is not available. There are many examples for religious and customs connected with chickens in nearly all cultures (WOOD-GuSH 1956).

Despite all cultural use chickens were mainly kept for eggs and meat production. Depending on local preferences breeds were developed for dual propose, primarily for laying or primarily for meat production. This focus evolved up to the highly specialized layer and broilers lines used today.

\subsubsection{Breeds}

The FAO has registered 734 chicken breeds (SCHERF 2000; SOW-ANGR 2007) worldwide, 158 of them being transboundary breeds that occur in several countries. In European fancy breed clubs approximately 170 breeds of chickens and bantams are attended to that may display in up to 20 colour and comb variations.

\subsubsection{Breeding practice}

Commercial chicken lines have the most specialized and industrialized production in all animal species showing similarities with plant breeding and highly elaborated breeding schemes and performing tests are used. After the vertical integration of egg and poultry production in the late fifties of the $20^{\text {th }}$ century all parental lines used for commercial hybrid production are managed by few companies, one of them located in Germany (Cuxhaven). In contrast, non-commercial breeds are kept by fancy breeders and small holders without an elaborated central breeding concept. A fancy breeder keeps about 10 animals on average (BDRG 2005). Cocks are traded for new ones in poultry shows but normally there are no recordings about pedigree or performance except for phenotypic characteristics defined in the standard of each breed. German fancy breeders club are in charge of about 200 standardised breeds.

\subsubsection{Phenotypes of colour, shape and plumage}

The phenotype is a product of genotype and environment (FALCONER and MACKAY 1996). It is an important feature for selection in local populations that are kept by 
fancy breeders since at least 50 years as non commercial breeds. These are both quantitative phenotypic traits (measurable on a continuous scale) such as body size and weight, as well as discrete qualitative trait like type of comb shape, plumage colour, naked neck or short legs. Different populations can be discriminated through their breeding history and in particular using phenotypic criteria. Depending on background and complexity of the phenotypic characteristics it can be a more or less reliable indicator for neutral diversity. Phenotypic diversity relates to the expressed genetic diversity and gives a quantitative measure of adaptation of breeds to the environment (HALL 2004).

For many of the phenotypes the genetic background is known at least partially and will be mentioned in chapter 4. Comb shape, incidence of a crest or beard, leg colour, eye colour, feather colour and pattern are used to group the breeds. In this present study ear lobe colour and egg shell colour can not be used because all breeds sampled showed the same variation for this trait. In addition not all colours and plumage patterns and comb shapes are present in the used samples as well as silky plumage, frizzle feathers, long tails, ear tuffs, rumplesness and dark meat. For larger studies with bigger sample size and maybe international breeds involved, these qualitative criteria can be of proper use. White ear lobes are the less common variant in all existing breeds, in the present study, however, the only one represented. This illustrates well the exemplary nature of the study, not claiming to represent the European or global population structure and diversity of chicken breeds. The mentioned phenotypic characteristics in addition to body weight and shape are the main selection criteria used for non-commercial chicken breeds. Disease resistance, behaviour, laying performance, carcass and meat quality are no selection criteria at all or just subordinated. Breed specific occurrence of these characteristics are known and - if possible - included in breeding decisions.

\subsubsection{Fanciers' role in development of strains and conservation of unique alleles}

A fancier is a person who likes poultry and keeps them out of interest, not out of financial necessity. Some serious fanciers develop very good breeding skills and generate successful stock. From among these fanciers came the earlier commercial producers and professional poultrymen. They developed the stock sense and 
practical breeding techniques which formed the basis of poultry husbandry (CAREFOOT 1990). Although aesthetic traits were incorporated early, fanciers realized that their creations had to be economically viable. Indian Game or Cornish breeders always took care of the typical type of body shape. Those standardized characteristics describe a very good table fowl. This was used later in commercial breeding programmes. Local adaptations created a great number of different varieties of breeds. Nonsitting breeds, typically layers are usually standardized as having white earlobes; they are slender in build, active, have a large comb and are laying white eggs. The Mediterranean breeds show yellow skin and no dermal melanin such as Leghorn or white skin and dark legs like Minorka. In colder regions large combs are in danger to freeze. New varieties of comb shapes were developed. Dual purpose breeds, with yellow skin and laying tinted eggs -such as Plymouth Rock, New Hampshire, Rhode Island Red and Wyandotte- were developed in USA due to local preferences for those meat and egg colouration. In continental Europe deep brown eggs and yellow meat have been favoured and breeds like Barnefelders, Welsumers evolved in Holland and Marans in France. Meanwhile a preference for white meat and tinted or brown eggs in England supported breeds like Sussex and Dorking. All those breeds were standardized and selected by fanciers into quite uniformed stocks. They provide the basis for all commercial breeding programmes (CAREFOOT 1990).

\subsection{Conservation}

\subsubsection{Conservation background}

Countries having subscribed to the Convention on Biological Diversity (CBD 2005) are obliged to develop strategies for the conservation of biological diversity including farm animals. Available funds for conservation, however, do not cover the costs for preserving the entire variety of breeds. To date, Germany lacks an official conservation and financial promotion concept for poultry. In order to develop a conservation concept, it is necessary to identify the breeds that should be included and to allocate an appropriate amount of monetary and other resources to the breeds of the selected pool. Additionally not only a large number of different breeds has to be maintained expressed as diversity between breeds but also the variability of 
breeds itself expressed as diversity within breeds, in some cases even merging different populations to one synthetic breed (BENNEWITZ et al. 2008). Since we do not even know what kind of future challenges chicken breeding will be confronted with or what kind of scientific value its diversity will have (DELANY 2003; 2006; HALL 2004), it may be the best strategy to maintain the highest neutral genetic diversity within the whole chicken population.

\subsubsection{Conservation programmes}

The Central Documentation of Animal Genetic Resources in Germany (TGRDEU) is established on behalf of the German Federal Ministry of Food, Agriculture and Consumer Protection (BMELV) through the Information and Coordination Centre for Biological Diversity (IBV) of the Federal Agency for Agriculture and Food (BLE). TGRDEU is focusing on horse, cattle, sheep, pig and goat, all species that underlie the German animal breeding law. Each federal state has a programme where local breeds are supported and paid different bonuses for keeping and buying breeding animals of endangered breeds, organizing breeding clubs and participating in cryoconservation banks. The breeding animal bonus paying method is an in situ approach. Advantages of in situ conservation -in contrast do ex situ- are opportunities for rural development, maintenance of agro-ecosystem diversity and rural cultural diversity, breed evolution and genetic adaptation and increased knowledge of breed characteristics. Disadvantage compared to cryoconservation is that the conserved populations are not safe against diseases and disasters and may be exposed to genetic drift (OLDENBROECK 2007). Until now there is no financial support for poultry. The main problem in poultry is the lack of herdbook records. Only $5 \%$ of privately kept poultry are registered and performance tested (BMELV). One reason for the lack of herdbooks for poultry is the huge effort required monitoring hatching and 'trip' nests, non-commercial poultry keepers can not manage.

In Germany, data for the cryoconservation of semen from poultry are unknown. The Friedrich Löffler Institut (former FAL-TZ) established a blood and DNA bank of around 100 poultry breeds (WEIGEND et al. 1999).

The most important non governmental organization in Germany in the field of farm animal conservation is The Society for the Conservation of Old and Endangered Livestock Breeds (GEH) founded 1981. It is member of Rare Breeds International, 
Donaulaender alliance for gene conservation and SAVE foundation. Those organisations play a promoting and advising role for interested stakeholders and fancy breeders. To promote in situ conservation they created an Arc Farm Project where animals listed in GEH's Red List of Endangered Stocks of Livestock Breeds are promoted and managed in breeding groups. For Chicken, privately organized breeder circles were initiated for Vorwerkhühner, Deutsche Lachshühner and Ostfriesische Möwen.

Private breeding associations have a long-term interest in conserving a wide array of alleles (KNAP and NeETESON-VAN NieUWENHOVEN 2005) but only if a utilisation in commercial breeding lines is probable. First the genotype must be of interest (for that it has to be known), it has to be not too hard to measure or of low heritability, the disadvantages in performance have to be sufficiently small to be removed in few rounds of selection, the risk of introducing pathogens by introgression of external breeds into the company's units has to be excluded and the costs for maintenance of new populations may not be too high in comparison with this breed's production level. This leads us -except of financial support and data supply for science from commercial associations- back to governmental and private communities of interests as mentioned above assigned to take care of livestock diversity.

\subsubsection{Conventional conservation strategy}

For the mammal species where funds are spent for conservation depending on the country and species there are different units supported: Bonus for kept breeding animal, litter bonus, foal bonus, bonus for raising, acquisition bonus, support for breeder clubs, subsidization for extraction and conservation of sperms and embryo or utilisation and conservation of the animals are currently paid (TGRDEU).

\subsubsection{Weitzman's approach and genetic diversity}

Financial resources are always limited. Therefore this resource has to be spent the most efficient way. In economics optimized models for resource allocation is a well developed field of research. To have a basis for calculations genetic and phenotypic data can serve our purpose. 
To estimate neutral genetic diversity it is consensus, that marker loci, as neutral as possible, are an appropriate tool. Microsatellite markers being short repeats of 1 to 4 base pair units in non-coding areas. They are highly polymorphic, abundant and evenly distributed throughout the genome. These properties have made them useful markers for mapping, paternity testing and population genetics (WEIGEND and ROMANOV 2002). Further advantages of microsatellites are their easy detection by using PCR and their co-dominance nature. Being a clone based marker type the sequence of each marker in the genome can be mapped and easily utilises for different genetic applications (SOLLER et al. 2006).

Once having marker information it is crucial how to use this information to compute first the relationship and distances of the populations, second the inner breed variation and third the conservation priorities and fund allocation. For this propose the American economist Martin Weitzmann (1992; 1993; 1998) suggested an approach where extinction probability, costs of altering extinction probabilities and the value of diversity are the main ingredients of a rational overall analysis of diversityconservation that will be explained and used in this study. The main characteristic of the results obtained by Weitzman's approach is that contradictory to intuition not always the most endangered breed will receive the greatest amount of support. Yet it seems to be much more efficient than other resource allocation methods used for animal conservation programmes (REIST-MARTI et al. 2005; REIST-MARTI et al. 2006; SIMIANER 2005b; SIMIANER et al. 2003).

The exact Weitzman algorithm has a limit of theoretical 36 different objects (populations, breeds or individuals) and in practice 35 cattle breeds (TAPIO 2006) and 28 chicken breeds in this study was the maximum calculated. This limitation exists mainly due to working memory capacity when searching analytically for the best combination and proportion of breeds. Computing complexity is proportional to $2^{\text {n }}$ with $\mathrm{n}$ objects. In this study we developed and tested an approximation to enhance the number of breeds and to make it possible to look at individuals' level. An efficient use of conservation funds encompasses two levels of activity (SIMIANER et al. 2003):

- Individuals' level. Make the breed safe and conserve the diversity within this breed.

- Over all endangered breeds. Distribute the total amount among all breeds and conserve the diversity between breeds. 


\subsection{Conclusion}

The Convention on Biological Diversity (CBD) has recognized "the special nature of agricultural biodiversity, its distinctive features, and problems needing distinctive solutions" (decisions II/15 and V/5).

FAO's Report on Strategic Priorities for Action listed the following steps countries should take:

On national level

- Complete breed inventories and implement monitoring.

- Enhance breed characterization.

- Establish national conservation programmes.

- Maintain traditional knowledge, practices and lifestyles that support conservation efforts.

- Integrate genetic resource management into livestock development planning.

- Improve management, research and institutional capacity for inventory, monitoring and characterization.

- Improve policy development and legal frameworks for animal genetic resources to address the complex driving forces that affect the livestock sector.

- Increase public awareness of the roles and values of animal genetic resources to encourage further investment in this sector.

Action at international level

- Encourage collaborative arrangements to help countries improve their inventories, and better conserve, use and develop their animal genetic resources.

- Improve the process of determining risk status for animal genetic resources.

- Collaborate on research into better methodologies for characterization, economic valuation and improved use of animal genetic resources.

- Bring together recipients and donors to mobilize greater support.

- Establish regional focal points for improved regional collaboration.

- Strengthen the role of international organizations for national programmes. 
In this study tools are developed to calculate conservation priorities for endangered breeds taking into account their potential relatedness with external populations and including both, between and within breed diversity. 


\section{$2^{\text {nd }}$ CHAPTER}

Weitzman's approach and conservation of breed diversity considering relations to external populations 


\section{Weitzman's approach and conservation of breed diversity considering relations to external populations}

\subsection{Introduction}

The genetic variability in chicken populations evolved during domestication in different housing systems, climate zones and breeding systems, represents a cultural value and a reservoir for future breeding work.

Countries having subscribed to the Convention on Biological Diversity (CBD 2005) are obliged to develop strategies for the conservation of biological diversity including farm animals. Available funds for conservation, however, do not cover the costs for preserving the entire variety of breeds. To date, Germany lacks a conservation and promotion concept for poultry, although there is a large number of different breeds and lines, especially in chicken. German fancy breeders keep nearly 200 chicken breeds, half of which are bantam. In order to develop a conservation concept, it is necessary to identify the breeds that should receive funding and to allocate an appropriate amount of monetary and other resources to the breeds of the selected pool.

To provide objective information to support decisions as to which breeds to choose, we made an evaluation of genetic diversity in a set of 20 non-commercial chicken breeds and eight commercial broiler and layer parental lines based on 29 microsatellite markers. These markers are assumed to represent a neutral measurement of the adaptation potential of the breeds. Molecular characterisation is an important complement to the assessment of diversity using phenotypic features as body shape and colour.

For diversity estimation, we made use of an econometric model suggested by Weitzman (1992; 1993). In recent studies it was shown that this approach can be helpful (LAVAL et al. 2000; THAON D'ARNOLDI et al. 1998). This model was used to evaluate African cattle breeds, and it was found that the efficiency of a conservation scheme could be enhanced by up to $60 \%$ (REIST-MARTI et al. 2005; REIST-MARTI et al. 2006; SIMIANER 2005b; SIMIANER et al. 2003). 


\subsection{Material and Methods}

\subsubsection{Breeds}

In the current project, we chose 20 non-commercial breeds representing European lineages. The European ancestries of these breeds were evaluated with help of both, the breed groups defined in the fancy breeders club BDRG (Bund Deutscher Rasse Geflügelzüchter e.V.) by historical knowledge (SIX and WEIGEND 2002) and microsatellite data. Both methods resulted in groups that broadly coincide. To this set of non-commercial breeds, we added eight commercial lines: one white layer, three brown layers, and four broiler purebred lines. Demographic parameters like population size and number of breeders were collected through the German Poultry breeding Club (BDRG). Attendance to data collection on the breeder's local branches of BDRG increased. Thus all data are corrected for participant rate $(69.31 \%$ in 2000 and $94 \%$ in 2005).

20 breeds kept in Germany and used for this study will be introduced in table I and further in the Appendix. Descriptions of origin and breed history are based on traditional knowledge (SCHMIDT 1999; WANDELT and WOLTERS 1996). 
Table I: List of breeds

Bergische Kräher

Bergische Schlotterkämme black

Brabanter black, gold, chamois

Brakel silver

Deutsche Sperber

Friesenhühner yellow pencilled

Hamburger sprangled

Hamburger pencilled

Italiener partridge

Italiener black

Kastillianer

Krüper balck

Lakenfelder

Ostfriesische Möwen silver

Paduaner chamois, black, silver, gold, white

Ramelsloher white

Rheinländer black

Thüringer Barthühner black, gold, chamois, silver

Vorwerkhühner

Westfälische Totleger silver

Broiler dam line. A

Broiler sire line. A

Broiler sire line. B

Broiler dam line $D$

Brown layer $A$

Brown layer $C$

Brown layer $D$

White layer $A$
BERKER

BSCHL

BRABA

BRAKE

DSPER

FRIES

HAMla

HAMsp

ITALP

ITALb

KASTI

KRUEP

LAKEN

OMOEW

PADOW

RAMEL

RHEIN

THBAR

VORWE

WETOT

BROdA

BROsA

BROsB

BROdD

BEGGA

BEGGC

BEGGD

WEGGA

When possible, full names will be mentioned in tables and figures. Under space restrictions the above listed abbreviations are valid. All considered plumage colours are mentioned to indicate the sample pool. They apply for the whole study and may also not be mentioned under space restrictions. In Germany called Italiener in some countries are known as Leghorn standard type. 
German native breeds listed on GEH's red list but not included in this study are: Augsburger, Deutsche Langschan, Deutsches Lachshuhn, Sachsenhuhn,

Sundheimer, Deutsches Reichshuhn and the Austrian Breeds Altsteirer and Sulmtaler kept in Germany for decades. Some further 'German' breeds developed recently out of foreign breeds like Bielefelder Kennhuhn (1970) or Niederrheiner are not included either.

\subsubsection{Genotyping}

Genotyping was realized by the Friedrich Löffler Institute (former FAL) in Marienesee. Blood was sampled from the wing vein of each bird on different German poultry exhibitions. The procedure is described by (HILLEL et al. 2003).

For 28 populations, 29 microsatellite genotypes and, on average, 30 individuals per population ( $\min 9$, max 60 ) were sampled. All markers are FAO recommended by MoDAD project for assessing chicken genetic diversity (FAO 2004). A table with all used markers is listed in Appendix III.

Multiplex polymerase chain reactions (PCR) were carried out according to FAO (FAO 2004) recommendations. Electrophoregram processing on LICOR 4200 and allele-size scoring were performed with RFLPscan software package (Scanalytics, Division of CSP, Billerica, U.S.A.).

\subsubsection{Genetic distances and phylogenetic trees}

We used two types of distance measurements. First, Reynolds' genetic distance (REYNOLDS et al. 1983) was estimated to detect and analyze micro evolutionary processes and therefore it serves well for breed dimensions of genetic differentiation. For comparison we also looked at NEl's standard distance (NEI 1972) that is also often used in genetic distance analyses on the species and breed level. Second, Weitzman's genetic distance (WEITZMAN 1992) that is part of Weitzman's approach was estimated for further calculations on marginal diversity and conservation potentials. 
We calculated a maximum likelihood tree using Weitzman's (1992) recursive algorithm. It is not a genealogical representation of breeds but only a one dimensional representation of genetic distances. There are some supposed advantages of maximum likelihood methods over other methods, e.g. lower variance than other methods and thus these methods are least affected by sampling errors, robust to many violations of the assumptions in the model, outperforming of other methods when using short sequences, statistically well founded, they are able to evaluate different tree topologies and to use all sequence information (OLIVERA et al. 1998). The biggest disadvantage is to be very CPU intensive, thus having a long runtime. Illustration of the trees was done with TreeView 32 (PAGE 1996). For comparison we computed a neighbor-joining tree using Phylip 3.6.2 (FELSENSTEIN 1980).

\subsubsection{Weitzman's Approach}

Beyond his distance measurement the economist Martin Weitzman (1992; 1993) has proposed an approach for decision making in what to preserve under resource constraints. The main issue in finding preservation priorities is to find a usable measure for diversity values. By postulating a function that provides a meaningful value of diversity, well defined forms of resource allocation can be applied on those diversity values and costs.

Once having a pairwise-dissimilarity distance values between species or breeds, they have to be converted into an over all measure of the diversity of a set of breeds. This idea of diversity used by Weitzman is a measure of collective dissimilarities. Direct benefits of the breeds such as use value or cultural value can be added but are not reflected in his value of diversity function. The aim is to minimize lost of diversity.

In this study total diversity, extinction probability, contribution and marginal diversity of the breeds is calculated to obtain conservation priorities aiming to consider costs and benefits of conservation of rare breeds. 


\subsubsection{Total Diversity}

The total Weitzman diversity $(D)$ of a set $S, D(S)$ is identical to the ordinates of all nodes in the maximum likelihood tree if the branch lengths are reduced by the total height of the tree (THAON D'ARNOLDI et al. 1998). It is defined recursively as:

$D(S)=\max _{i \in S}\left[D\left(S_{i \notin S}\right)+\left(d\left(i, S_{i \notin S}\right)\right]\right.$

Where the diversity function of any set $S$ of breeds, $S_{i \notin S}$ stands for set $S$ without breed $i$ and $d\left(i, S_{i \notin S}\right)$ for the distance between breed $i$ and the Set without I (EDING and BENNEWITZ 2007).

\subsubsection{Extinction probability $z$}

To make first calculations concerning diversity between breeds, for each breed the degree of endangerment was derived from total population size of the breed in Germany and was quantified as extinction probability. More sophisticated methods can be added and will be mentioned later.

\subsubsection{Contribution and marginal diversity of a breed}

For further use, marginal diversity was calculated that reflects the change of diversity in the whole population in case of an increase in extinction probability of one breed (SIMIANER et al. 2003). Its value depends on the position of the breed in the maximum likelihood tree and on extinction probabilities of the neighbouring breeds in this tree, but is independent of extinction probability of the breed itself. The marginal diversity $m_{\mathrm{i}}$ of breed $i$ is

$$
m_{\mathrm{i}}=+\frac{\partial E[D]}{\partial z_{i}},
$$

The contribution, $c_{1}$, of breed $i$ to the total diversity population $S$ is calculated as 


$$
c_{i}=D(S)-D(S \backslash i)
$$

where $\mathrm{D}(\mathrm{S} / \mathrm{i})$ is the diversity of the total population without breed $\mathrm{i}$. The contribution of an element is proportional to the reduction in tree length caused by its removal from the group.

\subsubsection{Conservation potential}

Finally, the conservation potential as a product of extinction probability and marginal diversity was calculated, which is a good indicator for the priority of a breed for conservation (SIMIANER et al. 2003; WEITZMAN 1993). These calculations were done in two versions: For the subset of 20 non-commercial breeds; for all breeds, including the commercial breeds. Marginal diversities and conservation potentials in both cases were only calculated for the 20 non-commercial breeds.

The conservation potential, $\mathrm{CP}_{\mathrm{i}}$ is the product of extinction probability $z$ and marginal diversity $m_{i}$ of the breed $i$

$$
C P_{i}=-z_{i} m_{i}
$$

\subsection{Results}

\subsubsection{Genetic distances and phylogenetic trees}

REYNOLDS' distance and NEl's distance measurements showed no apparent difference in our data, thus Reynolds' was used for further analyses. Comparing the neighbor-joining tree to our maximum likelihood tree computed using Weitzman's approach (figure 1) and to a neighbor-joining tree based on Reynolds' distances proposed by (SIX and WEIGEND 2002) similarities appeared. In all tree cases broiler parental lines form a close cluster, as do brown egg layer parental lines. Schlotterkaemme and Krueper representing two variations of the same population always show a close group. Italiener partridge and Italiener black have no close relation to each other. The same occurs with Hamburger sprangled and Hamburger pencilled. Further on Hamburger Pencilled never shows closer relations to other 
breeds. Vorwerk chicken is the closest to broilers but was not included in the studies by Six And Weigend (2002), thus only a comparison within our study was possible. On the other hand comparing our results generated by maximum likelihood tree to neighbour-joining tree some differences appeared. In maximum likelihood approach the white layer line clusters to brown layer whereas in neighbor-joining it does not. East European chicken type containing Bergischer Kraeher, Friesian, Hamburger pencilled, Brabanter, Brakel and Paduaner as proposed by Six and Weigend (2002) is a constant cluster regardless of which method was used with exception of Brakel that is not included in maximum likelihood (Figure 1 and 2). 


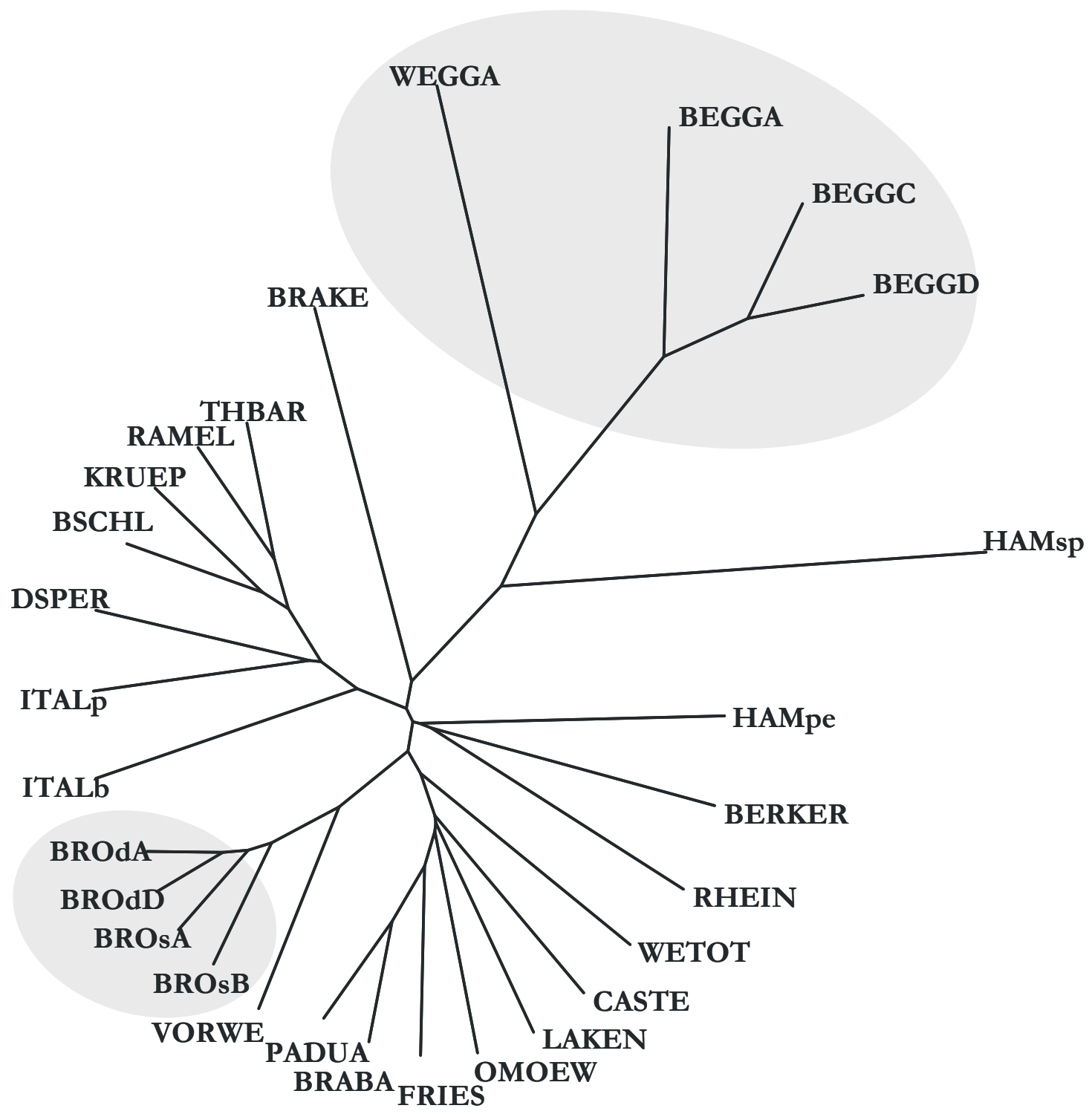

Figure 1: Maximum likelihood tree calculated based on Weitzman's diversity measurement. White and brown egg layers (upper branch) as well as the broiler group (lower branch) are highlighted. 


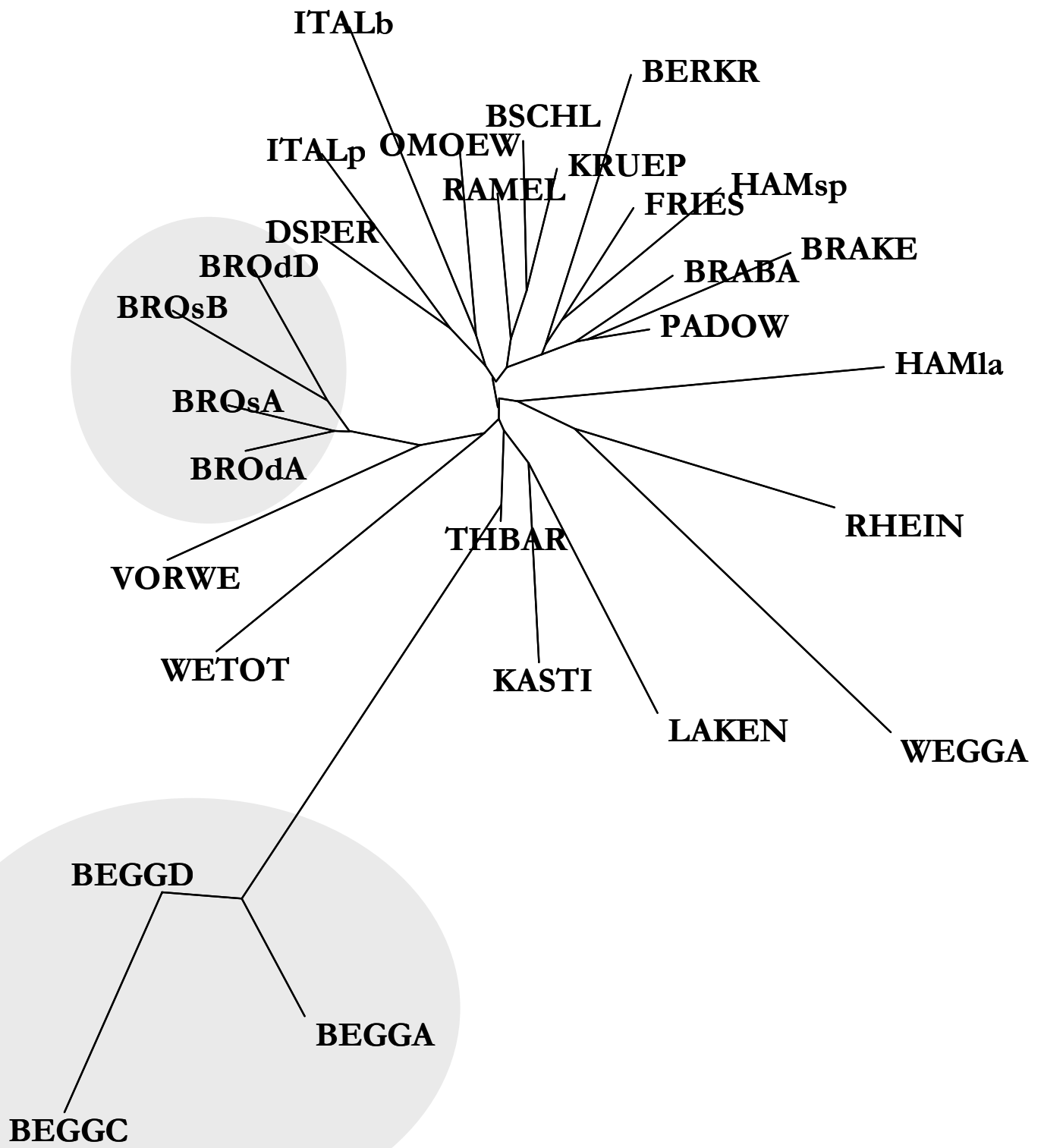

Figure 2: Neighbor-Joining tree calculated on Reynolds's distance. White and brown egg layers (upper branch) as well as the broiler group (lower branch) are highlighted.

Most results fit roughly with historical records and evaluations by the German Fancy Breeders Club. A precise comparison was not possible due to different breed composition. 


\subsubsection{Extinction probability}

Extinction probability was determined mainly by population size (see table II) for first calculations. As population size the number of all animals, male and female, used for breeding and specified by the breeders was used. This is suitable especially for the chosen set of breeds because breeding structure and use are similar. All considered breeds are white egg layers, kept only by fanciers, all are registered by BDRG and none is in a governmental program for conservation. Only Vorwerk chicken has been encouraged by a private initiative. It was the only breed that showed growing population size within the considered years (table II).

Table II: Population size of breeds in 2000 corrected for the proportion of participating breeders to the survey (all specified breeding animals by $B D R G$ )

\begin{tabular}{|lc|}
\hline & $\begin{array}{l}\text { total } \\
\text { population } \\
\text { size }\end{array}$ \\
Breed & $\mathbf{2 0 0 0}$ \\
\hline Bergische Kräher & 344,7 \\
Bergische Schlotterkämme black & 117,0 \\
Brabanter schwarz, gold, chamois & 111,7 \\
Brakel silver & 918,1 \\
Deutsche Sperber cocoo & 517,0 \\
Friesenhühner yellow-white pencilled & 743,6 \\
Hamburger silver sprangled & 1625,5 \\
Hamburger pencilled & 291,5 \\
ltaliener partridge & 7859,6 \\
Italiener black & 3831,9 \\
Kastillianer & 264,9 \\
Krüper black & 209,6 \\
Lakenfelder & 1085,0 \\
Ostfriesische Möwen silver pencilled & 1400,0 \\
Paduaner chamois, black, silver, gold, & \\
white & 458,5 \\
Ramelsloher white & 140,4 \\
Rheinländer black & 3202,1 \\
Thüringer Barthühner black, gold, \\
chamois, silver & 1394,7 \\
Vorwerkhühner & 4944,7 \\
Westfälische Totleger silver & 1321,3 \\
\hline
\end{tabular}


Extinction probabilities based on population size are shown in table III. Values range from 0.76 as the highest extinction probability for the breed Bergische Schlotterkaemme to 0.15 as lowest extinction probability for the breed Italiener partridge.

Table III: Calculated extinction probability of breeds

\begin{tabular}{|lr|}
\hline Breed & $\begin{array}{r}\text { extinction } \\
\text { probability }\end{array}$ \\
\hline Bergische Kräher & 0,529 \\
Bergische Schlotterkämme black & 0,763 \\
Brabanter schwarz, gold, chamois & 0,500 \\
Brakel silver & 0,296 \\
Deutsche Sperber cocoo & 0,451 \\
Friesenhühner yellow-white pencilled & 0,382 \\
Hamburger silver sprangled & 0,274 \\
Hamburger pencilled & 0,377 \\
Italiener partridge & 0,154 \\
Italiener black & 0,199 \\
Kastillianer & 0,342 \\
Krüper black & 0,419 \\
Lakenfelder & 0,444 \\
Ostfriesische Möwen silver pencilled & 0,302 \\
Paduaner chamois, black, silver, gold, white & 0,510 \\
Ramelsloher white & 0,675 \\
Rheinländer black & 0,203 \\
Thüringer Barthühner black, gold, chamois, silver & 0,276 \\
Vorwerkhühner & 0,328 \\
Westfälische Totleger silver & 0,243 \\
\hline
\end{tabular}




\subsubsection{Current and expected diversity and marginal diversity of a breed}

In this study we used diversity, contribution and marginal diversity of a breed only for computing the conservation potential that is our required value.

Table IV: Calculated conservation potential, marginal diversity and expected diversity of breeds for 20 fancy breeds only and considering 8 commercial lines.

\begin{tabular}{|c|c|c|c|c|}
\hline breed & marge20 & marge28 & expDiv20 & expDiv28 \\
\hline Bergische Kräher & 0,367 & 0,370 & 0,194 & 0,196 \\
\hline Bergische Schlotterkämme & 0210 & 0211 & O 150 & 0161 \\
\hline Brabanter schwarz, gold, & $0,<10$ & $0, \angle 11$ & 0,152 & 0,101 \\
\hline chamois & 0,469 & 0,553 & 0,235 & 0,276 \\
\hline Brakel silver & 0,224 & 0,229 & 0,066 & 0,067 \\
\hline Deutsche Sperber cocoo & 0,271 & 0,269 & 0,122 & 0,121 \\
\hline $\begin{array}{l}\text { Friesenhühner yellow-white } \\
\text { nencilled }\end{array}$ & 0.243 & 0241 & 0.100 & 0.092 \\
\hline Hamburger silver sprangled & 0,557 & 0,594 & 0,160 & 0,162 \\
\hline Hamburger pencilled & 0,398 & 0,401 & 0,150 & 0,151 \\
\hline Italiener partridge & 0,362 & 0,367 & 0,055 & 0,056 \\
\hline Italiener black & 0,319 & 0,320 & 0,063 & 0,063 \\
\hline Kastillianer & 0,292 & 0,292 & 0,110 & 0,100 \\
\hline Krüper black & 0,192 & 0,191 & 0,080 & 0,080 \\
\hline Lakenfelder & 0,294 & 0,290 & 0,129 & 0,129 \\
\hline $\begin{array}{l}\text { Ostfriesische Möwen silver } \\
\text { pencilled }\end{array}$ & 0268 & 0267 & ๑ ०81 & ח8ח ח \\
\hline Paduaner chamois, black, & & $u,<U$ & I, I & 0,000 \\
\hline silver, gold, white & 0,174 & 0,177 & 0,093 & 0,090 \\
\hline Ramelsloher white & 0,191 & 0,193 & 0,130 & 0,130 \\
\hline Rheinländer black & 0,362 & 0,362 & 0,073 & 0,074 \\
\hline Thüringer Barthühner black, & & & & \\
\hline gold, chamois, silver & 0,171 & 0,168 & 0,047 & 0,046 \\
\hline Vorwerkhühner & 0,335 & 0,260 & 0,089 & 0,085 \\
\hline Westfälische Totleger silver & 0,372 & 0,363 & 0,090 & 0,088 \\
\hline White egg layer $A$ & & 0,475 & & \\
\hline Brown egg layer $C$ & & 0,275 & & \\
\hline Brown egg layer $A$ & & 0,257 & & \\
\hline Brown egg layer $D$ & & 0,145 & & \\
\hline Broiler dam line $A$ & & 0,101 & & \\
\hline Broiler sire A & & 0,100 & & \\
\hline Broiler sire lineB & & 0,186 & & \\
\hline Broiler dam line D & & 0,093 & & \\
\hline
\end{tabular}




\subsubsection{Conservation potential}

As shown in Figure 4 conservation priorities change, if a reference population of safe breeds (in this case the commercial breeds) is taken into account. Endangered breeds which are genetically similar to a safe breed are downgraded in their conservation priority as it is seen in Kastilianer (from 0,110 to 0,100), Friesian (from 0,100 to 0,092 ) or Vorwerk chicken (fro 0,089 to 0,085 ). The other case of being upgraded is most clearly seen for the breed Brakel (from 0,235 to 0,276) or Brabanter (from 0,152 to 0,161 ). Table $V$ shows the exact values calculated for the shown example. Please notice that the order is changed in figure 3 to fit into the phylogenetic tree.

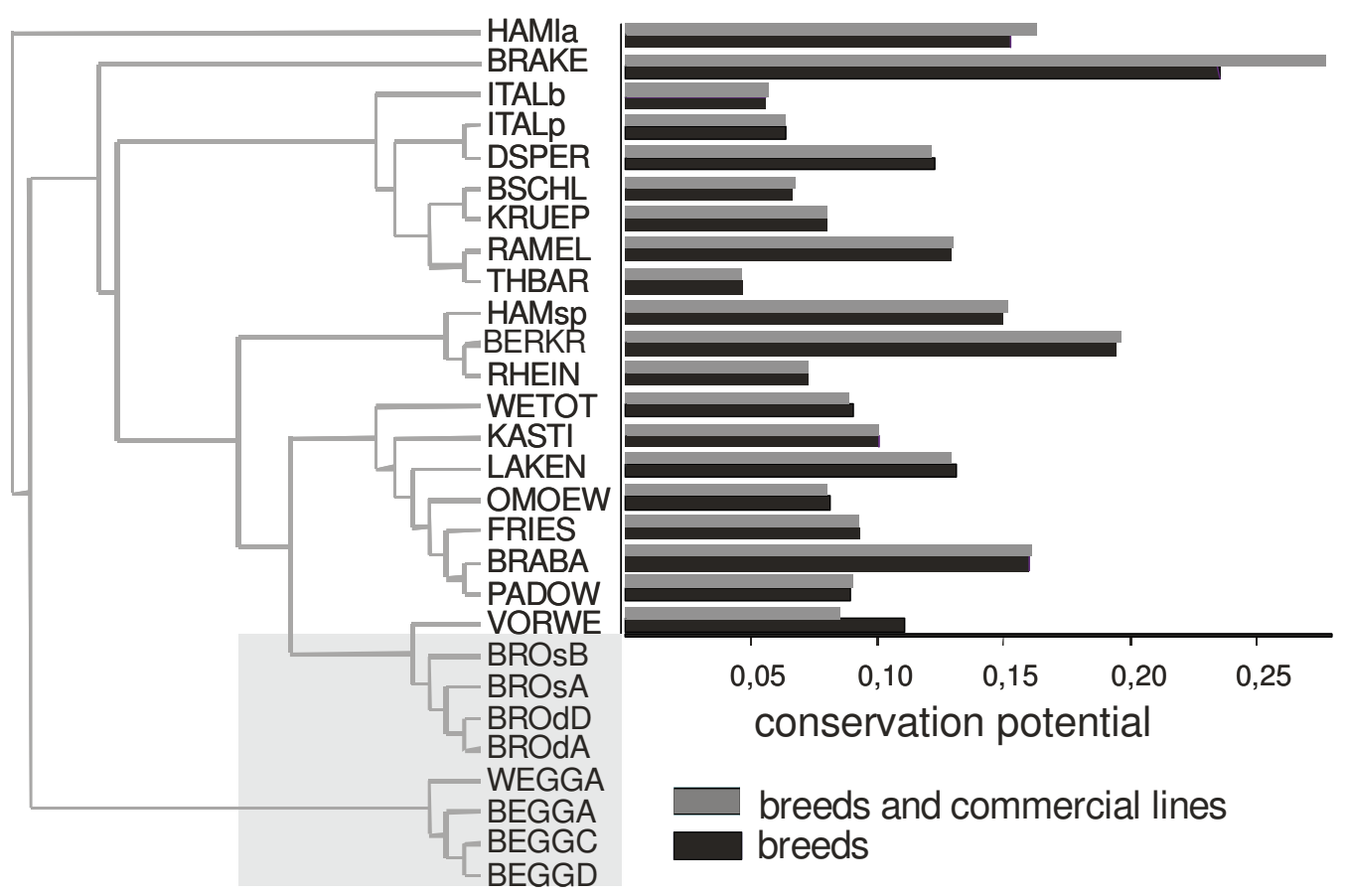

Figure 3: Calculated conservation potential for 20 fancy breeds only and considering 8 commercial lines

Table $\mathrm{V}$ shows the exact values of conservation potentials for all 20 breeds and in the last column conservation potentials for the same breeds but considering the presence of 8 commercial lines related to some of the breeds. 
Table V: Calculated conservation potential for 20 fancy breeds only and considering 8 commercial lines.

\begin{tabular}{|lll|}
\hline breed & consPot20 & consPot28 \\
\hline Bergische Kräher & 0,195 & 0,196 \\
Bergische Schlotterkämme black & 0,153 & 0,161 \\
Brabanter schwarz, gold, chamois & 0,235 & 0,277 \\
Brakel silver & 0,066 & 0,068 \\
Deutsche Sperber cocoo & 0,123 & 0,122 \\
Friesenhühner yellow-white pencilled & 0,100 & 0,092 \\
Hamburger silver sprangled & 0,161 & 0,163 \\
Hamburger pencilled & 0,150 & 0,152 \\
Italiener partridge & 0,056 & 0,057 \\
Italiener black & 0,063 & 0,064 \\
Kastillianer & 0,110 & 0,100 \\
Krüper black & 0,081 & 0,080 \\
Lakenfelder & 0,129 & 0,129 \\
Ostfriesische Möwen silver pencilled & 0,081 & 0,081 \\
Paduaner chamois, black, silver, gold, white & 0,093 & 0,090 \\
Ramelsloher white & 0,131 & 0,130 \\
Rheinländer black & 0,074 & 0,074 \\
Thüringer Barthühner black, gold, chamois, silver & 0,047 & 0,047 \\
Vorwerkhühner & 0,089 & 0,085 \\
Westfälische Totleger silver & 0,090 & 0,088 \\
White egg layer A & & $4,75 \mathrm{E}-8$ \\
Brown egg layer C & & $2,76 \mathrm{E}-08$ \\
Brown egg layer A & & $2,57 \mathrm{E}-08$ \\
Brown egg layer D & & $1,46 \mathrm{E}-08$ \\
Broiler dam line A & & $1,02 \mathrm{E}-08$ \\
Broiler sire A & & $1,01 \mathrm{E}-08$ \\
Broiler sire lineB & & $1,87 \mathrm{E}-08$ \\
Broiler dam line D & $9,34 \mathrm{E}-09$ \\
\hline
\end{tabular}




\subsection{Discussion}

\subsubsection{Genetic distances}

Breeds and colour variants that have complex feather patterns, caused by interaction of numerous different genes are less likely to be cross bred. The benefits of mixing foreign blood to these breeds are lower than the loss by disturbing an elaborate interplay of specific and coordinated genes. This is given in Hamburger sprangled which shows the highest divergence to the other breeds. Breeds with uniform colour may be more proper for melioration of colour intensity or body weight by crossbreeding. The same occurs on breeds that are characterized by only one or few features caused by one major gene. They occur for short legged, naked necked or frizzle variants (latter not present in this study). Short legs as in Krueper are homozygous lethal what makes it even impossible to breed short legged animals without the normal leg variant in the same population. This variation to Krueper is Bergische Schlotterkaemme and data show this connection between both breeds very clearly. The same breed structure is known in dog breeds like the dominant type of hairlessness that is lethal for homozygotes in uterus and uses a so called powder puff variant as homozygous wild type (ROBINSON 1985).

The unexpected close relation of Vorwerk chicken and commercial broiler lines in this study may be an example for colour melioration in local breeds. Vorwerk chicken evolved from Lakenfelder but displaying red colour whereas Lakenfelder are white. Asian chicken often have saturated yellow colour and at the same time are one of the founder chicken types for broiler lines. It can be assumed that they were used in the Vorwerk breed for colour and in broiler lines for body size and brought these two breeds closer in the maximum likelihood tree.

However, a difference in trees built based on different algorithms reminds us that one method shows just one aspect of the whole context. Different methods have different assumptions and vantages such as efficiency, power, consistency, robustness or falsifiability (PENNY et al. 1982). The diversity measurement of Weitzman is accepted as a good diversity measurement (EDING and BENNEWITZ 2007). It is robust to sampling errors and part of the Weitzman approach used in this study. 


\subsubsection{Extinction probability}

There are many factors influencing the extinction probability and some that surely have an effect like number of breeders, geographical distribution and special traits are documented and assessable. The fact that different known factors have an effect does not mean that it is known how it affects future survival of single breeds. In chapter 3 a score system is described in which different factors assumed to have an effect and are listed and estimated. If the given assumptions are proper future observations will show. We could use only two points in time where population size, number of breeds and geographical distribution could be corrected for the percentage number of participating breeders. To formulate founded predictions the new system of recording all data by BDRG in regular time intervals will be very helpful in future.

\subsubsection{Conservation potential}

The fact that external populations influence the breeds in different ways can be extended to the problem of national vs. international conservation schemes. If a conservation scheme is only optimized on the national scale, ignoring the fact that there may be closely related and relatively safe breeds in other countries, allocation of funds and conservation efficiency are expected to be sub-optimal (SIMIANER 2005). This fact should be considered when choosing particular breeds that should be conserved by obtaining financial support. FAO's Domestic Animal Diversity Information Service (www.fao.org/dadis/) published this year the additional information to the listed breeds if they are local or transboundary. This facilitates the access to worldwide information about external populations for international conservation schemes. 


\section{$3^{\text {rd }}$ Chapter}

An approximation to Weitzman's approach allowing bigger sample size and calculations considering between and within breed diversity 


\section{An approximation to Weitzman's approach allowing bigger sample size and calculations considering between and within breed diversity}

\subsection{Introduction}

To be able to cope with larger datasets, we suggest an algorithm to approximate the Weitzman diversity with significantly reduced memory and computing time requirements. The suggested methods are used to derive optimal conservation priorities accounting for within and between breed diversity.

This approximation allowed us to analyse whether maximization of the diversity between breeds leads to less diversity within breeds by favouring inbred lineages, because of their supposed differentiation, like EDING (2002) and CABALLERO AND TORO (2002) have supposed.

To answer the question whether maximization of diversity based on between-breeds diversity leads to a loss of within-breed diversity it was necessary to develop an approximation of the Weitzman algorithm. By approximating instead of calculating analytically, larger sample sizes can be computed. The diversity measure D proposed by WEITZMAN (1992) can be calculated exactly for a limited number of objects. While Weitzman indicated an exact calculation of $D$ should be possible for 35 objects, the maximum number applied objects so far were 28 chicken breeds in this study and 35 cattle breeds in a study done by TAPIO et al. (2006).

Approximations were proposed by THAON D' ARNOLDI et al. (1998) or GARCIA et al. (2005) and are based on a restriction in the combination possibilities, done in each step of the recursive algorithm proposed by WEITZMAN (1992). First consisting of randomly sampling trees among the $2^{\mathrm{n}-1}$ trees generated by the algorithm and taking the maximum of these values. While the exact algorithm can be implemented recursively this approximation can not leading to a point where the approximation takes more time than the exact one (GARCIA et al. 2005). Second consisting in splitting in each step into two sub-matrices, checking their dispersion, and if all the values in one sub-matrix are close enough together around a mean value, to use this value, multiplied by the remaining number of steps, as the diversity value for that submatrix, and if not, then proceed with the exact computation in the usual way. 
These approximations only allow a moderate increase of the number of objects to include. Besides running time primarily memory capacity is a limiting factor.

\subsection{Material and Methods}

\subsubsection{Exact algorithm}

Weitzman's (1992) total diversity is recursively defined as:

$$
D(S)=\max _{i \in S}\left[D\left(S_{i \notin S}\right)+\left(d\left(i, S_{i \notin S}\right)\right]\right.
$$

Where the diversity function of any set $S$ of breeds, $S_{i \notin S}$ stands for set $S$ without breed $i$ and $d\left(i, S_{i \notin S}\right)$ for the distance between breed $i$ and the Set without $I$. The marginal diversity $m_{\mathrm{i}}$ of breed $i$ is

$$
m_{\mathrm{i}}=+\frac{\partial E[D]}{\partial z_{i}},
$$

The contribution, $c_{i}$, of breed $i$ to the total diversity population $S$ is calculated as

$$
c_{i}=D(S)-D(S \backslash 1)
$$

where $\mathrm{D}(\mathrm{S} / \mathrm{i})$ is the diversity of the total population without breed $\mathrm{i}$. The contribution of an element is proportional to the reduction in tree length caused by its removal from the group.

The conservation potential, $\mathrm{CP}_{\mathrm{i}}$ is the product of extinction probability $z$ and marginal diversity $m_{i}$ of the breed $i$

$$
C P_{i}=-z_{i} m_{i}
$$




\subsubsection{Approximation}

The approach proposed in this study is based on a numerical procedure. Looking at the diversity contribution $B_{i}$ in each step of the Weitzman algorithm shown by THAON D' ARNOLDI (1998), it is shown that in each round a new link element is considered. $B_{i}$ is the shortest distance of this element to all other, "unconsumed" link elements. The object $\mathrm{y}$ with the shortest distance $\mathrm{d}_{\mathrm{xy}}$ to the observed object $\mathrm{x}$ is called the representative. It can appear several times in different steps whereas the link appears just once. One condition is that contribution has to be monotonically increasing, thus $B_{i+1} \geq B_{i}$. With $\mathrm{N}$ breeds, the Weitzman diversity is the sum of all contributions

$$
D=\sum_{i=1}^{N-1} B_{i}
$$

The calculation scheme is symbolized by $\mathbf{L}$, being the vector of sequence of all link elements. However there are many $\mathbf{L}$ vectors permitted, leading to different diversities $D \mid \mathbf{L}$. The Weitzman diversity is the maximum of these diversities. The aim is to find the link vector for which $D \mid \mathbf{L}$ is maximal. Given $\mathbf{N}$ objects there are $N$ ! possible $\mathbf{L}$ vectors. We suggest to estimate the maximization of this vectors by a two step procedure:

We generate $M_{1}$ random $\mathbf{L}$ vectors and verify them for validity. The valid vector with the biggest diversity value is saved.

Following the vector found in the first step is transformed in the way that two randomly chosen elements $i$ and $j$ are interchanged. If the obtained vector is valid and has a higher diversity value, this link vector is saved instead of the first. This procedure is done $M_{2}$ times.

For our data set this algorithm converged well using $M_{1}=500^{\prime} 000$ and $M_{2}=10^{\prime} 000$. The whole procedure was carried out 5 times with different random number seeds and the highest value was accepted. The four other values that were not chosen deviated less then $1 \%$ from the maximum value. Notice that a bad convergence still would always lead to an underestimation because the true value is the maximum of all diversities.

The accuracy of this approximation can be controlled only for data sizes that are small enough to be calculated exactly by Weitzman algorithm. In our case, dealing 
with 25 animals the approximation was always correct. As the approximation algorithm needs a very small memory capacity and runtime increases linear with $M_{1}$ and $M_{2}$ increasing, it can be used for much larger data sets, if necessary with larger values for $M_{1}$ and $M_{2}$ and more replicates.

\subsubsection{Extinction probability}

The probability that a breed will become effectively extinct in a given time frame can only be estimated due to future is not predictable. In his crane example WEITZMAN (1993) used the opinion of current crane specialists based on current population sizes and their likely future trend but not by any underlying consistent demographic methodology. He argues that there was no larger disagreement among the specialists concerning the ranking from most to least endangered species. REISTMARTI et al. (2005) developed a score system where different criteria could be taken into account.

In this study extinction probabilities were scored due to five criteria that seemed to be sufficiently precise since the study aims to develop a method that can be adapted for further use in different kind of conservation programmes.

The chosen criteria are: total population size, change in population size, geographical distribution, risk of indiscriminate cross and special traits as shown in table VI. Special traits were assumed to reduce the risk of extinction because of fanciers being aware of the peculiarity of the respective breed. All demographic information were provided by records of the German poultry breeders club (BDRG 2000; 2005). 
Table VI: Variables and criteria for estimation of the relative extinction probability in German chicken populations.

\begin{tabular}{|c|c|}
\hline Variable & Criterion and value \\
\hline \multirow[t]{5}{*}{ total population size } & $0.3<250$ \\
\hline & $0.2=251$ to 1000 \\
\hline & $0.1=1001$ to 3000 \\
\hline & $0.0>100000$ \\
\hline & missing value $=0.1$ \\
\hline \multirow{2}{*}{$\begin{array}{l}\text { change in Population size in the last } 5 \\
\text { years }\end{array}$} & $0.1=$ decreasing $(>20 \%)$ \\
\hline & $0.0=$ increasing or stable \\
\hline \multirow[t]{4}{*}{ geographical distribution } & $0.1=$ local (few breeders) $<150$ \\
\hline & $\begin{array}{l}0.05=\text { wide geographic distribution of } \\
\text { breeders or exotic breed }\end{array}$ \\
\hline & $0.0=$ international incidence \\
\hline & missing value $=0.0$ \\
\hline \multirow[t]{2}{*}{ risk of indiscriminate cross } & $0.1=$ high \\
\hline & $0.0=$ marginal \\
\hline \multirow[t]{3}{*}{ special trades } & $0.1=$ no \\
\hline & $0.0=$ yes \\
\hline & missing value $=0.1$ \\
\hline
\end{tabular}

These values were rescaled to avoid the assumptions of completely save $\left(z_{i}=0\right)$ or entirely doomed $\left(z_{i}=1.0\right)$ breeds. Commercial lines were considered not to be endangered, thus their extinction probability was set to zero.

$$
z_{i}=\frac{0.8}{0.7} * \sum_{a 0 i}^{5} z_{i} a+0.1
$$

The number of breeders and their distribution over the German territory as well as the local origin in contrast to exotic origins from other European countries were determined and added in a score system to integrate demographic and cultural aspects in our approach. 


\subsubsection{Relative diversity index (RDI)}

Because of different sample sizes due to difficult access to very rare breeds, the calculated diversities cannot be compared directly, as larger samples are more likely to display a higher diversity. The expected diversity given a certain sample size, not considering the membership of a given animal to a certain breed, was estimated. For that purpose samples were generated by sampling $N=10,20,40,60$, to 80 or 100 animals at random from all breeds and lines mixed. A linear regression with intercept 0 was used to quantify the functional relationship between sample size and between individual diversity. A second regression was fitted for the diversities obtained within the different breeds with given sample sizes. In this case, the between-breed diversity was not taken into account. The difference of the regression coefficients of these two lines reflects the proportion of within-breed diversity relative to the overall diversity.

For each breed we measured the relative diversity index (RDI) as the deviation of its diversity from the expected value conditional on sample size $N, E(D \mid N)$

$$
R D I=100 \times D / E(D \mid N) \text {. }
$$

To answer the question if maximization of the diversity between breeds leads to less diversity within breeds by favouring inbred lineages, the conservation potential and the RDI were compared. The first represents an optimisation based on diversity between breeds, the other represents diversity within breeds. If they were negatively correlated, this would support the assumption that using conservation potential selects for inbred lineages. 


\subsection{Results}

\subsubsection{Approximation}

The suggested approximation was applied on 724 single animals. Computing time was in the range of seconds. To compare the results to the exact algorithm the breeds which sample size did not exceed 25 animals were calculated with the exact Weitzman algorithm and compared to the values obtained by approximating with the mentioned procedure. The regression $r=0.999$ and $p=0.0001$, $s d=0.039$ with $\mathrm{n}=11$, shown in table VII and figure 4.

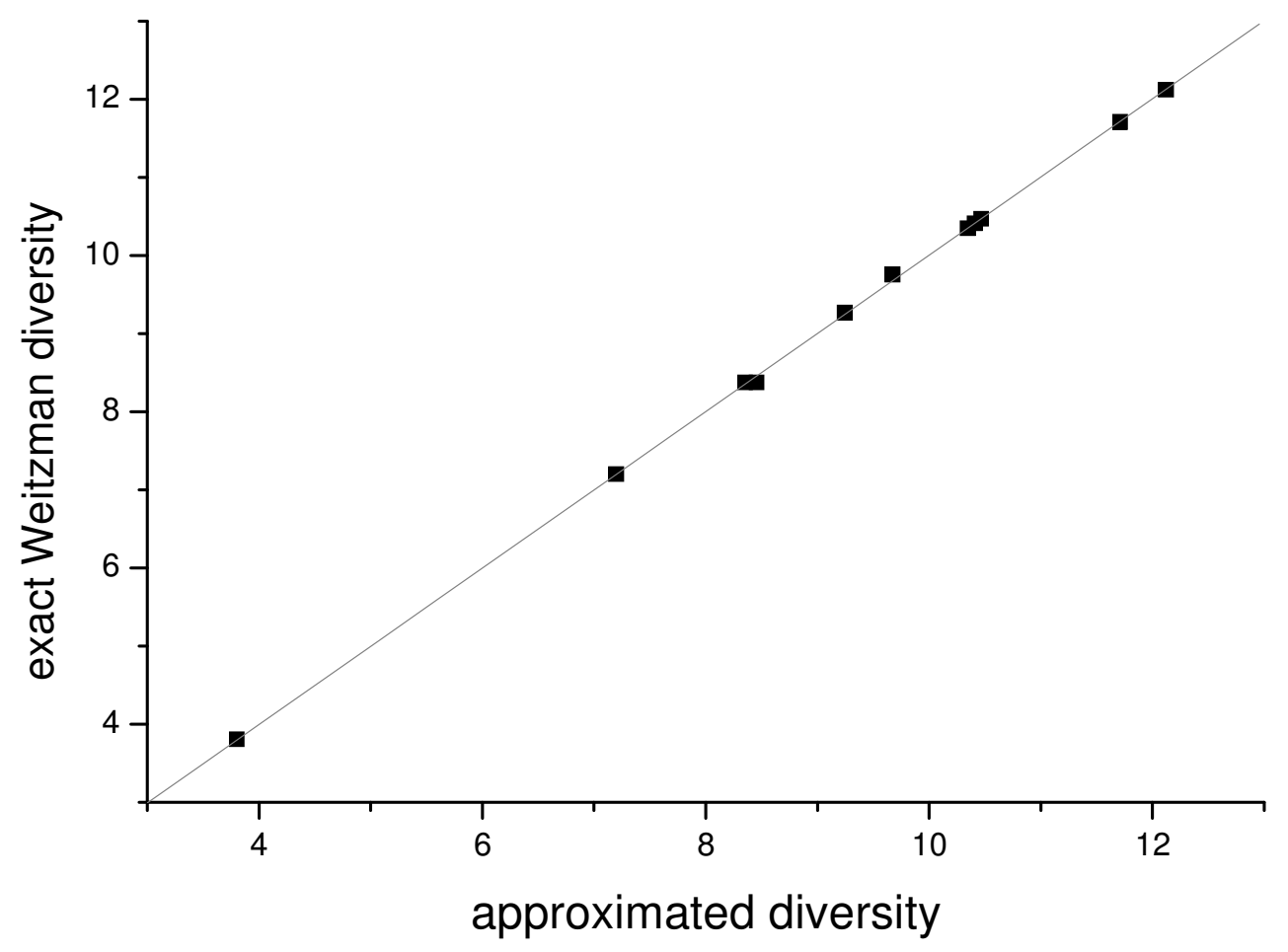

Figure 4: Approximated and exact diversity values for a subset of breeds. 


\subsubsection{Extinction probability}

According to the criteria listed in table $\mathrm{VI}$ a score was calculated for each breed. Calculated scores for all traits were summed for each breed Brabanter chicken having the highest and Vorwerk the lowest score (table VII).

Table VII: Estimated values for the extinction probability of breeds.

\begin{tabular}{|llllllll|}
\hline breed & $\begin{array}{l}\text { total } \\
\text { population } \\
\text { size }\end{array}$ & $\begin{array}{l}\text { change in } \\
\text { population } \\
\text { size }\end{array}$ & distribution & $\begin{array}{l}\text { risk of } \\
\text { crossing }\end{array}$ & $\begin{array}{l}\text { special } \\
\text { traits }\end{array}$ & $\Sigma$ & $\begin{array}{l}\text { scale } \\
\text { d ext. } \\
\text { prob. }\end{array}$ \\
\hline $\begin{array}{l}\text { Bergische Kräher } \\
\text { Bergische }\end{array}$ & 0.20 & 0.00 & 0.10 & 0.00 & 0.10 & 0.40 & 0,56 \\
Schlotterkämme & 0.30 & 0.00 & 0.10 & 0.10 & 0.10 & 0.60 & 0,78 \\
Brabanter & 0.30 & 0.10 & 0.10 & 0.10 & 0.10 & 0.70 & 0,90 \\
Brakel & 0.20 & 0.10 & 0.10 & 0.00 & 0.10 & 0.50 & 0,67 \\
Deutsche Sperber & 0.20 & 0.00 & 0.10 & 0.10 & 0.10 & 0.50 & 0,67 \\
Friesenhühner & 0.20 & 0.00 & 0.10 & 0.00 & 0.10 & 0.40 & 0,56 \\
Hamburger sprangled & 0.10 & 0.10 & 0.10 & 0.00 & 0.10 & 0.40 & 0,56 \\
Hamburger pencilled & 0.20 & 0.10 & 0.10 & 0.00 & 0.10 & 0.60 & 0,79 \\
Italiener partridge & 0.00 & 0.10 & 0.00 & 0.10 & 0.10 & 0.30 & 0,44 \\
Italiener black & 0.00 & 0.10 & 0.00 & 0.10 & 0.10 & 0.30 & 0,44 \\
Kastillianer & 0.20 & 0.10 & 0.05 & 0.10 & 0.10 & 0.55 & 0,73 \\
Krüper & 0.30 & 0.00 & 0.10 & 0.00 & 0.10 & 0.50 & 0,67 \\
Lakenfelder & 0.10 & 0.00 & 0.10 & 0.00 & 0.10 & 0.30 & 0,44 \\
Ostfriesische Möwen & 0.10 & 0.00 & 0.10 & 0.00 & 0.10 & 0.30 & 0,44 \\
Paduaner & 0.20 & 0.00 & 0.05 & 0.00 & 0.10 & 0.35 & 0,50 \\
Ramelsloher & 0.30 & 0.00 & 0.05 & 0.10 & 0.10 & 0.55 & 0,73 \\
Rheinländer & 0.00 & 0.10 & 0.05 & 0.10 & 0.10 & 0.35 & 0,50 \\
Thüringer Barthühner & 0.10 & 0.10 & 0.10 & 0.00 & 0.10 & 0.40 & 0,56 \\
Vorwerkhühner & 0.00 & 0.00 & 0.05 & 0.10 & 0.10 & 0.25 & 0,39 \\
Westfälische Totleger & 0.10 & 0.00 & 0.10 & 0.00 & 0.10 & 0.30 & 0,44 \\
\hline
\end{tabular}




\subsubsection{Relative diversity index (RDI)}

For all breeds a relative diversity index could be determined, describing the diversity contained in each breed in relation to the diversity expected in a population of the respective size (Table VIII).

Table VIII: Relative Diversity Index calculated for all breeds.

\begin{tabular}{|lr|}
\hline breed & RDI \\
\hline Bergische Kräher & 108,92 \\
Bergische Schlotterkämme & 92,24 \\
Brabanter & 102,52 \\
Brakel & 99,34 \\
Deutsche Sperber & 107,17 \\
Friesenhühner & 91,44 \\
Hamburger sprangled & 108,20 \\
Hamburger pencilled & 115,05 \\
Italiener partridge & 101,76 \\
Italiener black & 106,35 \\
Kastillianer & 101,16 \\
Krüper & 92,43 \\
Lakenfelder & 104,80 \\
Ostfriesische Möwen & 101,60 \\
Paduaner & 105,39 \\
Ramelsloher & 102,25 \\
Rheinländer & 111,67 \\
Thüringer Barthühner & 104,87 \\
Vorwerkhühner & 82,53 \\
Westfälische Totleger & 108,75 \\
Broiler dam line A & 98,20 \\
Broiler sire line A & 95,98 \\
Broiler sire line B & 103,29 \\
Broiler dam line D & 100,93 \\
Brown layer A & 97,16 \\
Brown layer C & 89,78 \\
Brown layer D & 98,15 \\
White layer A & \\
\hline
\end{tabular}


The same data plotted relatively to the expected diversity value in the over all breeds population given the sample size of each breed. The ranking of the single breeds are adapted to fit into a maximum likelihood tree calculated in chapter 2 .

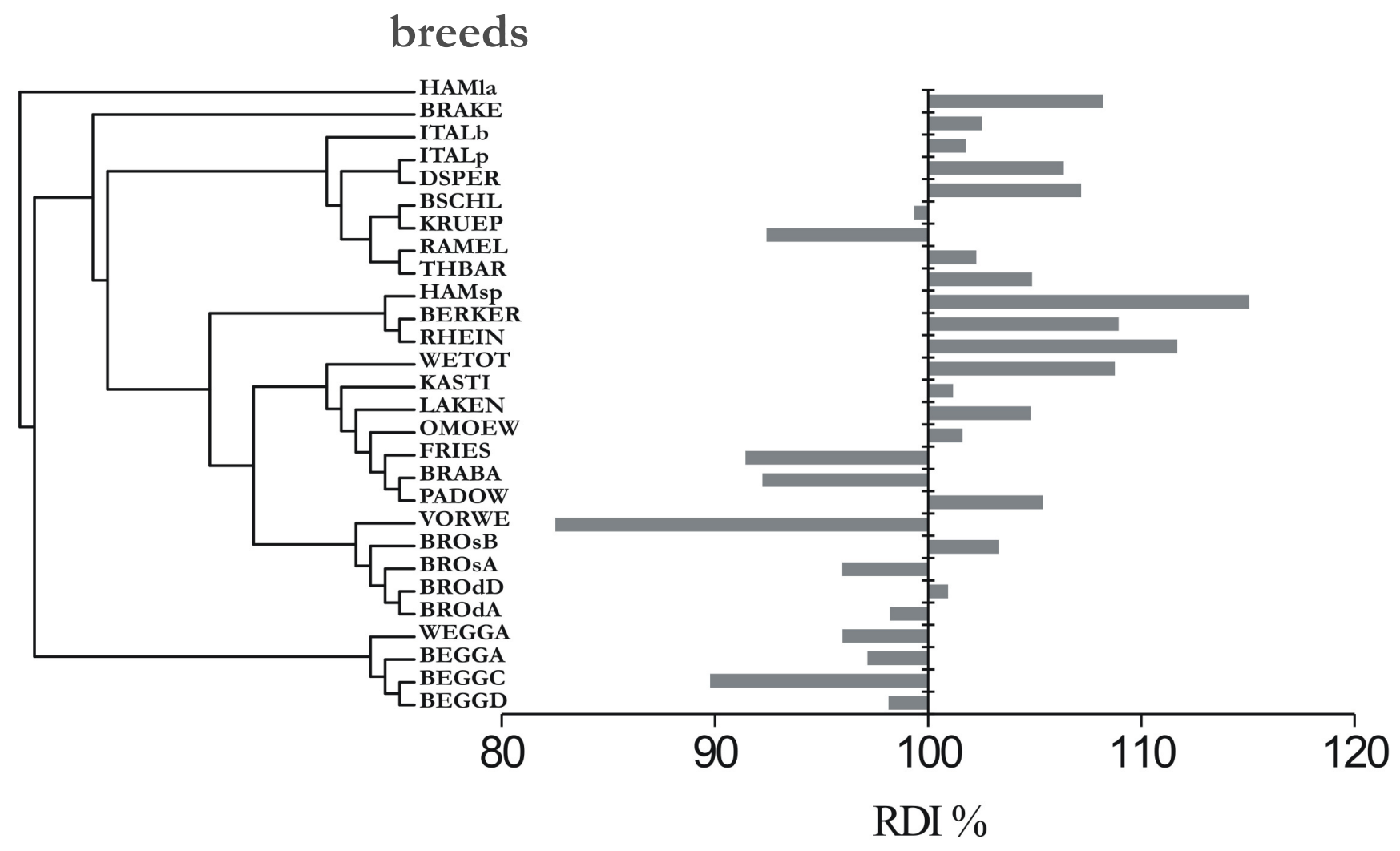

Figure 5: Relative Diversity Index of the breeds. 100\% represents the expected diversity for the sample size of each breed.

When applying diversity estimations on single animal data over several populations different sample sizes have to be taken into account.

In Figure 6, the linear regression of sample size on estimated diversity is displayed for the within-breed analysis $\left(r^{2}=0.97\right)$ and for the samples across breeds $\left(r^{2}=0.88\right)$, respectively. The slope of the latter exceeds the slope of the within-breed regression by 7.8 per cent, indicating that the within-breed diversity accounts for 92.7 per cent of the total variance, which is in line with similar findings in the literature (HALL 2004). This seems even more interesting since most conservation programs are based on between-breed diversity, maybe wasting the major part of possibilities. 


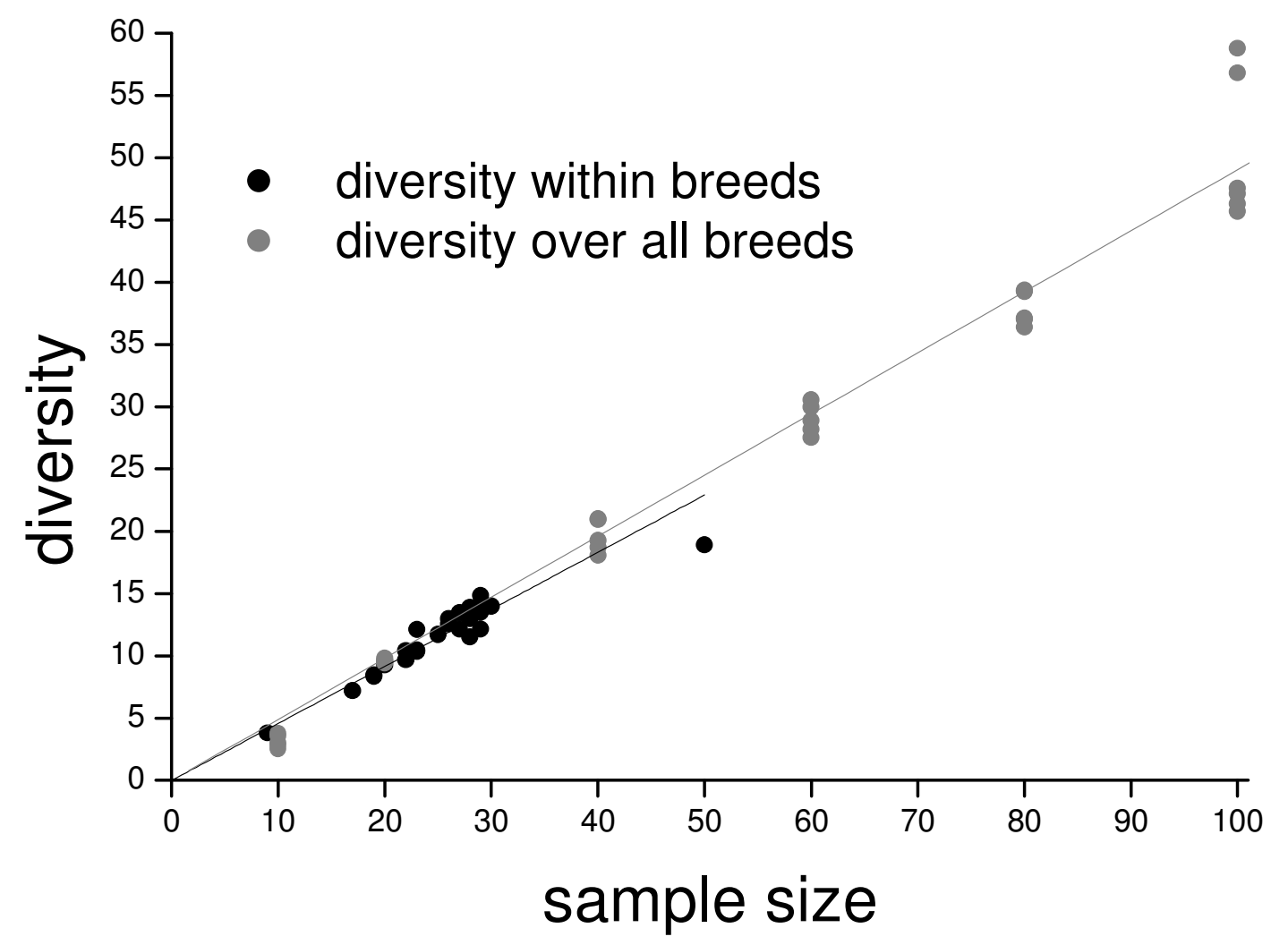

Figure 6: Regression of expected diversity for different sample size if including both, within and between breed diversity (grey line) and for samples out of each specific breed having a given sample size due to accessibility of individuals for the study (black line).

The utilization of conservation potential based on between-breed diversity for estimating conservation priorities and within-breed diversity represented by RDI was compared to conservation potential values calculated in chapter 2 . This comparison of two approaches, one based on between breed diversity but taking the extinction probability into account, the other taking both, between and within breed diversity is not significantly divergent from zero, the tendency is even slightly positive $\left(r^{2}=0,02\right.$, $p=0,5$ ) as shown in figure 7 and not negatively as it might be expected if selecting for conservation potential would favour inbred lines and RDI taking within breed diversity into account.

Estimating the Weitzman approach on individual level the effect of sample size had to be taken into account. 


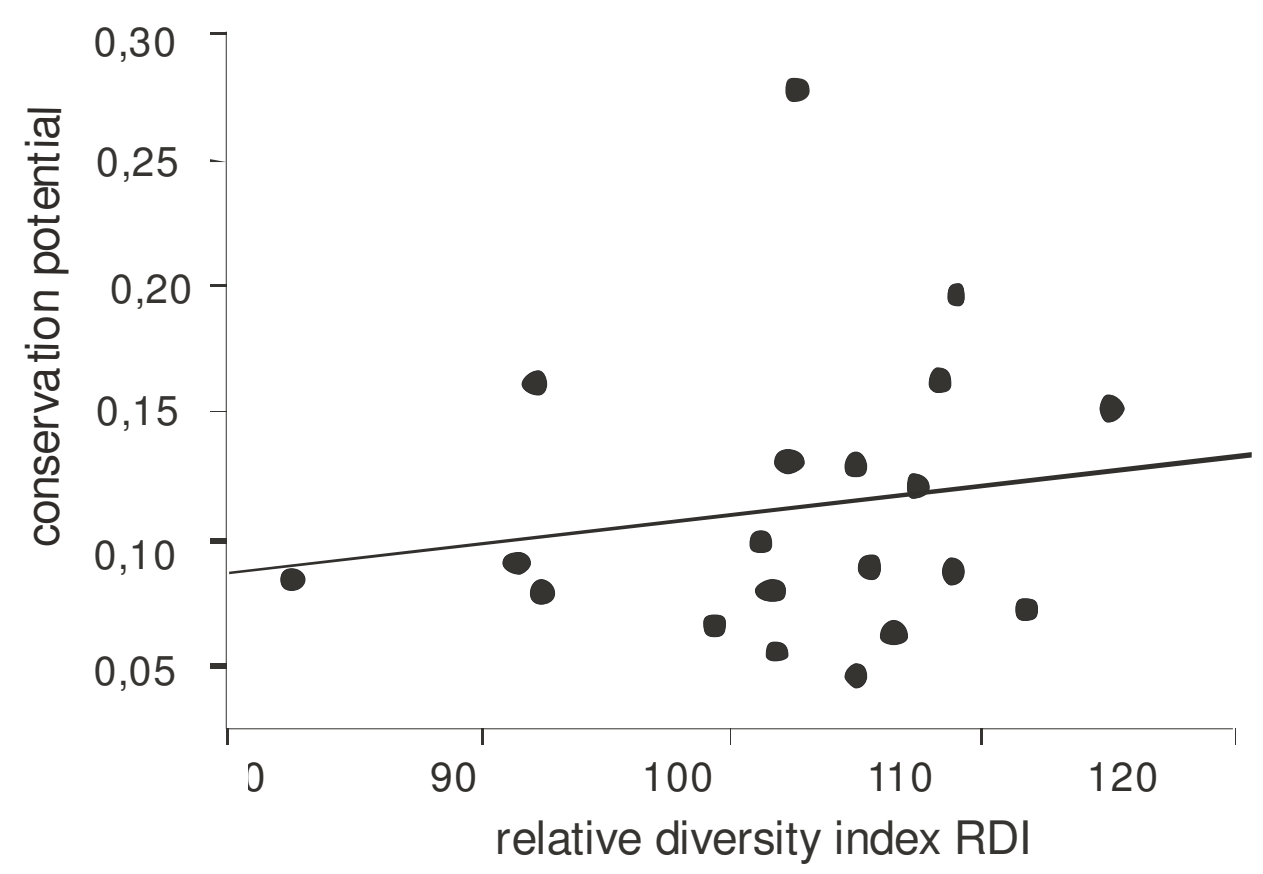

Figure 7: Relative diversity index RDI (representing the diversity within breeds) plotted against the conservation potential obtained using between breed diversity.

\subsection{Discussion}

\subsubsection{Approximation}

EdING's et al. (2002) and CABALLERO and TORO'S (2002) claim that selecting breeds for conservation using phylogenetic criteria will reduce the total diversity conserved was an additional motivation to develop a method that is able to answer this kind of questions. To answer to what extend selection methods used up to now leads to reduction of total diversity because the within-breed diversity was not taken into account we compared the results generated by the described approximation with Weitzman's conservation potential. The fact that the results were not contrary to each other is because conservation potential is precisely not only maximizing diversity between breeds. It depends on the extinction probability and that avoids selecting for very small and thereby inbred lines. This result indicates that breeds with very small population size are not favoured by the Weitzman's approach. Not favouring small populations in optimizing the allocation of conservation funds revealed to have a side-effect of indirectly considerer within population diversity that correlates with 
population size. Nevertheless the presented approximation enables to consider directly the diversity within breeds that is not only due to population size and will open new possibilities for maximizing genetic diversity.

\subsubsection{Relative diversity index RDI}

The RDI value contains between and within-breed diversity in equal parts. This simplifies diversity studies and enhances the results by including both sources for diversity.

For within breed diversity widely used measurements are allelic diversity and gene diversity (KREMER 1998; TORO and CABALLERO 2005), inbreeding coefficient (BALLOUX et al. 2002) or marker estimated kinship (FALCONER and MACKAY 1996) whereas for between breed diversity Wright's fixation index (WRIGHT 1969) or models with biological assumptions (NEI 1972) are used. To take both, within and between breed diversity into account it is necessary to combine two methods.

The number of alleles is considered the most relevant for within breed diversity (Barker 2001; Foulley and Ollivier 2006; Rémy J. Petit 1998). Due to its sensitivity to bottlenecks it can be used to consider fluctuations in population size. One problem is its sensitivity to sample size and due to not being sensitive to allele frequencies the inflated figure of rare alleles.

The second widely used index measuring expected heterozygosity or probability that two variants taken at random in the population are different. It depends mostly on the frequency of the most frequent allele. This leads to the problem of rare alleles not contributing much to gene diversity(KREMER 1998).

Marker estimated Kinship (MEK) is also used for within breed diversity estimation even if pedigree data are missing like it would be the case for non-commercial chicken breeds. It is possible to estimate the kinship based on microsatellite markers (EDING and BENNEWITZ 2007; EdING and MEUWISSEN 2003). This approach gives a measure of similarities within and between breed diversity. If corrected for the fact, that identical alleles may not always be due to kinship (identical by decent) but also 
through mutations (identical by state) the core set method is, beside Weitzman's approach, a suitable way of assessing conservation priorities(OLDENBROECK 2007).

Wrights Fixation index $F_{\text {ST }}$ gives a over all comparison of population structure where certain alleles get fixed when subpopulations are isolated (EDING 1999). The main criticism is that populations should differ only slightly since $F_{S T}$ never exceeds 1 . When using microsatellites that are known for high mutation rates, divergent population may have low values due to not detected alleles (BALLOux et al. 2002). A further disadvantage is that $\mathrm{F}_{\mathrm{ST}}$ assesses only pairwise distances simultaneously.

Methods with biological assumptions used for between breed diversity accounts for drift and mutation. One classical model is Nei's (1972) standard genetic distance but the short divergence time of domestic animals makes it less reliable (EDING and BENNEWITZ 2007). No admixture is a major assumption that is mostly not true for domestic animals (FELSENSTEIN 1982).

Calculating within and between diversity in one step both are equally valued because for the algorithm there is no difference between comparing individuals out of one breed or of different breeds. Weighting for conservation of specific traditional breeds or special trades is not included. This can be taken into account later due to a scoring system mentioned above. 
$4^{\text {th }}$ Chapter

Fancy breeds as a source of genetic diversity 


\section{Fancy breeds as a source of genetic diversity}

\subsection{Introduction}

Breeding companies tend to affirm that by taking care of inbreeding issues and keeping several parental lines they established a broad diversity among commercial lines. Some comments on congresses suggested that there is even more diversity within commercial lines than in fancy breeds (Internationale Legehennentagung 2004). TADANO et al.(2007) shows that commercial lines have high polymorphism, heterozygosity and differentiation levels among each other. There poultry breeding industry is concerned about genetic loss. Some commercial and experimental lines are kept as insurance but cost cutting measures mean that lines are eliminated (CAREFOOT 1990).

Fancy breeders on the other hand refer to the great variety in phenotype that may reflect genetic as well as cultural variety and researchers claim for unknown value of local breeds to science (DELANY 2006). In this chapter we applied the approximation introduced in Chapter 3 to compare the total diversity within and between breeds for a pool of commercial lines and on the other side of fancy breeds.

In a second part, we built phylogenetic trees based only on the phenotypic data recorded for the 20 fancy breeds used in this study to estimate whether phenotypic records and genetic markers data lead to similar kinship results. Because of lacking production traits we used phenotypes concerning the beauty standardized for each breed. 


\subsection{Material and Methods}

\subsubsection{Probability of normal densities}

To assess if commercial breeds harbour a major part of the genetic diversity, the following strategy was used. From the 28 fancy and commercial breeds, 8 breeds were chosen at random and from each of these 8 breeds, 10 animals were sampled. For this sample of 80 animals, the approximate Weitzman diversity was computed using the approach described in chapter 3 , and the whole procedure was repeated 1000 times. Then, the same procedure was done, but instead of sampling 8 breeds at random, the sampling was restricted to the 8 commercial breeds only. The comparison of the two results reveals, how much diversity was lost if only the commercial strains were maintained.

\subsubsection{Contribution}

Using the same procedure as mentioned above, sampling always 10 animals out of the total pool of animals, each time excluding one breed, the contribution of this specific breed can be estimated.

\subsubsection{Shape and colour phenotypes}

Only characteristics and colours used in this study will be mentioned (Table IX). Body weight, egg number or egg weight was not included because of lacking performance recordings. All breeds in this list have white ear lobes and lay white eggs. Some breeds were divided in two populations by feather colour or pattern. All traits were weighted equally although breeders have different rigor in prosecuting failure in different traits. The last column in table IX indicates the status given by GEH (Gesellschaft zur Erhaltung alter und gefährdeter Haustierrassen) a German NGO taking care of endangered native breeds. This status can be extreme endangered (I), very endangered (II), endangered (III) or under observation (obs). The Criteria for this categorization differs between species and is defined by an expert committee each year. 
Table IX: Phenotypic and cultural characteristics used in the study.

\begin{tabular}{|c|c|c|c|c|c|c|c|}
\hline Breed & $\begin{array}{l}\text { cultural } \\
\text { value }\end{array}$ & $\begin{array}{l}\text { plumage } \\
\text { colour }\end{array}$ & $\begin{array}{l}\text { comb } \\
\text { shape }\end{array}$ & $\begin{array}{l}\text { eye } \\
\text { colour }\end{array}$ & $\begin{array}{l}\text { leg } \\
\text { colour }\end{array}$ & $\begin{array}{l}\text { additional } \\
\text { trait }\end{array}$ & $\begin{array}{l}\text { status } \\
\text { by } \\
\text { GEH }\end{array}$ \\
\hline Bergische Kräher & native & duck wing & single & orange & $\begin{array}{l}\text { blue } \\
\text { grey }\end{array}$ & $\begin{array}{l}\text { long } \\
\text { crower }\end{array}$ & II \\
\hline $\begin{array}{l}\text { Bergische } \\
\text { Schlotterkämme }\end{array}$ & native & black & single & $\begin{array}{l}\text { red } \\
\text { brown }\end{array}$ & grey & & I \\
\hline Brabanter & & $\begin{array}{l}\text { black, gold, } \\
\text { chamois }\end{array}$ & v-shape & orange & - & crest & \\
\hline Brakel & native & $\begin{array}{l}\text { silver } \\
\text { pencilled }\end{array}$ & single & $\begin{array}{l}\text { dark } \\
\text { brown }\end{array}$ & $\begin{array}{l}\text { grey } \\
\text { with } \\
\text { white } \\
\text { nails }\end{array}$ & & obs \\
\hline $\begin{array}{l}\text { Deutsche } \\
\text { Sperber }\end{array}$ & native & barred & single & red & flesh & & II \\
\hline Friesenhühner & native & $\begin{array}{l}\text { yellow } \\
\text { pencilled }\end{array}$ & $\begin{array}{l}\text { single, } \\
\text { rose }\end{array}$ & red & $\begin{array}{l}\text { blue } \\
\text { grey }\end{array}$ & & \\
\hline Hamburger & native & $\begin{array}{l}\text { silver } \\
\text { sprangled }\end{array}$ & rose & red & grey & & \\
\hline Hamburger & native & pencilled & rose & red & grey & & \\
\hline Italiener & & partridge & single & red & yellow & & \\
\hline Italiener & & black & single & red & yellow & & \\
\hline Kastillianer & & black & single & brown & grey & & \\
\hline Krüper & native & black & single & brown & black & short legs & I \\
\hline Lakenfelder & native & lakenfelder & single & red & grey & & III \\
\hline $\begin{array}{l}\text { Ostfriesische } \\
\text { Möwen }\end{array}$ & native & $\begin{array}{l}\text { silver } \\
\text { pencilled }\end{array}$ & single & brown & grey & & II \\
\hline Paduaner & & $\begin{array}{l}\text { chamois, } \\
\text { black, } \\
\text { silver, gold, } \\
\text { white }\end{array}$ & v-shape & $\begin{array}{l}\text { red } \\
\text { brown }\end{array}$ & $\begin{array}{l}\text { blue } \\
\text { grey }\end{array}$ & crest & \\
\hline Ramelsloher & native & white & single & $\begin{array}{l}\text { dark } \\
\text { brown }\end{array}$ & blue & & I \\
\hline Rheinländer & & black & rose & $\begin{array}{l}\text { dark } \\
\text { brown }\end{array}$ & $\begin{array}{l}\text { grey, } \\
\text { black }\end{array}$ & & \\
\hline $\begin{array}{l}\text { Thüringer } \\
\text { Barthühner }\end{array}$ & native & $\begin{array}{l}\text { black, gold, } \\
\text { chamois, } \\
\text { silver }\end{array}$ & single & brown & $\begin{array}{l}\text { blue, } \\
\text { grey }\end{array}$ & beard & obs \\
\hline Vorwerkhühner & native & vorwerk & single & $\begin{array}{l}\text { orange, } \\
\text { yellow }\end{array}$ & grey & & obs \\
\hline $\begin{array}{l}\text { Westfälische } \\
\text { Totleger }\end{array}$ & native & $\begin{array}{l}\text { silver } \\
\text { pencilled }\end{array}$ & rose & $\begin{array}{l}\text { dark } \\
\text { brown }\end{array}$ & $\begin{array}{l}\text { blue } \\
\text { grey }\end{array}$ & & obs \\
\hline
\end{tabular}


As described in the book Poultry Breeding and Genetics by R.D. Crawford each mentioned trait will be explained shortly as follows:

White ear lobes are a phylogenetic trait based on pigmentation due to purine accumulation. This purine causes an opaque white pigmentation sometimes with greenish or yellowish glimmer. It overlays the red colour of the skin caused by strong blood circulation of the head attachments. Various genes are related with this polygenic trait and not sufficiently known yet.

For Brown Layers there are currently 13 genes discussed for the different variations of egg shell surface colour caused by oopryphrin. A greenish colouration caused by oocyanin within the shell is the other factor. Combinations of both deposits lead to a large number of brown, green, blue and red coloured chicken eggs.

A dark coloration of the skin is caused by pigmentation of the connective tissue. Again several genes are involved: inhibitors of dermal melanin, pigment cell activators and gender specific melanin inhibitors, which also affect plumage colour.

Different comb shapes are caused by two genes on two different chromosomes determining rose comb or pea comb. If none of these genes is active single comb (wild), if both are active a walnut comb will be developed.

Leg colours are a combination of dermis and epidermis colouring and other modifying genes such as gender specific cuckoo genes. The colours of the upper and lower layers of the skin are determined mainly by major genes such as $\mathrm{W}+$, id + and $\mathrm{e}+$ and than pronounced or diluted by modifying genes.

Eye colour varies too and is determined for most breed standards. It is the result of pigmentation of different structures like iris, retina, uvea and ciliary body. The underlying genetic has not yet been finally resolved. Reddish deviations from the wild-brown are caused by carotenoid pigments or increased blood circulation. Darker brown coloration is caused by eumelanin deposits in the entire eye. About the so called pearl eye little is known. (SMYTH 1990) assumed the same eumelanin display like in brown eyes but without carotinoides. Additionally the eye colour is affected by a variety colour improving and colour inhibiting modifying genes.

Plumage colour can be split in the base colour with their modifications, and the primary and secondary pattern. 79 standardized plumage colours were listed by JEFFREY (1977) in the USA and many of these could vary in leg colour or in shade of pigmentation. The basic colours are black and red (gold). They can be increased, diluted or masked. White can be achieved in different ways through inhibition of black 
and red by different gene combinations. In addition to the pigment colours perceived plumage colours can appear by reflections on specific surface structures of the feather without any pigmentation. Purple and emerald coloured animals owe it to the reflections on their feathers. Primary plumage patterns refer to the whole body, such as the Columbia, Lakenfelder and Vorwerk colour where black colouration is restricted to the neck, tail and point of shoulder. The secondary pattern refers to the individual feathers for example the simple and double laced speckles and other (SMYTH 1990).

Short legs like in Krueper display their heterozygosity for the lethal creeper (cp) gene when homozygous. Interactions with other genes may shift the degree of leg shortness and mortability of chicks (LANDAUER 1944; SOMES 1990a).

Crests and beards are autosomal incomplete dominant with variable peculiarity (SOMES 1990b).

The graphical illustration of phenotypic similarities was done based on different maximum parsimony methods using the PHYLIP package (FELSENSTEIN 1980). Maximum parsimony is a widely-used character-based tree estimation method for morphological data. It operates by evaluating candidate phylogenetic trees according to an explicit optimality criterion. The PHYLIP package contains different programs based on maximum parsimony that differ in assumptions made about the evolutionary model, knowledge about the data and optimality criterion. We used four different models to compare phenotype based results to the genetic based done in antecedent chapters.

PARS is a general parsimony program which carries out the Wagner parsimony method with multiple states. Wagner parsimony allows changes among all states. The criterion is to find the tree which requires the minimum number of changes. The Wagner method was originally developed by (ECK and DAYHOFF 1966) and by (KLUGE and FARRIS 1969). Following assumptions are made: Ancestral states are unknown; different characters evolve independently; different lineages evolve independently; changes to all other states are equally probable; these changes are a priori improbable over the evolutionary time spans involved in the differentiation of the group in question; other kinds of evolutionary event such as retention of polymorphism are far less probable than these state changes and rates of evolution 
in different lineages are sufficiently low that two changes in a long segment of the tree are far less probable than one change in a short segment.

MIX is a general parsimony program which carries out the Wagner and Camin-Sokal parsimony methods in mixture, where each character can have its method specified separately. We used Camin-Sokal (CAMIN and SoKAL 1965) parsimony where it is known which state is the ancestral one and, for that assumes that changes $0 \rightarrow 1$ are allowed but not changes $1 \rightarrow 0$. The criterion is to find the tree which requires the minimum number of changes. Following assumptions are made: Ancestral states are known; different characters evolve independently; different lineages evolve independently; changes $0 \rightarrow 1$ are much more probable than changes $1 \rightarrow 0$; both of these kinds of changes are a priori improbable over the evolutionary time spans involved in the differentiation of the group in question; other kinds of evolutionary event such as retention of polymorphism are far less probable than $0 \rightarrow 1$ changes and rates of evolution in different lineages are sufficiently low that two changes in a long segment of the tree are far less probable than one change in a short segment.

PENNY is a program that will find all of the most parsimonious trees implied by data. It does so not by examining all possible trees, but by using the more sophisticated algorithm. There is, however, a price to be paid for the certainty that one has found all members of the set of most parsimonious trees: this program, despite its algorithmic sophistication, is very slow. The search strategy used by Penny is a modified backtracking depth first search algorithm, a branch and bound algorithm, a standard computer science search strategy first applied to phylogenetic inference by (PENNy et al. 1982). The counting of the length of trees is done by an algorithm nearly identical to the corresponding algorithms in Mix, again we used Camin-Sokal.

DOLLPENNY, like penny, is a branch and bound algorithm but the counting of length of trees is done by a Dollo and polymorphism parsimony method. The Dollo parsimony method was first suggested by (LE QUESNE 1974) and was first wellspecified by (FARRIS 1977). The method is named after Louis Dollo since he was one of the first to assert that in evolution it is harder to gain a complex feature than to lose it. The algorithm explains the presence of the state 1 by allowing up to one forward change $0 \rightarrow 1$ and as many reversions $1 \rightarrow 0$ as are necessary to explain the pattern of states seen. The program attempts to minimize the number of $1 \rightarrow 0$ reversions necessary. Following assumptions are made: We know which state is the ancestral one (state 0); the characters evolve independently; different lineages evolve 
independently; the probability of a forward change $(0 \rightarrow 1)$ is small over the evolutionary times involved; the probability of a reversion $(1 \rightarrow 0)$ is also small, but still far larger than the probability of a forward change, so that many reversions are easier to envisage than even one extra forward change; retention of polymorphism for both states ( 0 and 1 ) is highly improbable; the lengths of the segments of the true tree are not so unequal that two changes in a long segment are as probable as one in a short segment.

\subsection{Results}

\subsubsection{Probability of normal densities}

Figure 9 shows the ordered values of diversity obtained from 1000 replicates from 10 animals sampled from either 8 randomly sampled breeds including commercial lines or from only out of 8 commercial lines. The resulting curves represent two probability functions of the corresponding normal densities. Both distributions differ by 7.05 per cent (41.22 vs. 44.13 for the midst value). Having in mind the above mentioned result that between-breed component accounts for only 7.8 per cent of the total diversity, this result shows that diversity within commercial breeds is of similar size as the diversity within a single randomly chosen breed. 


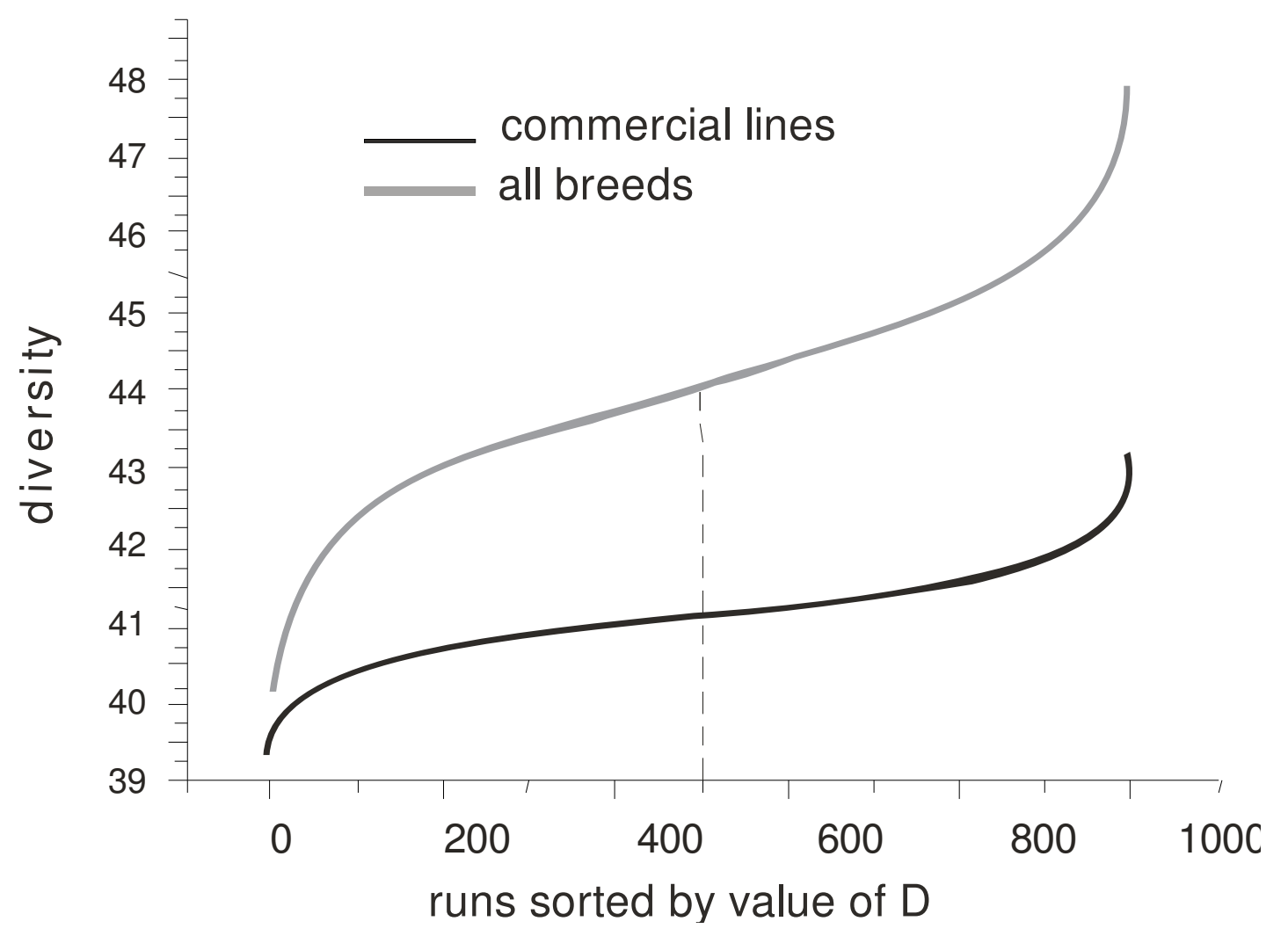

Figure 8: Sorted results of diversity estimations based on 1000 replicates from 10 animals, respectively, sampled from either 8 randomly sampled breeds or out of 8 commercial lines.

\subsubsection{Contribution}

The effect of single breeds to the total diversity measured when only a restricted number of breeds are allowed to be maintained is shown in figure 8. If some breeds were included to be possibly chosen for conservation by displacement they lower the chance for other breeds to be chosen. In the shown case where 10 animals from 8 breeds were allowed to be chosen out of the 28 breeds described in chapter 2 Paduaner and Brown layer $\mathrm{D}$ line have the lowest value. Their diversity values on the left site of the vertical indicates that including this breeds to be considered for conservation activities would cost other breeds the possibility that would add more additional diversity to the total pool. Thüringer Barthühner and Brakel would increase average diversity if 8 breeds with 10 representatives each would be chosen out of our 28 possibilities. In figure 9 the breeds are arranged in order to fit the maximum likelihood tree calculated in chapter 2 to give a over all context. 


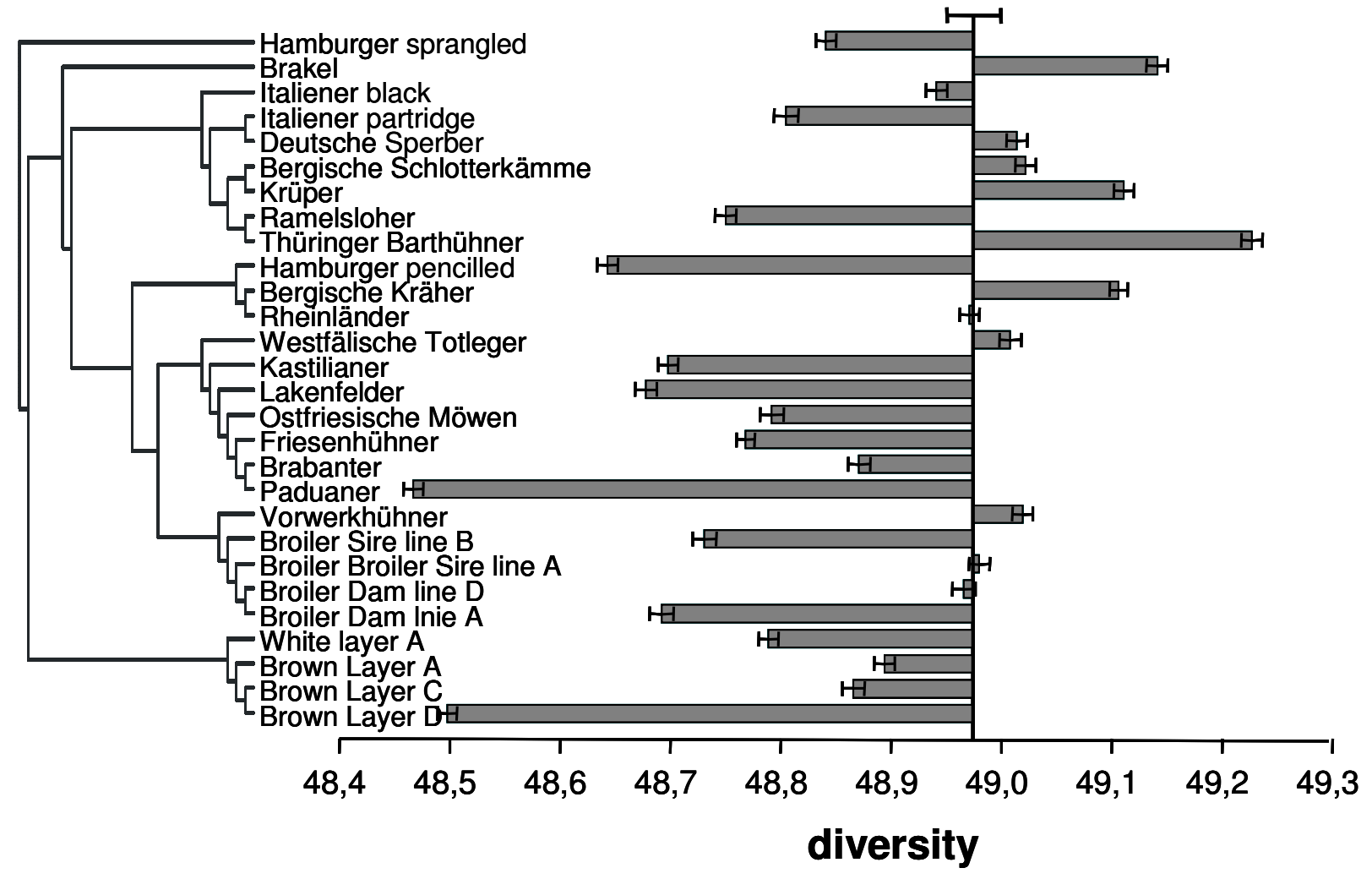

Figure 9: Contribution of breeds to total diversity. Zero line representing diversity obtained when all breeds are mixed and equal probably chosen by random.

\subsubsection{Shape and colour phenotypes}

Except of all Algorithms have clustered both Italiener (Leghorn Standard Type) colour variant and grouped both Hamburger (pencilled and sprangled) and the Rheinländer chicken in one group no further similarities could be found when using different maximum parsimony methods to the phenotypic data recorded in this study. 
a)

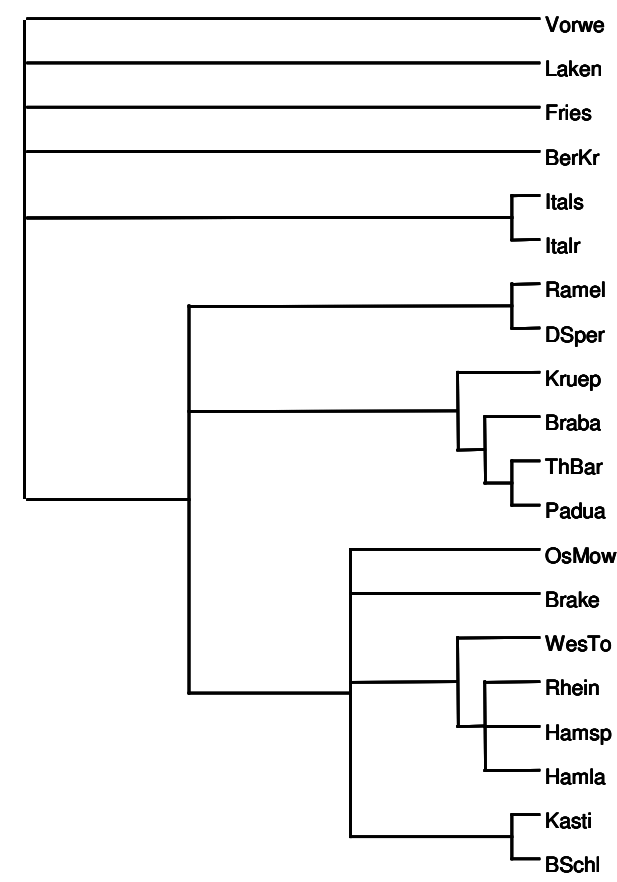

c)

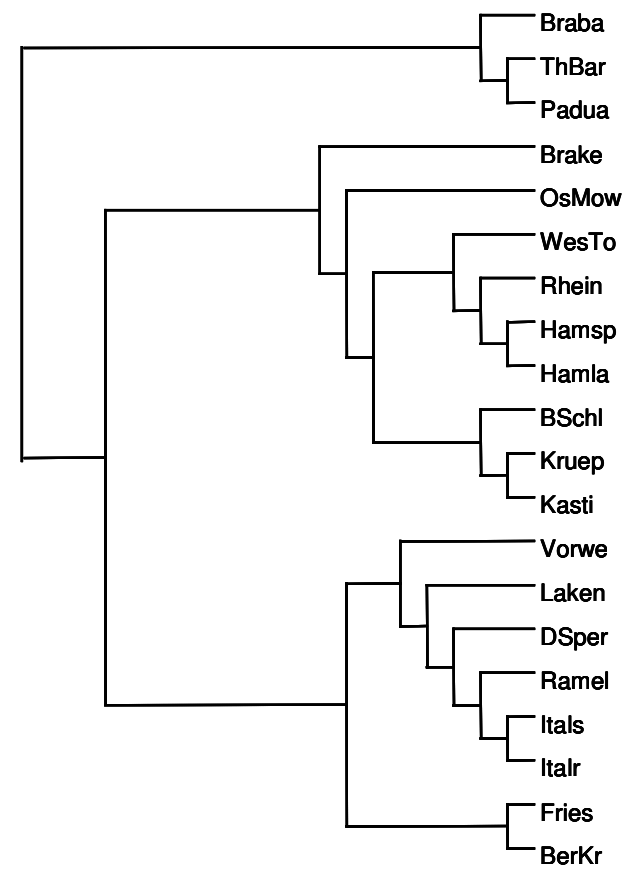

b)

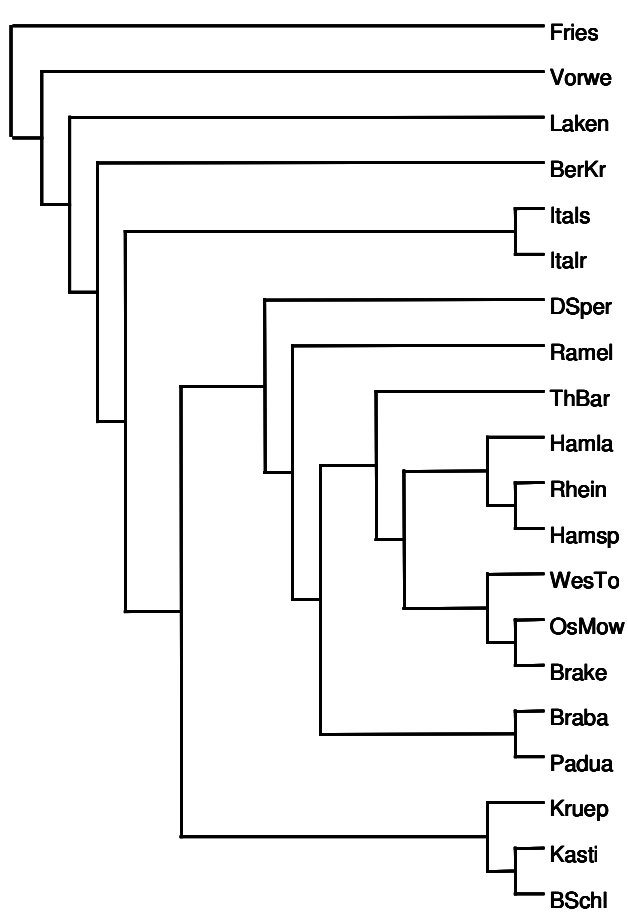

d)

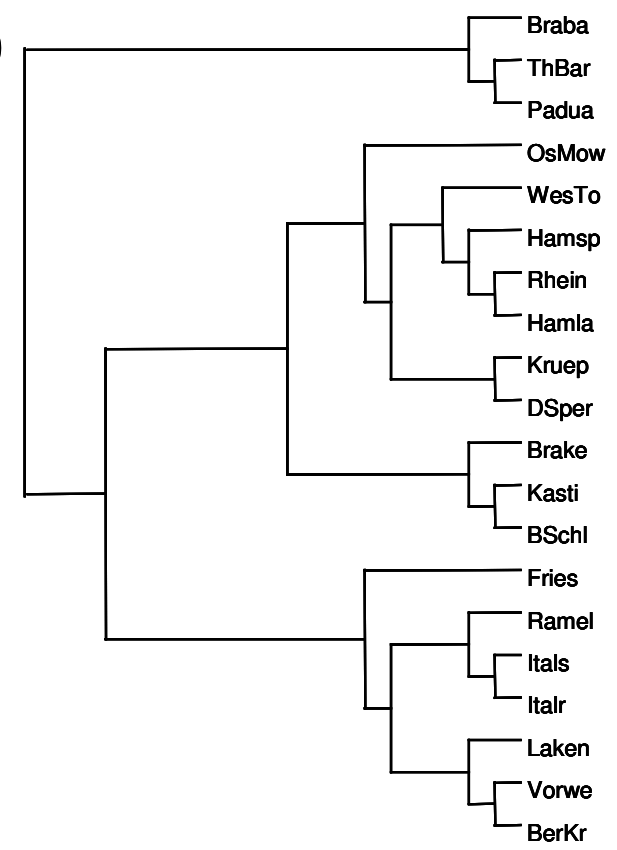

Figure 10: Phylogenetic tree based on phenotypic characteristics using a) PARS general parsimony b) DOLPENNY branch and bound program with Dollo algorithm. c) MIX general parsimony program with Camin-Sokal algorithm. d) PENNY branch and bound program with Camin-Sokal algorithm. 
The PARS Algorithm clustered, similar to DOLPENNY Vorwerk, Lakenfelder, Friesenhühner Bergische Kräher and both Italiener (Leghorn Standard type) as most distant to all others (figure 9).

Despite some similarities to PARS mentioned above, DOLLPENNY not grouping Thüringer Barthühner to Paduaner and Brabanter even though they are all crested breeds and that for known to be related (figure $9 \mathrm{a}$ and b). DOLLPENNY and MIX were the only one to show the relatedness of Krüper and Bergische Schlotterkämme They are more or less the same breed but Krüper having a heterozygous short leg gene. By breed standard leg colours of this breeds are defined differently (Bergische Schlotterkämme: black and Krüper: grey). This was apparently not weighted too much by those algorithms. The similarity of grey and black compared to fleshy was not defined in the data used but would certainly improve the results. For that purpose a clear definition and if possible physiological background would have to be defined. The definition in the breed standard varies between the single breeds and plumage colours.

The MIX algorithm using Carmin-Sokal has similarities to PENNY using CarminSokal, too. Both group Brabanter, Thüringer Barthühner and Paduaner not only together but as most distant to all other breeds (figure $9 \mathrm{c}$ and $\mathrm{d}$ ).

Figure $9 \mathrm{~d}$ shows a three build with PENNY algorithm using Camin-Sokal. Despite some similarities with MIX the group Friesenhühner, Ramelsloher, both Italiener (Leghorn Standard type), Lakenfelder. Vorwerk and Bergischer Kräher do not contain Deutscher Sperber like in MIX (figure $9 \mathrm{c}$ and $\mathrm{d}$ ).

\subsection{Discussion}

\subsubsection{Probability of normal densities}

Genetic diversity contained in commercial lines is smaller than in the same number of equal sized fancy breed populations. In our example it was possible to choose eight breeds from each group, commercial line ore fancy breed. The number of fancy breeds being kept in Germany is very large and it can be assumed that they contain a major part of the diversity among all chickens. Therefore commercial lines alone cannot be considered as a sufficient repository of neutral genetic diversity. This is an 
additional incentive for preservation of the numerous breeds existing in small populations kept by fanciers but containing a unique gene reservoir.

If conservation capacities are restricted however, considering too many breeds foe conservation would not achieve the best results. Breeds having a lower contribution would displace other breeds with higher contribution.

\subsubsection{Phenotypes}

Most noticeable are the very different relations between populations by using slightly different algorithms. This may have various reasons. Firstly there are few traits taken into account. Only six phenotype traits were used in contrast to 29 microsatellite markers and the chosen breeds are similar in various phenotypic characteristics. This leads to no clear grouping among close related breeds, all central European white layer type with dark or fleshy shanks. Secondly all models suppose a one directional evolution of the analyzed populations. This is not always true for species and it is never true for breeds, like in our case. Breeds are not mainly similar because they have common ancestors but because they are crossed with each other. Thirdly many variations in traits occur in various breeds even if this special variation was not included in this study. For example Italiener (Leghorn Standard Type) was sampled in two populations both having single comb, one population with black plumage and the other with partridge plumage. However, Italiener exists with rose comb, too and in 22 plumage colour variations having for each of these a bantam type. This reflects that eye-catching phenotypes are not necessarily a distinguishing mark for different breeds. It is more a combination of different phenotypic characters such as shape, colour, weight, type, performance and behaviour plus a historic background. This is hard to put into calculable units and would require a study focused on that issue. For our purpose of calculating similarities of German or European breeds for conservation priorities it is not suitable if used alone. Nevertheless these traits can be included into the Weitzman model described in the chapters 3 as an addition to genetic data.

Of course, since not every possible phenotypic characteristic could be measured and encoded for analysis, the selection of features to measure is a major inherent obstacle to this method of using only phenotypes. The decision of which traits to use 
as a basis for the matrix necessarily represents a hypothesis about which traits are important. 


$$
5^{\text {th }} \text { Chapter }
$$

\section{GENERAL DISCUSSION}




\section{GENERAL DISCUSSION}

The overall goal of this study was to enhance tools for calculating conservation priorities in farm animals for instance in German chicken breeds. This is especially necessary for poultry because no governmental conservation and promotion program exists. In poultry, especially in chicken the confusing large number of breeds and varieties makes decisions about conservation priorities, uniqueness and similarities difficult. This study developed a way of calculating neutral genetic values within and between a large number of populations and individuals and combined it with phenotypic particularities and cultural importance to make decisions about conservation priorities.

When using microsatellites as it is described in chapter 1 , the main problem that remains even when using them for breeds is the question about neutrality in respect to selected traits. Using FAO recommended markers we used established and preferably uncomplicated markers developed by specialised working groups but always keeping in mind possible linkages of markers to traits that are directly or indirectly selected by breeders or environment. Breeds that experience a similar environment or utilization may be assigned to be more similar due to microsatellite analysis as they would be if the whole genome was known. This could be corrected by including knowledge of factors that might influence selection and include more than one breed of each selection type.

As shown in Chapter 2, external populations influence priority rating for the breeds considered for conservation activities. This influence leads to the necessity of coordinating national and international conservation projects. If conservation activities are concentrated and optimized on local scale, ignoring the fact that there may be closely related breeds in other regions, allocation of funds and conservation efficiency are expected to be sub-optimal (SIMIANER 2005). FAO's Domestic Animal Diversity Information Service (www.fao.org/dadis/) newly published the additional information to the listed breeds if they are local or transboundary. This facilitates the access to worldwide information about external populations for conservation schemes. Problems in considering populations for governmental supported programmes beyond narrow regions of responsibility begin even inside Germany. 
Each federal state accounts for its territory to formulate animal breeding laws at least for mammals (TierZG §9). Cooperation between federal states and countries is especially supported by FAO and EU within member countries. One organization that suggests risk states on international level is the American Lifestock Breeds Consevancy (ALBC). SIMIANER (2005a) concluded in his review that since the major species are globally distributed, conservation of farm animal diversity is a global task. Since in contrary to this, conservation decisions are mostly made on the national level he claims that creating an internationally co-ordinated conservation policy is of crucial importance. The results shown in Chapter 2 underline this aspect.

Differences to other conservation programmes compared to Weitzman's approach are its iterative character designating the contribution to total diversity for each breed in dependence of all other breeds and calculating its conservation potential not only based on population size but on the gain of saved diversity per amount spent on that specific breed, including extinction probabilities, special traits and cultural values. The result may differ from intuitively tendency of always putting the biggest effort in the rarest breed. Political preferences for certain breeds can be included by setting a high cultural value for preferred breeds. Cooperation with other country's conservation programmes can easily be included as shown in chapter 2 .

The main objective of Chapter 3 was to develop a possibility to calculate Weitzman's approach for bigger sample sizes and this allowed for inner breed diversity to be taken into account. This was done by an approximation that estimates Weitzman diversity very accurately and was used to calculate diversity within and between breeds in one step and determine a new measurement that we called Relative Diversity Index (RDI). In contrast to the core set proposed by EDING et al (2002) that was developed to consider between and within breed diversity based on kinship, no estimator is needed in Weitzman's approach. Weitzman's mathematically wellfounded approach (WEITZMAN 1992; 1993; 1998) used in several studies (CAÑóN et al. 2001; Garcia et al. 2005; LAVAL et al. 2000; ReIST-MARTI et al. 2005; 2005a; SIMIANER 2005b; 2003; THAON D'ARNOLDI et al. 1998) can be utilized for more extensive sample sizes and for consideration of within population diversity. 
Chapter 4 presents a further possibility of application for the above mentioned approximation by calculating the probability of normal densities of diversity contained in small subsets of the whole chicken population or fancy breeds only. This simulation of small conservation units compared with the whole existing diversity underlines the importance of fancy breeds. Even though only a small number of 20 breeds out of about 200 breeds existing in Germany and these all being of a similar, white egg laying central European type they contained about the same diversity that was found in eight commercial lines representing broiler, white layer and brown layer types.

This great variance in fancy breeds that are selected mainly by appearance leaded us to have a look at how they would be arranged within a phylogenetic tree if considering only very obvious phenotypic traits. Poor precise information, similarities between the studied breeds, overlapping of traits and no increased emphasis in this issue led us to conclude that using only phenotypic traits described in the breeding standard is not applicable for our need of planning conservation schemes for genetic diversity. Even though plumage colour has been used for identification of chicken populations (YAMI 1995) because its easy assess, phenotypic variation is influenced by the environment (CroOIJMANS et al. 1996) and will not reflect true genetic diversity (EDING 1999). For standardized breeds however, especially if displaying complex patterns, it may be an indicator for being isolated populations kept by concerned breeders.

In Europe fanciers keep a great number of chicken breeds out of passion spending time, money and locality for keeping different breeds without economic interests. Not only in Europe but in nearly every country there are people keeping and breeding poultry for fun, game, ornament, tradition or other cultural reasons. This fact and the result of chapter 4 regarding the amount of genetic diversity contained in noncommercial breeds leads inevitably to a conservation concept using these resources to promote in situ programmes encouraging smallholders and fanciers. In-situ conservation copes with conservation of cultural aspects of farm animals and also maintains a breed dynamic to adapt to the environment and develop its characteristics. Breeds that live in a real word remain known at least by local people, it is adapted to different conditions and experience continuous breeding progress (Hall and Bradley 1995; Henson 1992). A combination between in situ and 
cryoconservation seem to be a desirable way for effective conservation of genetic backups of livestock (HALL 2004).

The scientific approach suggested in this thesis can be used as a tool to create and monitor conservation priorities what breeds should be supported and spend given funds on, the most efficient way in means of maximizing diversity. Funds can be spend in different ways of support such as developing local or niche markets, establishing herdbooks, promoting "forgotten" breeds and explore specialities of breeds by quantifying different traits in performance tests can be taken into account. SIMIANER (2005a) listed six major conservation activities that can be implemented in different ways:

- a premium paid to balance loss of income compared to keepers of more competitive breeds

- training courses to improve genetic management

- support of marketing activities

- a kryoconserve of embryos and semen

- organisation of exchange of male animals between herds

- invest in AIDS research because of the destruction of social structures by this disease which may put high risk on the breeds kept in those countries

In addition non-negligible costs for design and co-ordination of conservation projects should be taken into account (SIMIANER 2005a).

The questions that remain in breed conservation are more a matter of principle. Do we want to conserve mainly neutral diversity and are microsatellites really neutral? To what extend do we want to include known phenotypic traits and cultural values? How important are aesthetics and the recreational benefits? How to appoint the financial benefits in case of future use of conserved gene pools? How much money do we want to invest overall species and breeds? These questions, especially the latter cannot be derived from a scientific point of view, since this is rather a political decision. The difficulties in assigning cost and benefits of conservation as well as the imbalance of local and present conservation but global and future gain affect the outcome of such general decisions (SIMIANER 2005a). 
Germany lacks a conservation and diversity promoting programme for chicken. In contrast to other species such as cattle, pigs, sheep, goats and horses, poultry is not included in the German animal breeding law (TierZG) that regulates governmental conservation efforts for each country. This apparent disadvantage enables us to develop a transboundary concept at least for all German countries.

The breed samples utilized in this study are an example set to model a usable method. It contains 20 breeds all kept and sampled in Germany but not all being original German breeds in the sense that the first herd book was established in Germany nor are all German breeds included in the set of breeds as it is described in chapter 1. The Italiener chicken (also called Leghorn standard type), was sampled in two plumage colour variants and they were treated as two populations whereas other breeds were treated as one population even though different colours were included. This was done to reveal possible effects of plumage colour selection within breeds. This is arguable for our purpose of testing the method but of course leads to no statement about conservation priorities for German chicken breeds. Further on all utilized breeds were of a south European white egg laying type whereas the commercial lines were one white layer, tree brown layers and four broilers. This leads to distorted conclusions when looking at relationships and influences between local breads and commercial lines and even when looking at the amount of diversity in each of these groups when comparing them. Again, for showing that there is an influence and to some extend in which direction this influence acts, these samples were good enough but not for any kind of quantitative statement.

\section{Implications and recommendations}

First sampling of all German and other relevant breeds is necessary. Then political decisions on what the goals of conservation are. Third fields have to be weighted: future use, present use in niche markets and preservation of national treasures. Thus economy, agriculture and cultural tradition are the mainly divisions to involve. 


\section{REFERENCES}

AtZmon, G., S. Blum, M. Feldman, A. Cahaner, U. LaVI et al., 2008 QTLs detected in a multigenerational resource chicken population. J Hered 99: 528-538.

BallouX, F., OIS and N. LUGON-MOULIN, 2002 The estimation of population differentiation with microsatellite markers. Molecular Ecology 11: 155-165.

BARKER, J. S., 2001 Conservation and management of genetic diversity: a domestic animal perspective. Canadian Journal of Forest Research 31: 588-595.

BDRG, 2000 Zuchttierbesctandserfassung 2000, Bund Deutscher Rassegeflügelzüchter e.V.

BDRG, 2005 Zuchttierbesctandserfassung 2005, Bund Deutscher Rassegeflügelzüchter e.V.

BEINLICH, B., and P. POSCHLOD, 2002 Low intensity pig pastures as an alternative approach to habitat management. Springer, Berlin.

BENNEWITZ, J., H. SiMIANER and T. H. MeUWISSEN, 2008 Investigations on merging breeds in genetic conservation schemes. J Dairy Sci 91: 2512-2519.

BMELV, Animal Genetic Resources in Germany, Bonn.

BoogaARD, B. K., S. J. OOsting and B. B. Bock, 2008 Defining sustainability as a socio-cultural concept: Citizen panels visiting dairy farms in the Netherlands. Livestock Science 117: 24-33.

BROWN, G., and J. H. GolDSTEIN, 1984 A model for valuing endangered species. Journal of Environmental Economics and Management 11: 303-309.

Caballero, A., and M. A. Toro, 2002 Analysis of genetic diversity for the management of conserved subdivided populations. Conservation Genetics 3: 289-299.

CAMIN, J. H., and R. R. SOKAL, 1965 A method for deducing branching sequences in phylogeniy. Evolution 19: 311-326.

Cañón, J., P. Alexandrino, I. Bessa, C. Carleos, Y. Carretero et al., 2001 Genetic diversity measures of local European beef cattle breeds for conservation purposes. Genetics Selection Evolution 33: 311-332.

CAREFOOT, W. C., 1990 Breeding and selection by poultry fanciers, pp. 1029-1048 in Poultry Breeding and Genetics, edited by R. D. CRAWFORD. Elsevier Science Publishers. 
CBD, 2005 Handbook of the convention on biological diversity including its cartagena protocol on biosafety Secretariat of the Convention on Biological Diversity, Montreal, Canada.

Crooljmans, R. P., A. F. Groen, A. J. Van Kampen, S. Van der Beek, J. J. Van der POEL et al., 1996 Microsatellite polymorphism in commercial broiler and layer lines estimated using pooled blood samples. Poult Sci 75: 904-909.

DeLANY, M. E., 2003 Genetic diversity and conservation of poultry. CABI Publishing, Wallingford, UK.

Delany, M. E., 2006 Avian genetic stocks: the high and low points from an academia researcher. Poult Sci 85: 223-226.

ECK, R. V., and M. O. DAYHOFF, 1966 Evolution of the Structure of Ferredoxin Based on Living Relics of Primitive Amino Acid Sequences. Science 152: 363-366.

EDING, H., and J. BENNEWITZ, 2007 Measuring genetic diversity in farm animals in Utilisation and conservation of farm animal genetic resources Wageningen Academic Publishers. Wageningen.

Eding, H., R. P. Croolumans, M. A. Groenen and T. H. Meuwissen, 2002 Assessing the contribution of breeds to genetic diversity in conservation schemes. Genet Sel Evol 34: 613-633.

EdING, H., and T. H. E. MEUWISSEN, 2003 Linear methods to estimate kinships from genetic marker data for the construction of core sets in genetic conservation schemes. Journal of Animal Breeding and Genetics 120: 289-302.

EDING, J. H. L., G., 1999 Measuring genetic uniqueness in livestock, pp. 33-58 in Animal genetics and breeding. Institute for Animal Science and Health IDDLO, Lelystad (Netherlands).

EriKsSON, J., G. LARSON, U. GUNNARSSON, B. BED'HOM, M. TIXIER-BOICHARD et al., 2008 Identification of the yellow skin gene reveals a hybrid origin of the domestic chicken. PLoS Genet 4: e1000010.

FALCONER, D. S., and T. F. C. MACKAY, 1996 Introduction to Quantitative Genetics. Addison-Wesley.

FAO, 2004, Primary Guidelines for Development of National Farm Animal Genetic Management Plans, Rome.

FARRIS, J. S., 1977 Phylogenetic analysis under Dollo's Law. Systematic Zoology 26: 77-88.

FelSENSTEIN, J., 1978 Number of evolutionary trees. Syst. Zool.; Vol/Issue: 27:1: Pages: 27-33.

Felsenstein, J., 1980 A View of Population Genetics. Science 208: 1253. 
FELSENSTEIN, J., 1982 How can we infer geography and history from gene frequencies? J Theor Biol 96: 9-20.

Foulley, J.-L., and L. OLLIVIER, 2006 Estimating allelic richness and its diversity. Livestock Science 101: 150-158.

GARCIA, D., N. CORRAL and J. CANON, 2005 Combining Inter- and Intrapopulation Information with the Weitzman Approach to Diversity Conservation. J Hered 96: 704-712.

HALL, S. J., 2004 Livestock biodiversity: genetic resources for the future. Blackwell Science, Oxford. United Kingdom.

HALL, S. J. G., and D. G. BRADLEY, 1995 Conserving livestock breed biodiversity. Trends in Ecology \& Evolution 10: 267-270.

HENSON, E. L., 1992 In situ conservation of livestock and poultry, Rome.

Hillel, J., M. A. Groenen, M. Tixier-Boichard, A. B. Korol, L. David et al., 2003 Biodiversity of 52 chicken populations assessed by microsatellite typing of DNA pools. Genet Sel Evol 35: 533-557.

HutT, F. B., 1949 Genetics of the fowl. McGraw-Hill, New York.

Tapio, I. VÄrV, S., BennewitZ, J., Maleviciute, J., Fimland, E., Grislis, Z., MeuWISSEN, T.H.E., Miceicene, I. OlsakeR, I., VIINALASS, H., VILKKI, J., AND KANTANEN, J., 2006 Prioritization for Conservation of Northern European Cattle Breeds Based on Analysis of Microsatellite Data. Conservation Biology 20: 1768-1779.

JARNE, P., and P. J. L. LAGODA, 1996 Microsatellites, from molecules to populations and back. Trends in Ecology and Evolution 11.

Jaturasitha, S., T. SRIKANChAi, M. KREUZER and M. WiCKE, 2008 Differences in carcass and meat characteristics between chicken indigenous to northern Thailand (Black-boned and Thai native) and imported extensive breeds (Bresse and Rhode Island red). Poult Sci 87: 160-169.

KLUGe, A. G., and J. S. FARRIS, 1969 Quantitative Phyletics and the Evolution of Anurans. Systematic Zoology 18: 1-32.

Knap, P. W., and A.-M. Neeteson-Van NieuWenhoven, 2005 Private and public roles in conservation, pp. in International Workshop "Options and Strategies for the Conservation of Farm Animal Genetic Resources". AGROPOLIS, Montpellier, France.

Kremer, A., Remy, J., Pons, P., Pons, O., 1998 Measures of polymorphism within and among populations, pp. 301-311 in Molecular Tools for Screening Biodiversity, edited by A. KARP, PETER, G., INGRAM, I., INGRAM, D.S. Chapman and Hall, London. 
LANDAUER, W., 1944 Length of Survival of Homozygous Creeper Fowl Embryos. Science 100: 553-554.

Laval, G., N. Iannuccelli, C. Legault, D. Milan, M. A. Groenen et al., 2000 Genetic diversity of eleven European pig breeds. Genet Sel Evol 32: 187-203.

LE QUESNE, W. J., 1974 The uniquely derived character concept and its dadistic application. Systmatic Zoology 26: 218-223.

LIU, Y. P., G. S. WU, Y. G. YAO, Y. W. MIAO, G. LUIKART et al., 2006 Multiple maternal origins of chickens: out of the Asian jungles. Mol Phylogenet Evol 38: 12-19.

NEI, M., 1972 Genetic Distance between Populations. The American Naturalist 106: 283.

OLDENBROECK, K., 2007 Utilisation and conservation of farm animal genetic resources. Wageningen Academic Publishers, Wageningen.

Olivera, G. H., D. M. Shepard, P. J. ReckWerdt, K. Ruchala, J. Zachman et al., 1998 Maximum likelihood as a common computational framework in tomotherapy. Physics in Medicine and Biology 43: 3277-3294.

PAGE, R. D., 1996 TreeView: an application to display phylogenetic trees on personal computers. Comput Appl Biosci 12: 357-358.

PenNy, D., L. R. FouldS and M. D. Hendy, 1982 Testing the theory of evolution by comparing phylogenetic trees constructed from five different protein sequences. Nature 297: 197-200.

ReIST-MARTI, S. B., A. AbDUlal and H. SimianeR, 2005 Conservation programmes for African cattle: design, cost and benefits. J Anim Breed Genet 122: 95-109.

ReIST-MARTI, S. B., A. Abdulal and H. SimiAneR, 2006 Optimum allocation of conservation funds and choice of conservation programs for a set of African cattle breeds. Genet Sel Evol 38: 99-126.

Rémy J. Petit, A. E. M. O. P., 1998 Identifying Populations for Conservation on the Basis of Genetic Markers. Conservation Biology 12: 844-855.

REYNOLDS, J., B. S. WeIR and C. C. CoCKERHAM, 1983 Estimation of the Coancestry Coefficient: Basis for a Short-Term Genetic Distance. Genetics 105: 767-779.

RIKIMARU, K., and H. TAKAHASHI, 2007 A method for discriminating a Japanese brand of chicken, the Hinai-jidori, using microsatellite markers. Poult Sci 86: 18811886.

RoBINSON, R., 1985 Chinese crested dog. J Hered 76: 217-218.

Rubin, C. J., H. Brandstrom, D. Wright, S. Kerje, U. GunNarsson et al., 2007 Quantitative trait loci for BMD and bone strength in an intercross between domestic and wildtype chickens. J Bone Miner Res 22: 375-384. 
Sambraus, H. H., 1989 [The native domestic animal breeds of Japan]. Tierarztl Prax 17: $237-243$.

SCHERF, B. D., 2000 World watch list for domestic animal diversity. FAO, Rome (Italy).

SCHIBLER, J., and A. SCHLUMBAUM, 2007 [History and economic importance of cattle (Bos taurus L.) in Switzerland from Neolithic to Early Middle Ages]. Schweiz Arch Tierheilkd 149: 23-29.

SCHMIDT , H., 1999 Hühner und Zwerghühner. Ulmer Verlag.

SchuTZ, K., S. KeRJE, O. CARLBORG, L. JACOBSSON, L. ANDERSSON et al., 2002 QTL analysis of a red junglefowl $x$ White Leghorn intercross reveals trade-off in resource allocation between behavior and production traits. Behav Genet 32: 423-433.

SIMIANER, H., 2005a Decision making in livestock conservation. Ecological Economics 53: 559-572.

SIMIANER, H., 2005b Using expected allele number as objective function to design between and within breed conservation of farm animal biodiversity. J Anim Breed Genet 122: 177-187.

Simianer, H., S. B. Marti, J. Gibson, O. Hanotte and J. E. O. Rege, 2003 An approach to the optimal allocation of conservation funds to minimize losses of genetic diversity between livestock breeds. Ecological Economics 45: $377-$ 392.

SIX, A., and S. WEIGEND, 2002 Projekt: Charakterisierung genetischer Vielfalt beim Haushuhn mit molekularen Markern. Teil 1, pp. Bundesforschungsanstalt für Landwirtschaft (FAL) Neustadt-Mariensee and Bund Deutscher Rassegeflügelzüchter (BDRG).

SMITH, C., 1984 Genetic aspects of conservation in farm livestock. Livestock Production Science 11: 37-48.

SMYTH, J. R. J., 1990 Genetics of plumage, skin and eye pigmentation in chickens, pp. 109-168 in Poultry breeding and Genetics edited by R. D. CraWFORD. Elsevier, Amsterdam, Oxford, New York, Tokyo.

Soller, M., S. Weigend, M. N. Romanov, J. C. DekKers and S. J. LAmont, 2006 Strategies to assess structural variation in the chicken genome and its associations with biodiversity and biological performance. Poult Sci 85: 20612078.

SOMES, R. G. J., 1990a Mutations and major variants of muscles and skeleton in chickens., pp. 209-238 in Poultry breeding and Genetics

edited by R. D. CraWFord. Elsevier, Amsterdam, Oxford, New York, Tokyo. 
SOMES, R. G. J., 1990b Mutations and major variants of plumage and skin in chickens., pp. 209-238 in Poultry breeding and Genetics edited by R. D. CraWFORD. Elsevier, Amsterdam, Oxford, New York, Tokyo.

SOW-ANGR, 2007 THE STATE OF THE WORLD'S ANIMAL GENETIC RESOURCES FOR FOOD AND AGRICULTURE. FAO, Rome.

TAdANO, R., M. NishiBORI, N. Nagasaka and M. TsudZUKI, 2007 Assessing Genetic Diversity and Population Structure for Commercial Chicken Lines Based on Forty Microsatellite Analyses. Poult Sci 86: 2301-2308.

Tapio, I., VÄRv, S., Bennewitz,J., Maleviciute, J., Fimland, E., GRislis, Z., MEUWISSEN, T. H. E., MICEIKIENE I., OLSAKER, I., VIINALASS,H., VILKKI, J. KANTANEN, J., 2006 Prioritization for Conservation of Northern European Cattle Breeds Based on Analysis of Microsatellite Data. Conservation Biology 20: 1768-1779.

TGRDEU, http://www.genres.de/CF/tgrdeu/foerderung/index.cfm.

ThaON d'ARnoldi, C., J. Foulley and L. Ollivier, 1998 An overview of the Weitzman approach to diversity. Genetics Selection Evolution 30: 149- 161.

TISDELL, C., 2003 Socioeconomic causes of loss of animal genetic diversity: analysis and assessment. Ecological Economics 45: 365-376.

Toro, M. A., and A. CABALlero, 2005 Characterization and conservation of genetic diversity in subdivided populations. Philos Trans R Soc Lond B Biol Sci 360: 1367-1378.

WANDELt, R., and J. Wolters, 1996 Handbuch der Hühnerrassen, die Hühner der Welt. Verlag Wolters, Bottrop.

WANG, Q., Y. P. LIU, X. S. JIANG, C. W. YANG, H. R. Du et al., 2007 [Correlation analysis of relationships between polymorphisms of high quality chicken myogenin gene and slaughter and meat quality traits]. Yi Chuan 29: 10891098.

Weigend, S., and M. N. Romanov, 2002 The World Watch List for Domestic Animal Diversity in the context of conservation and utilisation of poultry biodiversity. World's Poultry Science Journal 58: 411-430.

Weigend, S. C., M. A. M. Groenen, M. Tixier-Boichard, A. Vignal, J. Hillel, WIMMERS et al., 1999 AVIANDIV Development of Strategy and Application of Molecular Tools to Assess Biodiversity in Chicken Genetic Resources pp. European Commission Project, copntact no BIO4-CT98-0342.

WeITZMAN, M. L., 1992 On diversity. Quarterly Journal of Economics CVII: 363-405.

WeITZMAN, M. L., 1993 What to preserve? An application of diversity theory to crane conservation. Quarterly Journal of Economics CVIII: 157-183. 
WeitZmAn, M. L., 1998 The Noah's ark problem. Econometrica 66: 1279-1298.

WeitZMAnN, M. L., 1992 On diversity. Quarterly Journal of Economics CVII: 363-405.

WEITZMANN, M. L., 1993 What to preserve? An application of diversity theory to crane conservation. Quarterly Journal of Economics CVIII: 157-183.

WeitZMAnN, M. L., 1998 The Noah's ark problem. Econometrica 66: 1279-1298.

WESt, B., and B.-X. ZHOU, 1988 Did chickens go North? New evidence for domestication. Journal of Archaeological Science 15: 515-533.

WILSON, R. T., 2008 Fit for purpose - the right animal in the right place. Trop Anim Health Prod

Wood-GuSH, D. G. M., 1956 A history of the domestic chicken from antiquity to the 19th century. Poultry Science 38: 321-326.

Woolliams, J. A., and M. TORO, 2007 What is genetic diversity?, pp. 55-74 in Utilisation and conservation of farm animal genetic resources. Wageningen Academic Publishers.

WRIGHT, S., 1969 Evolution and the genetics of populations. The theory of gene frequencies. University of Chicago Press. USA.

YAMI, A., 1995 Poultry production in Ethiopia. World's Poultry Science Journal 51: 197-201.

ZHANG, Z. R., Y. P. LIU, X. JIANG, H. R. DU and Q. ZHU, 2008 Study on association of single nucleotide polymorphism of CAPN1 gene with muscle fibre and carcass traits in quality chicken populations. J Anim Breed Genet 125: 258-264.

Zhou, H., N. Deeb, C. M. Evock-Clover, C. M. Ashwell and S. J. Lamont, 2006a Genome-wide linkage analysis to identify chromosomal regions affecting phenotypic traits in the chicken. I. Growth and average daily gain. Poult Sci 85: 1700-1711.

Zhou, H., N. Deeb, C. M. Evock-Clover, C. M. Ashwell and S. J. Lamont, 2006b Genome-wide linkage analysis to identify chromosomal regions affecting phenotypic traits in the chicken. II. Body composition. Poult Sci 85: 17121721.

Zhou, H., N. Deeb, C. M. Evock-Clover, A. D. Mitchell, C. M. Ashwell et al., 2007a Genome-wide linkage analysis to identify chromosomal regions affecting phenotypic traits in the chicken. III. Skeletal integrity. Poult Sci 86: 255-266.

Zhou, H., C. M. Evock-Clover, J. P. McMurtry, C. M. Ashwell and S. J. LAMONT, 2007b Genome-wide linkage analysis to identify chromosomal regions affecting phenotypic traits in the chicken. IV. Metabolic traits. Poult Sci 86: 267-276. 
Zhou, M., M. LeI, Y. RaO, Q. Nie, H. Zeng et al., 2008 Polymorphisms of vasoactive intestinal peptide receptor-1 gene and their genetic effects on broodiness in chickens. Poult Sci 87: 893-903. 


\section{APPENDIX}

\section{Involved organizations}

\section{BLE}

On behalf of the German ministry for food, agriculture and consumer protection (BMELV) the federal institute for agriculture and food (BLE) oversees scientific projects. Among other they have two subject areas where biological diversity is the main topic:

- Inventories and surveys in the area of biological diversity.

- Pilot and demonstration projects in the field of innovative conservation and sustainable use of biological diversity. The BLE was giving financial support to this study.

\section{Friedrich-Loeffler Institut (former FAL)}

In close work with this facility of the German ministry for food, agriculture and consumer protection all lab work was done in the Institute for Animal Health in Mariensee.

\section{BDRG}

The German fancy poultry breeders club (BDRG) cares for the standard of local and exotic poultry breeds. About 300.000 people are joining. The BDRG supported blood sampling activities on poultry shows.

\section{ILRI}

The International Livestock Research Institute (ILRI) works at the crossroads of livestock and poverty, bringing high-quality science and capacity-building to bear on poverty reduction and sustainable development. The ILRI provided parts of the software used in this study. 


\section{Breeds and traits used in this study}

\section{Bergische Kräher}

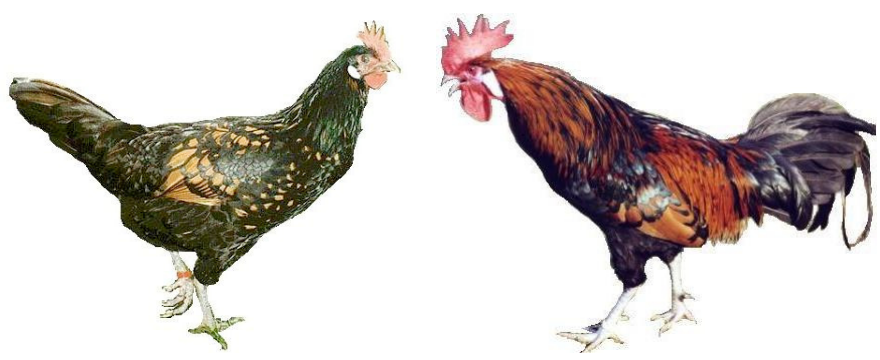

Cultural value: A legend about this German breed says that the Earl Eberhard von Berg (died 1152) was retrieved from a lost ballet by the crow of a cock. He bought the cock from a charburner and a convent owned by the earl continued breeding this chickens. They crow five times longer than other breeds and in contrast to others they keep on walking while crowing and lower the head slowly until reaching the ground. Because of a later enthusiasm of people for betting on crow competition, laws were implemented to regularize these activities. Like other long crower breeds of Japan and China they have an arched back.

Colour: The typical colour is rare in other breeds but the only they display in.

Comb: single

Legs: grey-blue

Eyes: orange or light red

It is listed as strongly endangered German breed by the GEH.

Bergische Schlotterkämme Black

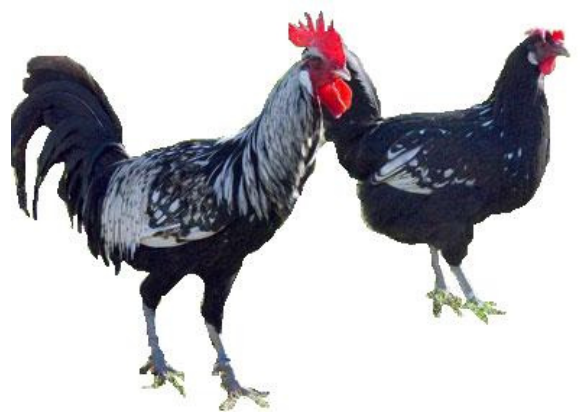

Cultural value: In the same area as the Bergischer Kräher for centuries people kept this other German breed. Due to geographical nearness and the fact that this breed 
can display in the same rare colour pattern as the Bergische Kräher there surely occurred crossbreeding. Krüper and Castellana were also crossed in.

Colour: In this study only the black coloured were sampled

Comb: single

Legs: In this case dark grey

Eyes: brown red

It is listed as extremely endangered German breed by the GEH.

Brabanter Black, Gold, Chamois

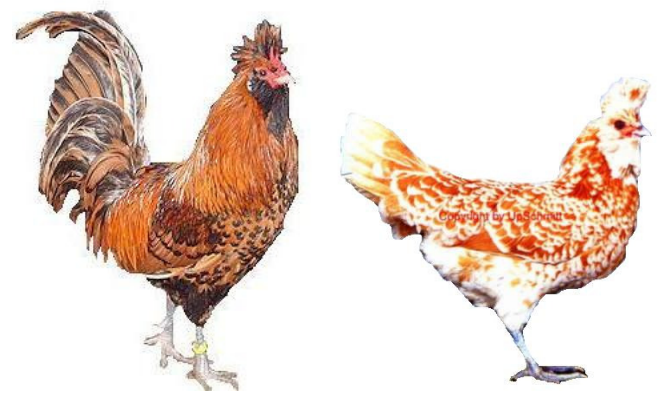

Cultural value: A Dutch breed documented first in a painting of Melchior d'Hondecoeter (1636 - 1694). In France and Germany they crossed La Flèche to obtain a "proud" body posture. Colour: In this study only the black, gold and chamois where sampled

Comb: two v-shaped horns

Legs: blue grey

Eyes: orange or red

Additional trait: sharp crest and beard

Brakel Silver

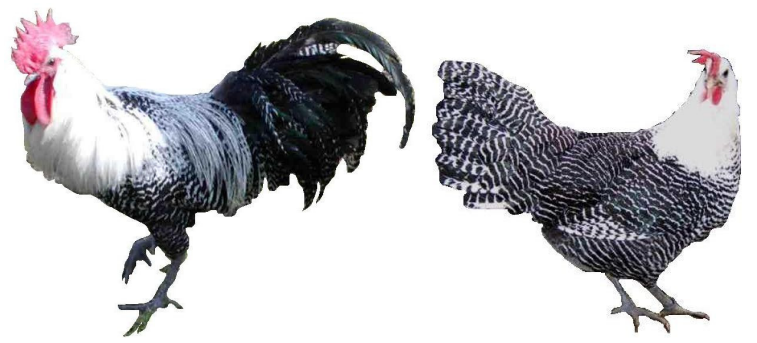

Cultural value: Brakel is a Dutch rooted breed that was modified by Belgians and than spread in Germany since 1895. It is assigned as German breed. 
Colour: It has a feather pattern similar to pencilled, like Totleger, but it should be stripier than those.

Comb: single

Eyes: dark brown surrounded by black eye lid

Legs: bluish with white toe tips.

It is listed as to be observed in the German red list for breed by the GEH.

Deutsche Sperber

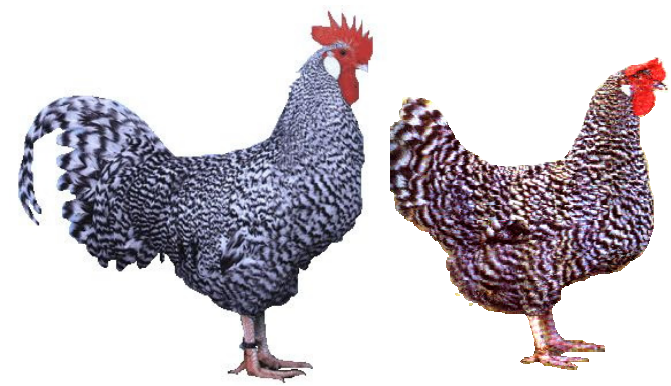

Cultural value: This German breed is a result of crossing Italiener (Leghorn standard type) with Plymouth Rocks and later Minorca and Schlotterkaemme since 1900. It is known to be a calm breed that does not tend to overtake fences.

Colour: cuckoo

Comb: single

Eyes: red brown

Legs: fleshy

It is listed as strongly endangered German breed by the GEH.

Friesenhühner Yellow Pencilled
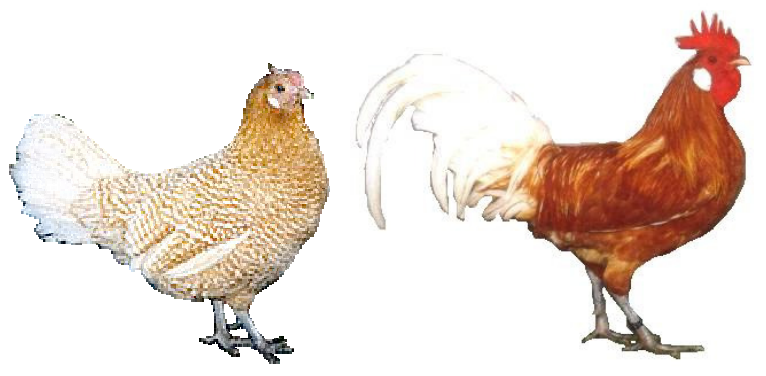

Cultural value: A primordial Dutch breed. They are supposed to immigrate with the Frisian tribe into the Netherlands. It is a delicate and agile animal. They are known to overtake high fences. 
Colour: Their feather pattern is similar to pencilled and was described in 1880 as the same of and rough-textured tissue. In German it is called "geflockt" in contrast to "sprenkel" and "gebaendert". Though in English all are called pencilled the pattern of single feathers and its distribution over the body is different. In this study only the yellow pencilled original colouration was sampled.

Comb: single

Eyes: Big dark orange red eyes

Legs: grey blue

Hamburger Silver Sprangled

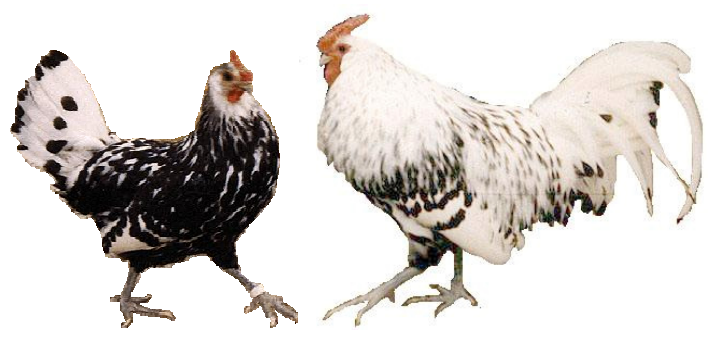

Cultural value: This old German breed was painted by the English artist Albin in 1740. It was subtitled "Hamburghs" indicating its origins. They originate from old German pencilled breeds, Paduans and English Mooney (Redcap) breed. Later, back in Germany it was crossbred with Sumatra, Moewen, Westfaelische Totleger, Spanish and Minorca for body shape, feather density, sheen and colouration. It is a gracile but not to small animal.

Colour: only sprangled was sampled for one population in this study

Comb: rose comb that narrows to a spur as a typical characteristic of Hamburger chickens. Eyes.dark red brown

Legs: grey blue or black 
Hamburger Pencilled

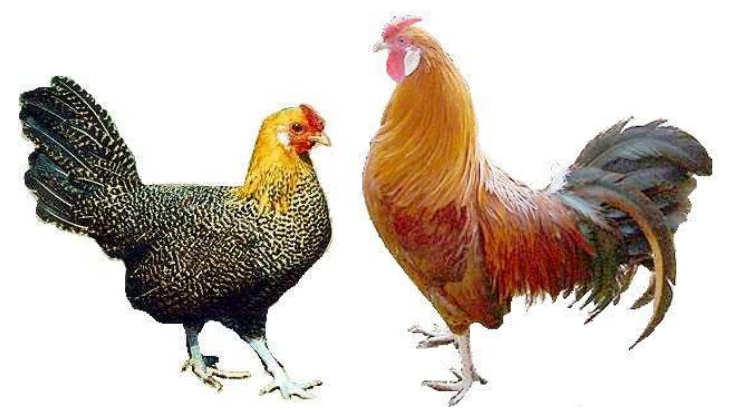

Colour: only pencilled was sampled for one population in this study

Italiener (Leghorn standard type) Partridge and black

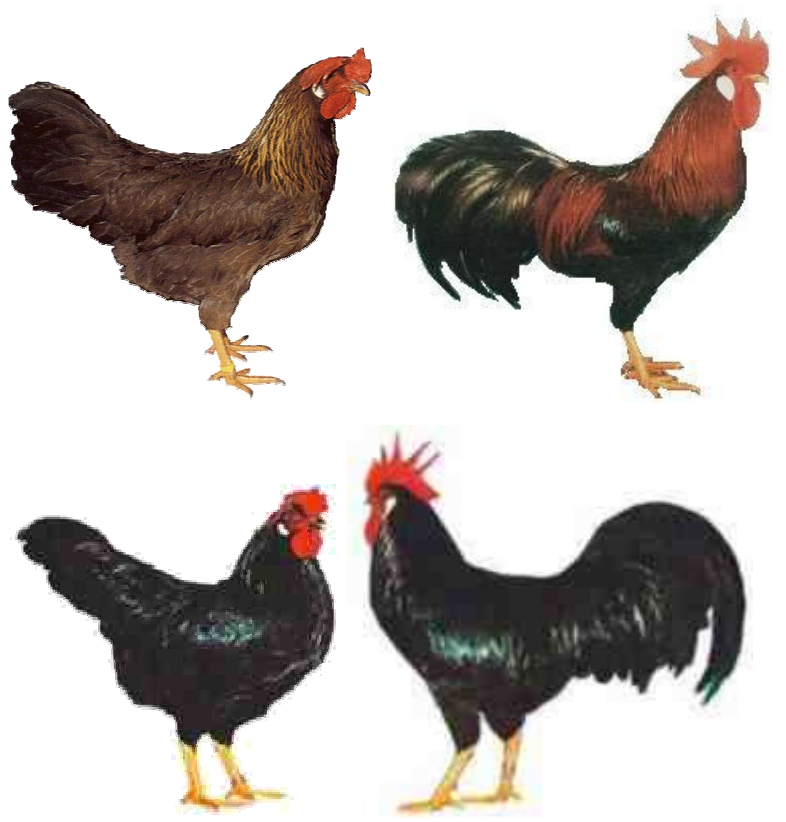

Cultural value: Since 1870 the Romans from Lombardy spread their chickens from Italy and England to the whole continent. There are some assumptions that these chickens arrived Germanic areas when colonised by the Romans. This partridge coloured animals were known as brown Leghorn. It is a genuine layer.

Colour: only partridge and black were sampled for one population in this study Comb: single Eyes: orange red Legs: yellow 
Castelliana
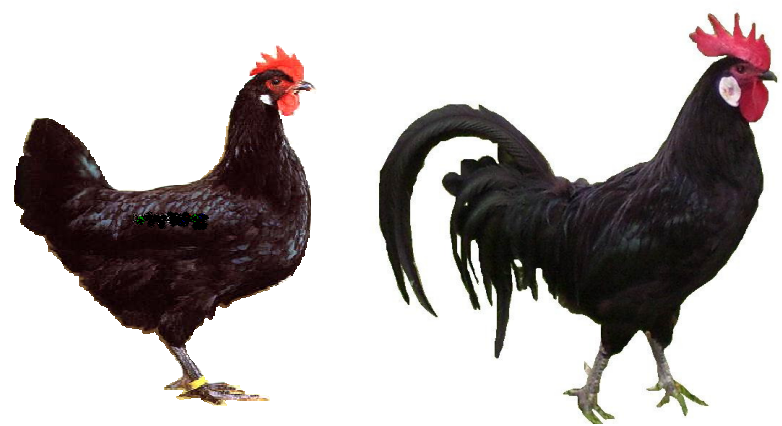

Cultural value: A Spanish breed that is supposed to be described in the year 800 in Spain.

Colour: black shining like a beetle

Comb: single

Eyes: brown

Legs: grey

Krüper Black

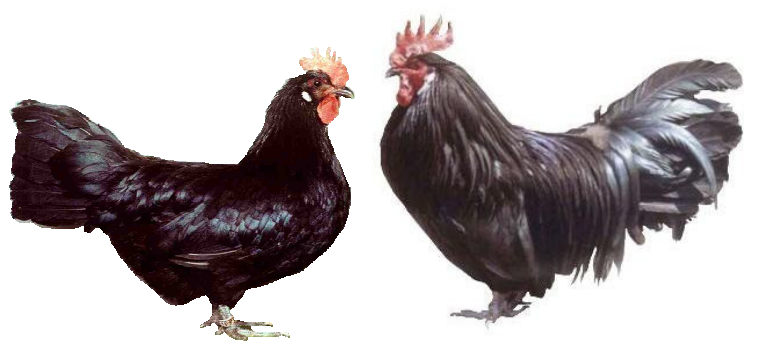

Colour: In this study only the black coloured were sampled

Comb: single

Eyes: brown

Legs: grey

Additional trait The main characteristic of this German breed is its short legs. It is due to a heterozygote occurrence of a lethal gene $\mathrm{cp}$ that makes it necessary to keep a non-short legged line. This mutation is supposed to have occurred independently several times.

It is listed as extremely endangered German breed by the GEH. 


\section{Lakenfelder}

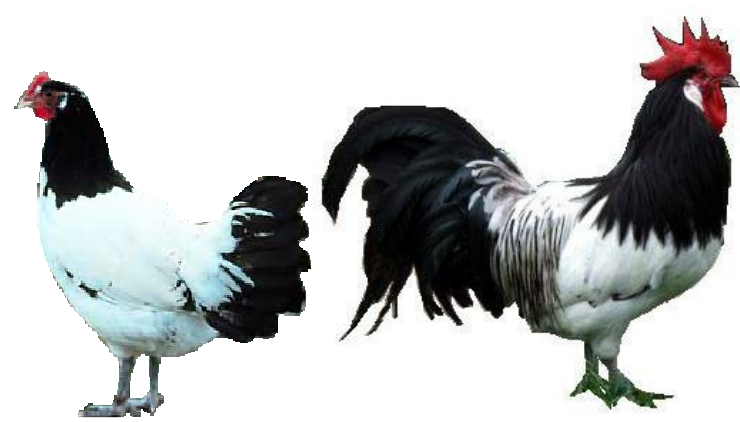

Cultural value: A German breed developed from the pencilled chicken type of the north. First descriptions of the breed are from in 1835.

Colour: white with black head, neck and tail. It occurs exclusively in this breed.

Comb: single

Eyes: dark red

Legs: grey blue

It is listed as endangered German breed by the GEH.

\section{Ostfriesische Möwen Silver pencilled}

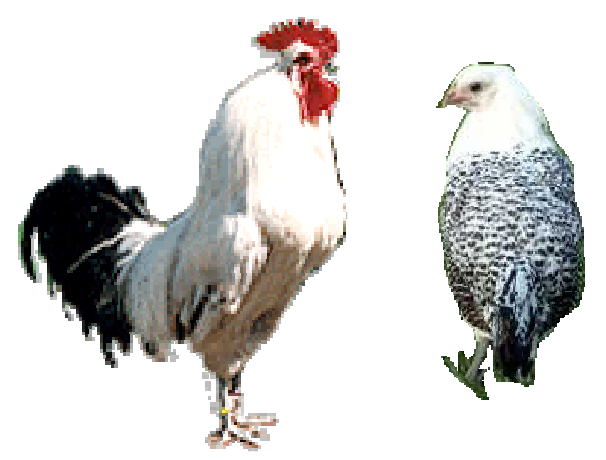

Cultural value: A German breed descendant of pencilled north type chickens.

Colour: a typical rough textured colour pattern next to sprangled. All black spots must have a green sheen.

Comb: single

Eyes: brown or dark red

Legs: grey blue

It is listed as strongly endangered German breed by the GEH. 
Paduans Chamois, Black, Silver, Gold, White

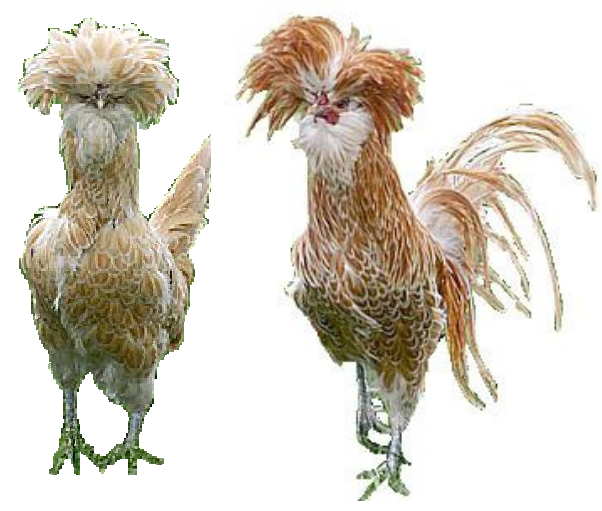

Cultural value: It is known to be the oldest crested breed. Assumedly ancestors from Russia it is known since the $15^{\text {th }}$ century. The breed was developed in Poland, Italy and England. First documentation in Germany was a painting of Frisch in 1763.

Colour: For this study only Chamois, gold, silver, black and white animals were sampled.

Comb: no comb

Eyes: brown or orange red depending on the feather colour

Legs: blue grey

Additional trait The main feature is its crest caused by a protuberance of the brain and cranium. It is necessary to comb the crest feathers because the animals are not able to remove pinfeathers and parasites. Because of restrictions of the visual field due to a big crest it is an issue discussed in animal welfare topics. Breeders have to care for a free sight.

Ramelsloher White
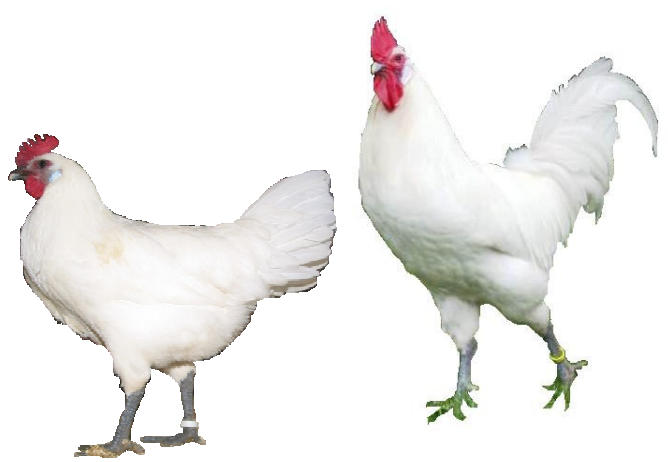

Cultural value: A German breed developed in the convent of Ramelsloh 1870.

Colour: Only white coloured were sampled in this study 
Comb: single

Eyes: dark with black eyelid

Legs: blue with white toes

It is listed as extremely endangered German breed by the GEH.

\section{Rheinländer Black}

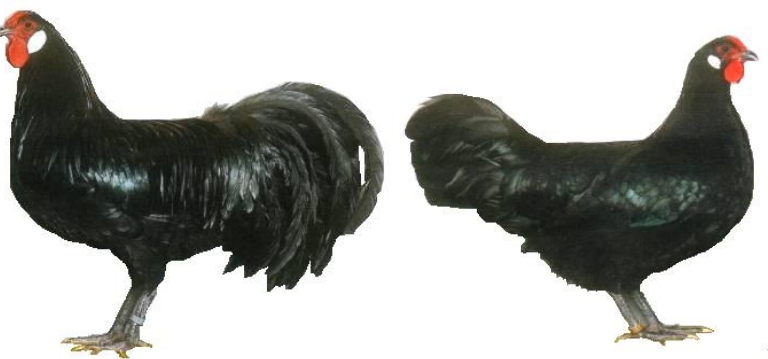

Cultural value: A German breeder created this chicken and wrote 1894 that his main interest was egg production. They were influenced by Bergische Kraeher and Le Mans.

Colour: only black coloured were sampled in this study

Comb: rose

Eyes: dark brown

Legs: black

Thüringer Barthühner Black, Gold, Chamois, Silver

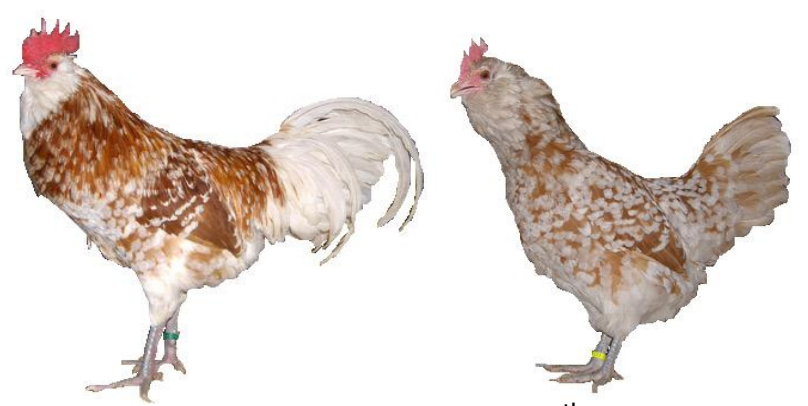

Cultural value: A German breed known since early $18^{\text {th }}$ century originates from native "Otterkoepfe" and influenced by Paduans. It always displayed in several colours. In 188012 different colours were known.

Colour: only Black, Gold, Chamois and Silver coloured were sampled in this study Comb: single

Eyes: different 
Legs: blue grey

Additional trait: bearded

It listed as to be observed in the German red list for breed by the GEH.

Vorwerkhühner

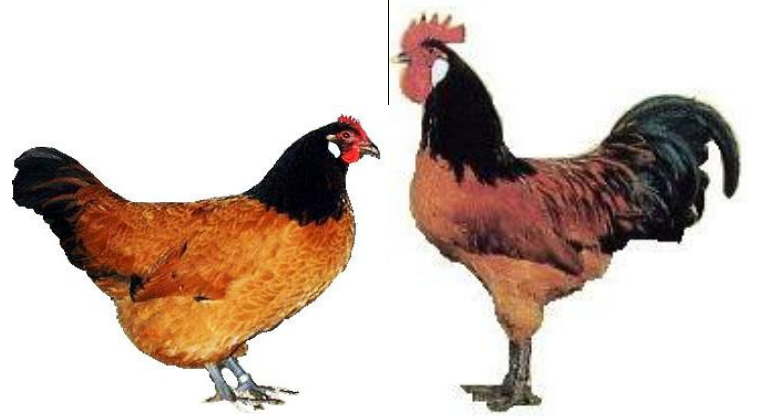

Cultural value: Is a German breed developed from the Lakenfelder around 1900. It was bred as a dual propose breed in yellow plumage, a favoured colour that times. The yellow colour was introduced through Sussex, Orpington and Andalusian.

Colour: black markings like only Lakenfelder have but yellow instead of white.

Comb: single

Eyes: yellow-red

Legs: grey-blue

It is listed as to be observed in the German red list for breed by the GEH.

Westfälische Totleger Silver
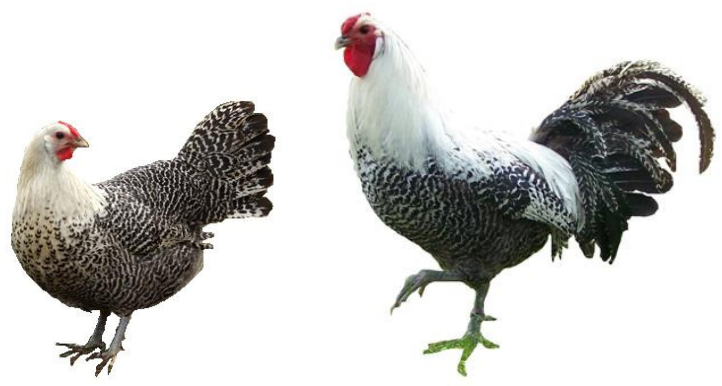

Cultural value: In contrast to single combed pencilled chickens from Belgium and north Germany this rose combed breed was kept in central Germany, in Westphalia in beginnings of the $19^{\text {th }}$ century. Its name indicates that it was mainly kept for egg production and "lays until it dies".

Colour: In this study only silver pencilled were sampled 


\section{Eyes: dark brown}

Legs: grey

It is listed as to be observed in the German red list for breed by the GEH. 


\section{Microsatellite markers}

Table X: Used microsatellite markers

\begin{tabular}{|c|c|c|c|c|c|}
\hline \multirow[b]{2}{*}{ Marker } & \multicolumn{2}{|l|}{ Ort } & \multirow[b]{2}{*}{ foreward-Primer } & \multirow[b]{2}{*}{ reverse-Primer } & \multirow[b]{2}{*}{$\begin{array}{l}\text { Annealing } \\
\text { Temperatur } \\
\text { e }\end{array}$} \\
\hline & $\begin{array}{l}\text { Chromo } \\
\text { som }\end{array}$ & Position & & & \\
\hline MCW0034 & 2 & 230 & $\begin{array}{l}\text { TGCACGCACTTA } \\
\text { CATACTTAGAGA }\end{array}$ & $\begin{array}{l}\text { TGTCCTTCCAATT } \\
\text { ACATTCATGGG }\end{array}$ & $60^{\circ} \mathrm{C}$ \\
\hline ADL0268 & 1 & 288 & $\begin{array}{l}\text { CTCCACCCСТCT } \\
\text { CAGAACTA }\end{array}$ & $\begin{array}{l}\text { СААСТTСССАТСТ } \\
\text { АССТАСТ }\end{array}$ & $60^{\circ} \mathrm{C}$ \\
\hline MCW0069 & $\begin{array}{l}\text { E60C04 } \\
\text { W23 }\end{array}$ & 23 & $\begin{array}{l}\text { GCACTCGAGAAA } \\
\text { ACTTCCTGCG }\end{array}$ & $\begin{array}{l}\text { ATTGCTTCAGCAA } \\
\text { GCATGGGAGGA }\end{array}$ & $60^{\circ} \mathrm{C}$ \\
\hline MCW0183 & 7 & 79 & $\begin{array}{l}\text { ATCCCAGTGTCG } \\
\text { AGTATCCGA }\end{array}$ & $\begin{array}{l}\text { TGAGATTTACTGG } \\
\text { AGCCTGCC }\end{array}$ & $67^{\circ} \mathrm{C}$ \\
\hline ADL0112 & 10 & 0 & $\begin{array}{l}\text { GGCTTAAGCTGA } \\
\text { CCCATTAT }\end{array}$ & $\begin{array}{l}\text { ATCTCAAATGTAA } \\
\text { TGCGTGC }\end{array}$ & $58^{\circ} \mathrm{C}$ \\
\hline MCW0295 & 4 & 75 & $\begin{array}{l}\text { ATCACTACAGAAC } \\
\text { АСССTCTC }\end{array}$ & $\begin{array}{l}\text { TATGTATGCACGC } \\
\text { AGATATCC }\end{array}$ & $58^{\circ} \mathrm{C}$ \\
\hline MCW0206 & 2 & 104 & $\begin{array}{l}\text { ACATCTAGAATTG } \\
\text { ATGTTCAC }\end{array}$ & $\begin{array}{l}\text { CTTGACAGTGAT } \\
\text { GCATTAAATG }\end{array}$ & $60^{\circ} \mathrm{C}$ \\
\hline MCW0111 & 1 & 118 & $\begin{array}{l}\text { GCTCCATGTGAA } \\
\text { GTGGTTTA }\end{array}$ & $\begin{array}{l}\text { ATGTCCACTTGTC } \\
\text { AATGATG }\end{array}$ & $62^{\circ} \mathrm{C}$ \\
\hline MCW0016 & 3 & 96 & $\begin{array}{l}\text { ATGGCGCAGAAG } \\
\text { GCAAAGCGATAT }\end{array}$ & $\begin{array}{l}\text { TGGCTTCTGAAG } \\
\text { CAGTTGCTATGG }\end{array}$ & $55^{\circ} \mathrm{C}$ \\
\hline ADL0278 & 8 & 87 & $\begin{array}{l}\text { CCAGCAGTCTAC } \\
\text { CTTCCTAT }\end{array}$ & $\begin{array}{l}\text { TGTCATCCAAGAA } \\
\text { CAGTGTG }\end{array}$ & $62^{\circ} \mathrm{C}$ \\
\hline MCW0078 & 8 & 87 & $\begin{array}{l}\text { CCACACGGAGAG } \\
\text { GAGAAGGTCT }\end{array}$ & $\begin{array}{l}\text { TAGCATATGAGTG } \\
\text { TACTGAGCTTC }\end{array}$ & $60^{\circ} \mathrm{C}$ \\
\hline MCW0037 & 3 & 317 & $\begin{array}{l}\text { ACCGGTGCCATC } \\
\text { AATTACCTATTA }\end{array}$ & $\begin{array}{l}\text { GAAAGCTCACAT } \\
\text { GACACTGCGAAA }\end{array}$ & $66^{\circ} \mathrm{C}$ \\
\hline MCW0067 & 10 & 61 & $\begin{array}{l}\text { GCACTACTGTGT } \\
\text { GCTGCAGTTT }\end{array}$ & $\begin{array}{l}\text { GAGATGTAGTTG } \\
\text { CCACATTCCGAC }\end{array}$ & $60^{\circ} \mathrm{C}$ \\
\hline MCW0081 & 5 & 123 & $\begin{array}{l}\text { GTTGCTGAGAGC } \\
\text { CTGGTGCAG }\end{array}$ & $\begin{array}{l}\text { CCTGTATGTGGAA } \\
\text { TTACTTCTC }\end{array}$ & $60^{\circ} \mathrm{C}$ \\
\hline MCW0222 & 3 & 86 & $\begin{array}{l}\text { GCAGTTACATTGA } \\
\text { AATGATTCC }\end{array}$ & $\begin{array}{l}\text { TTCTCAAAACACC } \\
\text { TAGAAGAC }\end{array}$ & $60^{\circ} \mathrm{C}$ \\
\hline MCW0216 & 13 & 28 & $\begin{array}{l}\text { GGGTTTTACAGG } \\
\text { ATGGGACG }\end{array}$ & $\begin{array}{l}\text { AGTTTCACTCCCA } \\
\text { GGGCTCG }\end{array}$ & $58^{\circ} \mathrm{C}$ \\
\hline
\end{tabular}




\begin{tabular}{|c|c|c|c|c|c|}
\hline MCW0103 & 3 & 210 & $\begin{array}{l}\text { AACTGCGTTGAG } \\
\text { AGTGAATGC }\end{array}$ & $\begin{array}{l}\text { TTTCCTAACTGGA } \\
\text { TGCTTCTG }\end{array}$ & $64^{\circ} \mathrm{C}$ \\
\hline MCW0248 & 1 & 20 & $\begin{array}{l}\text { GTTGTTCAAAAGA } \\
\text { AGATGCATG }\end{array}$ & $\begin{array}{l}\text { TTGCATTAACTGG } \\
\text { GCACTTTC }\end{array}$ & $60^{\circ} \mathrm{C}$ \\
\hline MCW0098 & 4 & 217 & $\begin{array}{l}\text { GGCTGCTTTGTG } \\
\text { CTCTTCTCG }\end{array}$ & $\begin{array}{l}\text { CGATGGTCGTAAT } \\
\text { TCTCACGT }\end{array}$ & $60^{\circ} \mathrm{C}$ \\
\hline LEI0234 & 2 & 50 & $\begin{array}{l}\text { ATGCATCAGATTG } \\
\text { GTATTCAA }\end{array}$ & $\begin{array}{l}\text { CGTGGCTGTGAA } \\
\text { CAAATATG }\end{array}$ & $55^{\circ} \mathrm{C}$ \\
\hline LEI0094 & 4 & 153 & $\begin{array}{l}\text { GATCTCACCAGTA } \\
\text { TGAGCTGC }\end{array}$ & $\begin{array}{l}\text { TCTCACACTGTAA } \\
\text { CACAGTGC }\end{array}$ & $62^{\circ} \mathrm{C}$ \\
\hline LEI0166 & 3 & 300 & $\begin{array}{l}\text { CTCCTGCCCTTA } \\
\text { GCTACGCA }\end{array}$ & $\begin{array}{l}\text { TATCCCCTGGCT } \\
\text { GGGAGTTT }\end{array}$ & $62^{\circ} \mathrm{C}$ \\
\hline MCW0014 & 6 & 96 & $\begin{array}{l}\text { (AAAA)TATTGGCT } \\
\text { CTAGGAACTGTC }\end{array}$ & $\begin{array}{l}\text { (ACCG)GAAATGA } \\
\text { AGGTAAGACTAG } \\
\text { C }\end{array}$ & $55^{\circ} \mathrm{C}$ \\
\hline MCW0020 & 1 & 460 & $\begin{array}{l}\text { TCTTCTTTGACAT } \\
\text { GAATTGGCA }\end{array}$ & $\begin{array}{l}\text { GCAAGGAAGATT } \\
\text { TTGTACAAAATC }\end{array}$ & $60^{\circ} \mathrm{C}$ \\
\hline MCW0080 & 15 & 49 & $\begin{array}{l}\text { GAAATGGTACAG } \\
\text { TGCAGTTGG }\end{array}$ & $\begin{array}{l}\text { CCGTGCATTCTTA } \\
\text { ATTGACAG }\end{array}$ & $60^{\circ} \mathrm{C}$ \\
\hline MCW0104 & 13 & & $\begin{array}{l}\text { TAGCACAACTCAA } \\
\text { GCTGTGAG }\end{array}$ & $\begin{array}{l}\text { AGACTTGCACAG } \\
\text { CTGTGTACC }\end{array}$ & $60^{\circ} \mathrm{C}$ \\
\hline MCW0165 & 23 & & $\begin{array}{l}\text { CAGACATGCATG } \\
\text { CCCAGATGA }\end{array}$ & $\begin{array}{l}\text { CAGACATGCATG } \\
\text { CCCAGATGA }\end{array}$ & $60^{\circ} \mathrm{C}$ \\
\hline MCW0123 & 14 & 45 & $\begin{array}{l}\text { CCACTAGAAAAG } \\
\text { AACATCCTC }\end{array}$ & $\begin{array}{l}\text { GGCTGATGTAAG } \\
\text { AAGGGATGA }\end{array}$ & $60^{\circ} \mathrm{C}$ \\
\hline MCW0330 & 17 & 41 & $\begin{array}{l}\text { TGGACCTCATCA } \\
\text { GTCTGACAG }\end{array}$ & $\begin{array}{l}\text { AATGTTCTCATAG } \\
\text { AGTTCCTGC }\end{array}$ & $60^{\circ} \mathrm{C}$ \\
\hline
\end{tabular}




\section{How to use the programmes}

To use Weitzman programmes in combination with the Phylip package following sequence has to be exercised. means that the file has to be renamed.

\section{program name file name}

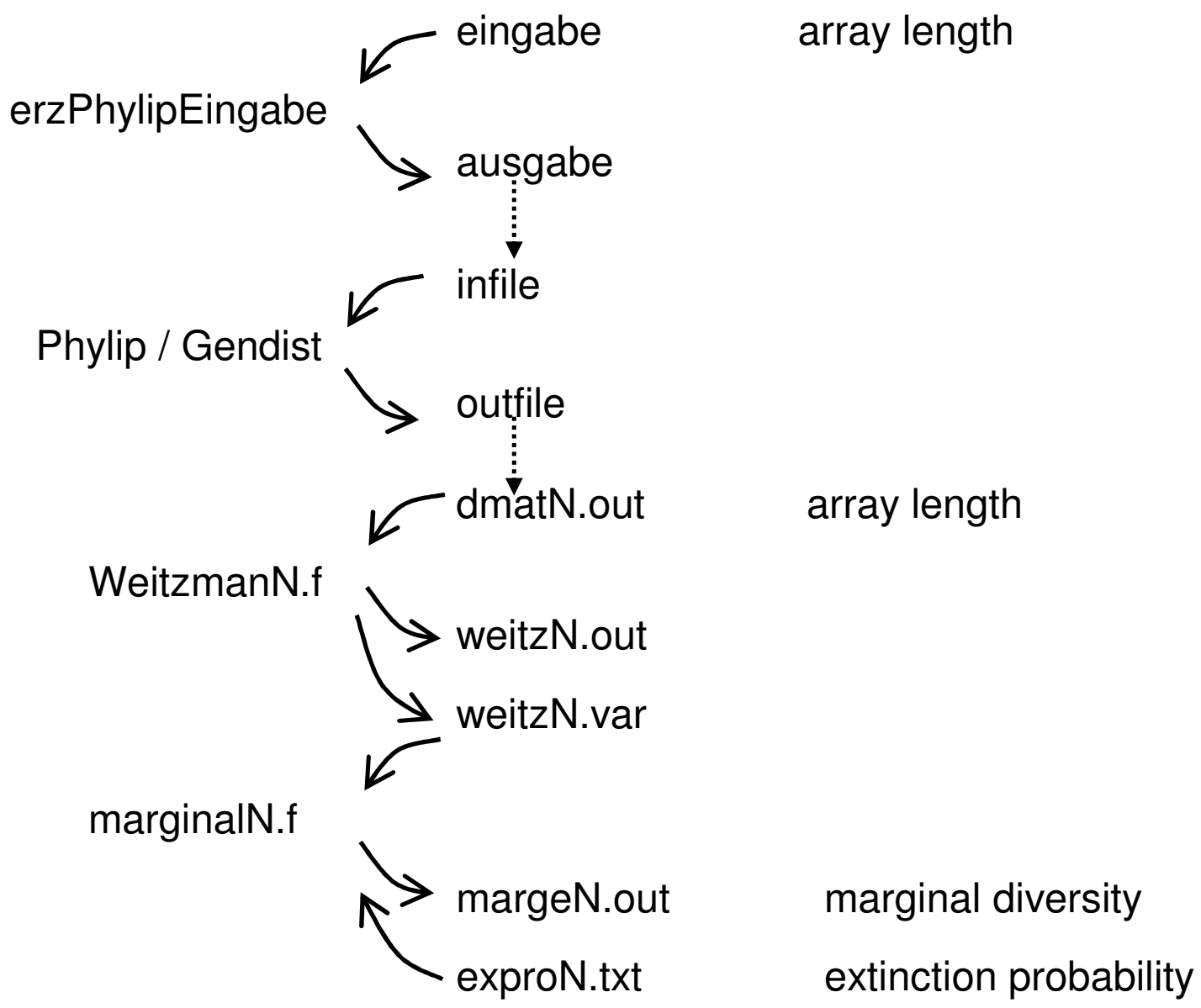

\section{data type}

array length 
Family name: Pinent

Name: $\quad$ Tamina

Date of Birth: $\quad 01$ September 1976

Place of Birth: $\quad$ Paris, France

Gender: Female

Nationality: $\quad$ German / Brazilian

\section{Education Background}

2004-2008: $\quad$ PhD fellow, Institute of Animal Breeding and Genetics, Georg-August Universität, Göttingen, Germany

1996-2004: Diploma in Biology (Theoretical Biology and Cybernetics, "Sehr Gut"), University of Bielefeld, Germany

1995-1996: Advanced Certificate of Secondary Education (Abitur, 2,2), Marianne-Weber-Gymnasium, Lemgo, Germany

1994-1995: General Certificate of Secondary Education, BürgermeisterGräfer-Realschule, Lemgo, Germany

1992-1994: $\quad$ Colégio Cruzeiro do Sul, Porto Alegre, RS, Brazil

1991-1992 Colégio Bom Conselho, Porto Alegre, RS, Brazil

1988-1989 Realschule Ascheberg, Ascheberg, Germany

1985-1988 Grundschule Davensberg, Germany

1984-1985 Grundschule Loevelingloh, Germany 
